\title{
Development of a test facility to evaluate hot gas filtration characteristics of a candle filter
}

\author{
Juan Pablo Rincon \\ West Virginia University
}

Follow this and additional works at: https://researchrepository.wvu.edu/etd

\section{Recommended Citation}

Rincon, Juan Pablo, "Development of a test facility to evaluate hot gas filtration characteristics of a candle filter" (2003). Graduate Theses, Dissertations, and Problem Reports. 1309.

https://researchrepository.wvu.edu/etd/1309

This Thesis is protected by copyright and/or related rights. It has been brought to you by the The Research Repository @ WVU with permission from the rights-holder(s). You are free to use this Thesis in any way that is permitted by the copyright and related rights legislation that applies to your use. For other uses you must obtain permission from the rights-holder(s) directly, unless additional rights are indicated by a Creative Commons license in the record and/ or on the work itself. This Thesis has been accepted for inclusion in WVU Graduate Theses, Dissertations, and Problem Reports collection by an authorized administrator of The Research Repository @ WVU. For more information, please contact researchrepository@mail.wvu.edu. 
Development of a Test Facility to evaluate hot gas filtration characteristics of a candle filter

\author{
Juan Pablo Rincón
}

Thesis submitted to the College of Engineering and Mineral Resources at West Virginia University in partial fulfillment of the requirements for the degree of

\author{
Master of Science \\ In \\ Mechanical Engineering
}

\author{
Eric K Johnson, Ph.D., Chair \\ Bruce Kang, Ph.D., Co-Chair \\ Ken Means, Ph.D.
}

Department of Mechanical and Aerospace Engineering

\author{
Morgantown, West Virginia \\ 2003
}

Keywords: Hot gas filtration, surface regeneration, candle filter 


\begin{abstract}
Development of a Test Facility to Evaluate Hot Gas Filtration Characteristics of a Candle Filter.

Juan Pablo Rincón
\end{abstract}

Hot gas particulate filtration is a basic component in advanced power generation systems such as Integrated Gasification Combined Cycle (IGCC) and Pressurized Fluidized Bed Combustion (PFBC). These systems require effective particulate removal to protect the downstream gas turbine and also to meet environmental emission requirements. The ceramic barrier filter is one of the options for hot gas filtration. Hot gases flow through ceramic candle filters depositing ash on the outer surface of the filter. After this cleaning process there may be some residual ash remaining on the filter surface. This residual ash layer may grow after many cycles of filtering, contributing to a possible cause of mechanical failure of the filter.

A High Temperature Test facility (HTTF) was built to investigate the ash characteristics during surface regeneration at high temperatures. The system was capable of conducting surface regeneration tests of a single candle filter at temperatures up to $1500^{\circ} \mathrm{F}$. The description of the HTTF apparatus as well as some preliminary test results are presented in this thesis. 


\section{Acknowledgements}

I would like to express my gratitude to my research advisor and committee chairman, Dr. Eric K. Johnson, for his guidance and help during the development and completion of this research and thesis.

Also I would like to thank my committee co-chairman, Dr. Bruce Kang, for his advice and guidance throughout the research project.

Thanks to Venkatesh Vasudevan, Tanner Johnson and Ming Zhang for their help in the construction and testing phases of the project.

Special thanks also goes to my friend Franklin Bryan for his great assistance in editing this thesis.

I would like to express my special thanks to my wife Maria del Pilar and my two daughters Ana Maria and Maria Paula for their patience and emotional support. 


\section{Table of Contents}

Title

Abstract

Acknowledgements iii

Table of Contents $\quad$ iv

List of figures $\quad$ vi

List of tables $\quad$ xii

Chapter 1. Introduction

1.1 General Problem 1

1.2 Objective 3

Chapter 2. Background

2.1 Hot gas filtration 4

2.2 Advanced power generation systems 6

2.3 Candle filter cleaning process 9

2.4 Literature review of other HTTF's 18

Chapter 3 . The test facility

3.1 The System 26

3.1.1 General description 26

3.1.2 Measureable variables $\quad 29$

3.1.3 Development and construction details of the HTTF 33

3.1.3.1 The Gas Control Panel 33

3.1.3.2 The Air Preheater 34

3.1.3.3 The Chamber $\quad 35$

3.1.3.4 The Temperature Control System 39

3.1.3.5 The Pressure Sensors and Cooling System 40

3.1.3.6 The Data Acquisition System 46

3.1.3.7 The Image Capturing System 4

3.1.3.8 Window design 48 
3.2 Operation Procedure 49

3.2.1 Start up $\quad 50$

3.2.2 Cycling operation 52

3.2.3 Shut-down 54

Chapter 4. Test Results

4.1 Test matrix $\quad 55$

4.2 Analysis of data obtained in the test 57

$\begin{array}{ll}4.3 \text { Particle distribution analysis } & 100\end{array}$

Chapter 5. A Study of Gas Velocities during surface Regeneration

5.1 Gas velocity measurements 104

$\begin{array}{ll}5.2 \text { The mathematical model } & 107\end{array}$

$\begin{array}{ll}5.3 \text { Results } & 111\end{array}$

Chapter 6. Conclusions and Recommendations

6.1 System design

6.1.1 Facility

113

6.1.2 Instrumentation 113

6.2 Operability of the system 114

6.3 Suggestions, recommendations and proposed improvements 115

$\begin{array}{ll}\text { References } & 117\end{array}$

$\begin{array}{ll}\text { Appendix } & 120\end{array}$

$\begin{array}{ll}\text { Vita } & 121\end{array}$ 


\section{List of Figures}

$\begin{array}{lll}\text { Figure 2.2.1 } & \text { PFBC Power plant flow diagram } & 7\end{array}$

$\begin{array}{llll}\text { Figure 2.2.2 } & \text { IGCC } & \text { Power plant flow diagram } & 8\end{array}$

$\begin{array}{lll}\text { Figure 2.3.1 } & \text { Basic filter operation } & 10\end{array}$

Figure 2.3.2 Pressure distribution in filter and cake during reverse flow 11

$\begin{array}{lll}\text { Figure 2.3.3 Filtrati } & 12\end{array}$

$\begin{array}{lll}\text { Figure 2.3.4 Idealized filter pressure drop } & 13\end{array}$

Figure 2.3.5 Differential pressure across the filter element during pulse 14 for different pulse pressures

Figure 2.3.6 Transient pressure across the filter element during pulse 15 for different pulse duration

Figure 2.3.7 Transient pressure across the filter element during pulse, 16 along the length of the filter

Figure 2.3.8 Effects of reservoir pressure on the transient pressure in 17 the filter element

$\begin{array}{lll}\text { Figure 2.4.1 } & \text { Berbner and Lofflet hot gas experimental set up } & 19\end{array}$

$\begin{array}{lll}\text { Figure } 2.4 .2 \quad \text { J.H Choi hot test unit } & 21\end{array}$

$\begin{array}{lll}\text { Figure 2.4.3 K. Hubner et al. Testing unit. } 23 & \text { K }\end{array}$

Figure $\quad 3.1 .1 .1 \quad$ The High Temperature Testing Facility 27

$\begin{array}{lll}\text { Figure } 3.1 .1 .2 & \text { The gas control panel } & 30\end{array}$

$\begin{array}{lll}\text { Figure } & \text { 3.1.1.3 Nitrogen pressure regulator } & 31\end{array}$

Figure $3.1 .1 .4 \quad$ Air flow model for face velocity derivation 32 
$\begin{array}{lll}\text { Figure } & \text { 3.1.3.2.1 } & \text { First damaged air preheater }\end{array}$

$\begin{array}{lll}\text { Figure } & \text { 3.1.3.3.1 } & \text { Chamber construction detail }\end{array}$

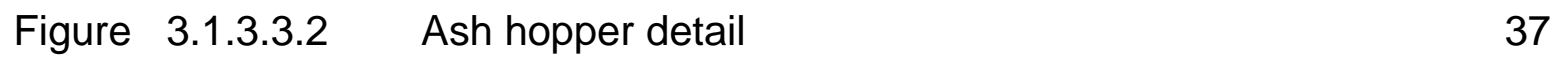

Figure 3 3.1.3.3.3 Typical heating profile curve for $1300 \mathrm{~F}$ test 38

$\begin{array}{lll}\text { Figure } & \text { 3.1.3.4.1 } & \text { Temperature controller }\end{array}$

$\begin{array}{lll}\text { Figure } 3.1 .3 .4 .2 & \text { Ceramic heating pad } & 40\end{array}$

$\begin{array}{lll}\text { Figure } 3.1 .3 .5 .1 & \text { Miniature pressure transducer } & 41\end{array}$

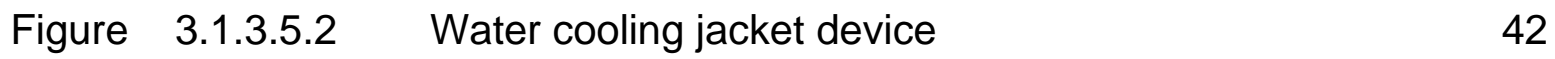

$\begin{array}{lll}\text { Figure } 3.1 .3 .5 .3 \quad \text { Miniature sensor cooling device } & 43\end{array}$

Figure $\quad$ 3.1.3.5.4 Internal view of the T cooling device 44

$\begin{array}{lll}\text { Figure } & \text { 3.1.3.5.5 } & \text { Pressure sensor cooling system }\end{array}$

$\begin{array}{llll}\text { Figure } & \text { 3.1.3.6.1 Data acquisition system } & 46\end{array}$

$\begin{array}{llll}\text { Figure } & \text { 3.1.3.7.1 } & \text { The Image capturing system } & 47\end{array}$

$\begin{array}{llll}\text { Figure } & \text { 4.2.1 } & \text { Analysis variable definition for a typical pressure drop } 58\end{array}$ curve in a surface regeneration cycle

Figure $\quad 4.2 .2 \quad$ Pressure profiles during surface regeneration at $1100 \mathrm{~F} \quad 64$

$\begin{array}{llll}\text { Figure } & 4.2 .3 & \text { Initial pressure drop at } 1100 \mathrm{~F} & 64\end{array}$

$\begin{array}{llll}\text { Figure } & \text { 4.2.4 } & \text { Maximum pressure drop at } 1100 \mathrm{~F} & 65\end{array}$

$\begin{array}{llll}\text { Figure } & 4.2 .5 & \text { Initial }- \text { final pressure drop difference at } 1100 \mathrm{~F} & 65\end{array}$

$\begin{array}{llll}\text { Figure } & \text { 4.2.6 } & \text { First cycle regeneration (thick ash) at } 1100 \mathrm{~F} & 66\end{array}$

$\begin{array}{llll}\text { Figure } & 4.2 .7 & \text { Second cycle regeneration (thin ash) at } 1100 \mathrm{~F} & 66\end{array}$

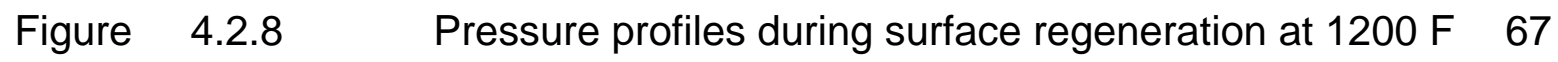

$\begin{array}{llll}\text { Figure } & 4.2 .9 & \text { Initial pressure drop at } 1200 \mathrm{~F} . & 67\end{array}$

$\begin{array}{lll}\text { Figure } & 4.2 .10 \quad \text { Maximum pressure drop at } 1200 \mathrm{~F} . & 68\end{array}$ 


$\begin{array}{llll}\text { Figure } & 4.2 .11 & \text { Initial }- \text { final pressure drop difference at } 1200 \mathrm{~F} . & 68 \\ \text { Figure } & 4.2 .12 & \text { First cycle regeneration (thin ash) at } 1200 \mathrm{~F} . & 69 \\ \text { Figure } & 4.2 .13 & \text { Fourth regeneration (thick ash) at } 1200 \mathrm{~F} . & 69 \\ \text { Figure } & 4.2 .14 & \text { Regeneration at } 1300 \mathrm{~F}, 5 \mathrm{~cm} / \mathrm{s} \text { face velocity. Cycle \# 4. } 70 \\ \text { Figure } & 4.2 .15 & \text { Regeneration at } 1300 \mathrm{~F}, 5 \mathrm{~cm} / \mathrm{s} \text { face velocity. Cycle \# } 5.70 \\ \text { Figure } & 4.2 .16 & \text { Regeneration at } 1300 \mathrm{~F}, 5 \mathrm{~cm} / \mathrm{s} \text { face velocity. Cycle \# 6. } 71 \\ \text { Figure } & 4.2 .17 & \text { Pressure profiles during surface regeneration at } 1300 \mathrm{~F}, 71 \\ & & 5 \mathrm{~cm} / \mathrm{s} \text {. Long term test. } & 72 \\ \text { Figure } & 4.2 .18 & \text { Initial pressure drop at } 1300 \mathrm{~F}, 5 \mathrm{~cm} / \mathrm{s} & 72 \\ \text { Figure } & 4.2 .19 & \text { Maximum pressure drop at } 1300 \mathrm{~F}, 5 \mathrm{~cm} / \mathrm{s} & 73 \\ \text { Figure } & 4.2 .20 & \text { Final pressure drop at } 1300 \mathrm{~F}, 5 \mathrm{~cm} / \mathrm{s} & 73 \\ \text { Figure } & 4.2 .21 & \text { Initial }- \text { final pressure drop difference at } 1300 \mathrm{~F}, 5 \mathrm{~cm} / \mathrm{s} & 73 \\ \text { Figure } & 4.2 .22 & \text { Regeneration \# } 4 \text { at test } 1300 \mathrm{~F}, 5 \mathrm{~cm} / \mathrm{s} & 75 \\ \text { Figure } & 4.2 .23 & \text { Regeneration \# } 5 \text { at test } 1300 \mathrm{~F}, 5 \mathrm{~cm} / \mathrm{s} & 76 \\ \text { Figure } & 4.2 .24 & \text { Pressure profiles during surface regeneration at } 1300 \mathrm{~F}, 76 & \\ & & 7 \mathrm{~cm} / \mathrm{s} \text {. Long term test. } & 75\end{array}$

Figure $\quad 4.2 .25 \quad$ Initial pressure drop at $1300 \mathrm{~F}, 7 \mathrm{~cm} / \mathrm{s} \quad 76$

Figure 4.2.26 Maximum pressure drop at $1300 \mathrm{~F}, 7 \mathrm{~cm} / \mathrm{s} \quad 77$

$\begin{array}{llll}\text { Figure } & 4.2 .27 & \text { Final pressure drop at } 1300 \mathrm{~F}, 7 \mathrm{~cm} / \mathrm{s} & 77\end{array}$

Figure $\quad 4.2 .28 \quad$ Initial - final pressure drop difference at $1300 \mathrm{~F}, 7 \mathrm{~cm} / \mathrm{s} \quad 78$

Figure 4.2.29 Comparison between initial pressure drop at $1300 \mathrm{~F}$ for 79 two different face velocities.

Figure $\quad 4.2 .30 \quad$ Comparison between maximum pressure drop at $1300 \mathrm{~F} 79$ for two different face velocities. 
Figure $\quad 4.2 .31 \quad$ Comparison between (initial - final) pressure drop at 80 $1300 \mathrm{~F}$ for two different face velocities.

Figure $\quad 4.2 .32 \quad$ Pressure profile for first cycle at $1300 \mathrm{~F}$ at two 81 different face velocities.

Figure $\quad 4.2 .33 \quad$ Pressure profile for third regeneration at $1300 \mathrm{~F}, 7$ $\mathrm{cm} / \mathrm{s}$.

Figure $4.2 .34 \quad$ Pressure profile for $18^{\text {th }}$ regeneration at $1300 \mathrm{~F}, 7 \mathrm{~cm} / \mathrm{s} 82$

Figure $\quad 4.2 .35 \quad$ Sequence of regenerations at $1400 \mathrm{~F}, 5 \mathrm{~cm} / \mathrm{s} \quad 83$

Figure $4.2 .36 \quad$ Initial pressure drop at $1400 \mathrm{~F}, 5 \mathrm{~cm} / \mathrm{s}$

Figure 4.2.37 Maximum pressure drop at $1400 \mathrm{~F}, 5 \mathrm{~cm} / \mathrm{s} \quad 84$

Figure 4.2.38 Final pressure drop at $1400 \mathrm{~F}, 5 \mathrm{~cm} / \mathrm{s}$

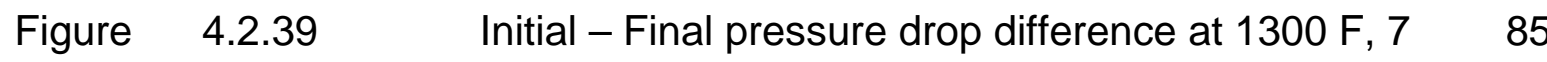
$\mathrm{cm} / \mathrm{s}$.

Figure $\quad 4.2 .40 \quad$ Sequence of regenerations at $1400 \mathrm{~F}, 7 \mathrm{~cm} / \mathrm{s} \quad 86$

Figure $\quad 4.2 .41 \quad$ Initial pressure drop at $1400 \mathrm{~F}, 7 \mathrm{~cm} / \mathrm{s} \quad 86$

Figure $\quad 4.2 .42 \quad$ Maximum pressure drop at $1400 \mathrm{~F}, 7 \mathrm{~cm} / \mathrm{s} \quad 87$

$\begin{array}{llll}\text { Figure } & 4.2 .43 & \text { Final pressure drop at } 1400 \mathrm{~F}, 7 \mathrm{~cm} / \mathrm{s} & 87\end{array}$

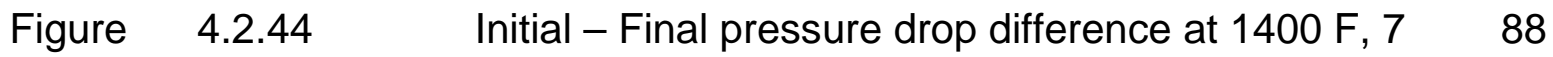

$\mathrm{cm} / \mathrm{s}$

Figure $\quad 4.2 .45 \quad$ Comparison between initial pressure drop at $1400 \mathrm{~F} \quad 89$ for two different face velocities

Figure $\quad 4.2 .46 \quad$ Comparison between maximum pressure drop at $\quad 89$ $1400 \mathrm{~F}$ for two different face velocities 
Figure

4.2 .47

Figure

4.2.48

Figure

4.2 .49

Figure

4.2 .50

Figure

4.2 .51

Comparison between initial - final pressure drop

90

difference at $1400 \mathrm{~F}$ for two different face velocities

Thick ash regeneration at first cycle with residual ash 90 formation at $1400 \mathrm{~F}, 5 \mathrm{~cm} / \mathrm{s}$.

Thin ash regeneration at fifth cycle. $1400 \mathrm{~F}, 5 \mathrm{~cm} / \mathrm{s}$.

91

Thick ash regeneration at first cycle with residual

91

ash formation. $1400 \mathrm{~F}, 7 \mathrm{~cm} / \mathrm{s}$.

Thin ash regeneration at second cycle, 1400 F, 7

92 $\mathrm{cm} / \mathrm{s}$.

Figure

4.2 .52

Regeneration with very few particles flying out at

92 $15^{\text {th }}$ cycle, $1400 \mathrm{~F}, 7 \mathrm{~cm} / \mathrm{s}$.

Figure $\quad$ 4.2.53 Regeneration with many particles flying out

at $16^{\text {th }}$ cycle , $1400 \mathrm{~F}, 7 \mathrm{~cm} / \mathrm{s}$

Figure $\quad 4.2 .54$

Evidence of particle reentrainment at $16^{\text {th }}$

94

regeneration cycle, $1400 \mathrm{~F}, 7 \mathrm{~cm} / \mathrm{s}$

Figure $\quad 4.2 .55$

Regeneration \# 9 at $1400 \mathrm{~F}, 7 \mathrm{~cm} / \mathrm{s}$

95

Figure $\quad 4.2 .56$

Regeneration \# 10 at $1400 \mathrm{~F}, 7 \mathrm{~cm} / \mathrm{s}$

96

Figure $\quad 4.2 .57$

Pressure profile for sequence of regenerations at

96 $1500 \mathrm{~F}, 7 \mathrm{~cm} / \mathrm{s}$

Figure

4.2 .58

Initial pressure drop at $1500 \mathrm{~F}, 7 \mathrm{~cm} / \mathrm{s}$

97

Figure $\quad 4.2 .59$

Maximum pressure drop at $1500 \mathrm{~F}, 7 \mathrm{~cm} / \mathrm{s}$

97

Figure

4.2 .60

Final pressure drop at $1500 \mathrm{~F}, 7 \mathrm{~cm} / \mathrm{s}$

98 


\begin{tabular}{|c|c|c|c|}
\hline Figure & 4.2 .61 & $\begin{array}{l}\text { Initial - Final pressure drop difference at } 1500 \mathrm{~F}, 7 \\
\mathrm{~cm} / \mathrm{s}\end{array}$ & 99 \\
\hline Figure & 4.2 .62 & $\begin{array}{l}\text { Thick ash regeneration at first cycle, } 1500 \mathrm{~F}, 7 \\
\mathrm{~cm} / \mathrm{s}\end{array}$ & 99 \\
\hline Figure & 4.2 .63 & $\begin{array}{l}\text { Thick ash regeneration at fourth cycle, } 1500 \mathrm{~F}, 7 \\
\mathrm{~cm} / \mathrm{s}\end{array}$ & 100 \\
\hline Figure & 4.3.1 & $\begin{array}{l}\text { Particle counting for different sizes at } 1400 \mathrm{~F}, 7 \\
\mathrm{~cm} / \mathrm{s} \text {. Thick ash regeneration mechanism. }\end{array}$ & 101 \\
\hline Figure & 4.3.2 & $\begin{array}{l}\text { Particle counting for different sizes at } 1400 \mathrm{~F}, 7 \\
\mathrm{~cm} / \mathrm{s} \text {. Thin ash regeneration mechanism. }\end{array}$ & 101 \\
\hline Figure & 4.3.3 & $\begin{array}{l}\text { Particle counting for different sizes at } 1400 \mathrm{~F}, 7 \\
\mathrm{~cm} / \mathrm{s} \text {. Particle flying out regeneration mechanism. }\end{array}$ & 102 \\
\hline Figure & 5.1 .1 & Gas velocity measurement set up & 104 \\
\hline Figure & 5.1 .2 & Probe calibration device & 105 \\
\hline Figure & 5.1 .3 & $\begin{array}{l}\text { Gas velocity measurement for a } 95 \text { psi } \\
\text { regeneration pulse }\end{array}$ & 106 \\
\hline Figure & 5.2 .1 & $\begin{array}{l}\text { Path followed by a particle of } 250 \mu \text {, after a } 95 \\
\text { psi regeneration back pulse. }\end{array}$ & 110 \\
\hline Figure & 5.2 .2 & $\begin{array}{l}\text { Path followed by a particle of } 100 \mu \text {, after a } 95 \\
\text { psi regeneration back pulse. }\end{array}$ & 111 \\
\hline
\end{tabular}




\section{List of Tables}

$\begin{array}{lll}\text { Table } 4.1 .1 & \text { Test matrix } & 56\end{array}$

Table $\quad$ 4.2.1 General results for long term tests at 1300, $1400 \quad 60$ and $1500{ }^{\circ} \mathrm{F}$.

Table 5.3.1 Maximum horizontal and vertical displacements for 112 different diameter particles. 


\section{Chapter 1. Introduction}

\subsection{General Problem}

Hot gas particulate filtration is a basic component in advanced power generation systems such as Integrated Gasification Combined Cycle (IGCC) and Pressurized Fluidized Bed Combustion (PFBC). These systems require effective particulate removal to protect the downstream gas turbine and also to meet environmental emission requirements. The ceramic barrier filter is one of the options for hot gas filtration. Hot gases flow through ceramic candle filters leaving ash deposited on the outer surface of the filter. A process known as surface regeneration removes the deposited ash periodically by using a high pressure back pulse to create a backflush flow to clean the surface. After this cleaning process there may be some residual ash remaining on the filter surface. This residual ash layer may grow after many cycles of filtering, contributing to a possible cause of mechanical failure of the filter.

A High Temperature Test Facility (HTTF) was built to investigate the ash characteristics during surface regeneration at high temperatures. The system was capable of conducting surface regeneration tests of a single candle filter at temperatures up to $1500^{\circ} \mathrm{F}$. The description of the HTTF apparatus as well as some preliminary test results are presented in this thesis. A high resolution, high speed image acquisition system was integrated into the HTTF system. This 
acquisition system produced sequential digital images of ash particle size and location during the surface regeneration process. The regeneration pressure and the transient pressure difference between the inside of the candle filter and the chamber during regeneration were measured using a high speed PC data acquisition system. Pictures of the surface regeneration process were synchronized with the pressure pulse; therefore, data was obtained relating the appearance of a crack in the ash layer to the pressure drop across the filter at that instant.

Filtration at high temperatures is a technology that attracts significant attention in a wide variety of processes. This is because it has been shown that product quality, process stream efficiency and economics can be improved through the use of high temperature filtration. In many processes, high filtration temperatures are required to avoid undesirable condensation or desublimation reactions, which result in the fouling of filters or the polluting of products. The filtration of high temperature process gases also provides the opportunity to use particle free, high temperature gas in coupled or subsequent process steps [1] . In particular, new power plant concepts require clean gas for downstream equipment (turbines, etc). The effect of these new plants would be reduced if the gases had to be cooled, cleaned and then reheated.

In most of the literature available, hot gas filtration refers to temperatures ranging from $400 \mathrm{~F}$ to $1500 \mathrm{~F}(200 \mathrm{C}$ to $800 \mathrm{C}$ ), although there are some sources that expand the range up to $1800 \mathrm{~F}(1000 \mathrm{C})$ [1]. 


\subsection{Objective}

The purpose of this thesis was to develop a high temperature test facility (HTTF) capable of testing a single candle filter under a simulated hot gas filtration environment, similar to those found in the power plants. As a proof of concept and design, the HTTF was to go through a series of tests. These tests were to demonstrate that the HTTF was capable of operating at temperatures corresponding to actual practice and up to $1500 \mathrm{~F}$. 


\section{Chapter 2. Background}

\subsection{Hot Gas Filtration}

Many different types of particulate collection devices exist for applications in hot gas filtration. Some of the more relevant ones are:

- high performance mechanical collectors

- high efficiency barrier filtration filters

$\circ$ bag filters

- ceramic candle filters

- ceramic cross flow filters

- electrostatic precipitators

- sonic agglomerators ahead of mechanical collectors

- electrostatic agglomerators ahead of mechanical collectors.

Mechanical collectors such as cyclones utilize the inertial separating force on the particles resulting from the high velocity axial or tangential entry of flue gas into the collector vessel. The inertial force drives the particles to the collector walls, and its magnitude is dependent on the particle size. The cyclones are considered to be the most reliable and least expensive of all devices considered in this section, although they do not separate fine particles as well as the other types of particulate collection devices. 
Barrier filtration devices are different from mechanical collectors in that unlike cyclones, there is a mechanical barrier between the dirty and clean gas streams. For bag filters, particulate collection in the case of fabric filtration occurs initially by interception and impaction on the bag fibers which act as the barrier. Subsequent filtration occurs on the dust cake itself which typically has smaller interstitial pores than the bag weave.

Candle filters and ceramic cross flow filters are rigidly built with very narrow pore size distribution ( 5 to 100 microns). These filters rely less on the formation of dust cake and more on the barrier itself for particle collection. Pressure drops across a rigid candle or cross flow filters is generally higher than that of fabric filters: 0.8 to 8 $\mathrm{kPa}$ for candle filters versus 1.6 to $2.5 \mathrm{kPa}$ for fabric filters at ambient conditions. Operating pressure drop will be in direct proportion to operating gas density. [4]

In the electrostatic precipitators the gas passes through an ionizer screen, where electrons colliding with gas molecules generate positive ions. These ions adhere to dust and other small particles that are present, giving them a positive charge. The charged dust particles then enter a region filled with closely spaced parallel metal plates alternatively charged with positive and negative voltages of the order of 6000 V DC. Positive plates repel the charged particles, which are attracted by and retained on the negative plates by electrostatic forces, further supplemented by intermolecular forces, causing the dust to agglomerate. [4] 
Agglomeration concepts are geared to improve the performance of high efficiency cyclones. By the application of external forces such as sonic or electric fields interparticulate contact is established in the agglomerator. Subsequent growth of particulates through inter-particulate contact is essential for the success of agglomeration concepts. For successful agglomeration, the particulates have to be sticky or molten enough for cohesive growth to take place. [4]

\subsection{Advanced power generation systems.}

Coal is America's most abundant fossil fuel resource and the source of 56 percent of its electricity. [1] Historically, coal has been the fuel of choice because of its availability and low cost. Recent power generation technology has enabled the combination of coal use with environmental protection. These new ultra-clean highefficiency systems minimize the pollutants associated with coal fired plants of the 1970's.

Hot gas cleaning using ceramic barrier filter systems can enhance the future use of clean coal technologies such as Pressurized Fluidized Bed Combustion (PFBC), Integrated Coal Gasification Combined Cycle (IGCC), and Direct Coal-Fueled Turbines (DCFT). In these applications the hot gas filter removes sufficient ash and other waste materials to protect downstream equipment from particulate corrosion and erosion effects and allows the cleaned gas to meet environmental emission requirements upon discharge without further flue gas treatment. [3] 
In the PFBC process, jets of air in a fluidized bed suspend a mixture of coal and limestone or dolomite during combustion, converting the mixture into red-hot particles that flows like a fluid. The limestone captures sulfur oxides that are released by the burning coal (see Figure 2.2.1).

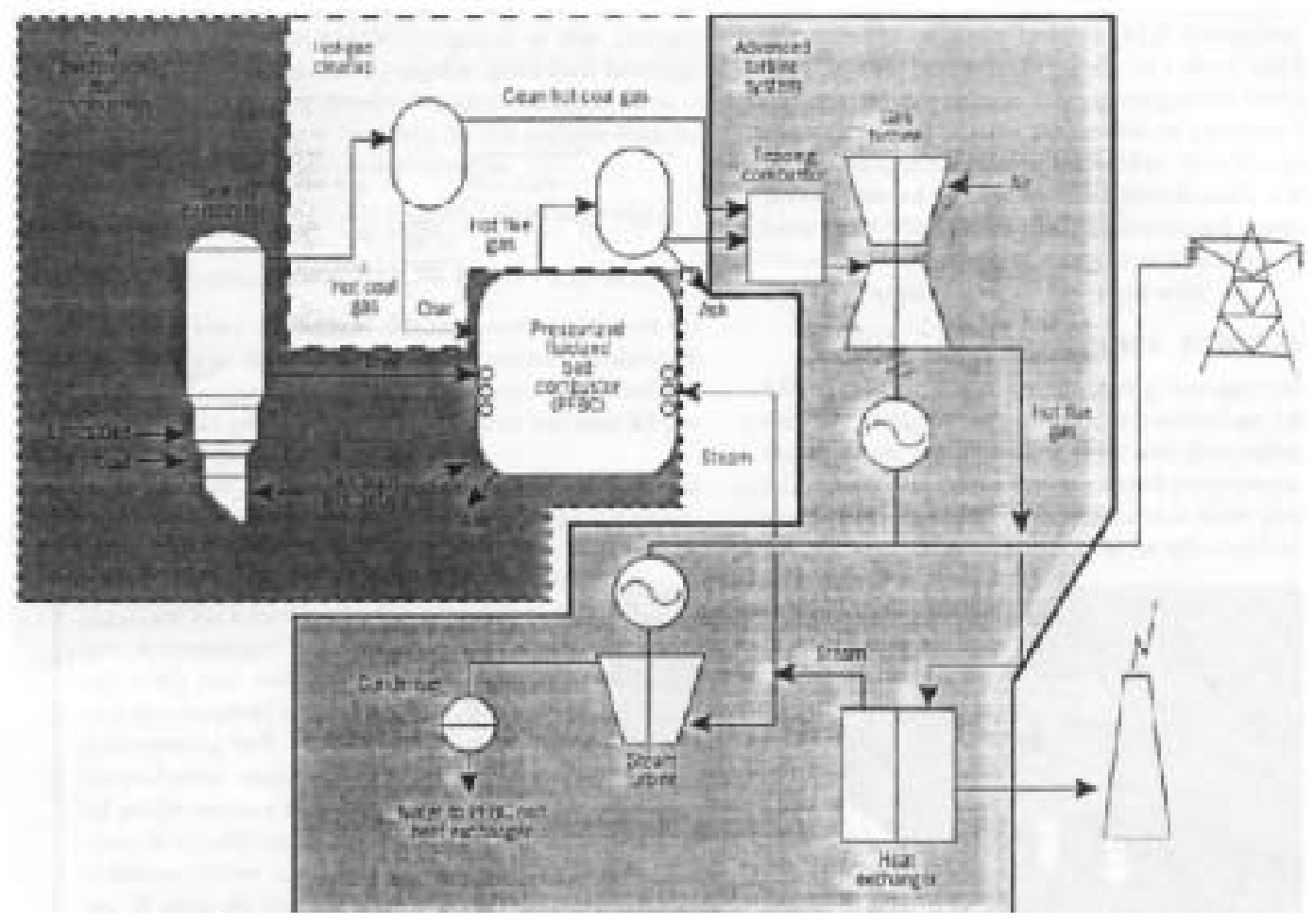

Figure No. 2.2.1 PFBC Power Plant flow Diagram.

In this system the hot-gas cleanup is performed on the product gases at a higher temperature range, 1500 to $1600 \mathrm{~F}$.

In an IGCC system, fuel gas, which is composed of hydrogen and carbon oxides, is generated in a gasifier by coal reacting with steam and air or oxygen. The 
pressurized fuel gas is then cleaned and fed to a high-efficiency combustion gas turbine/generator. The hot turbine exhaust gas produces steam to drive a steam / turbine generator. (Figure 2.2.2)

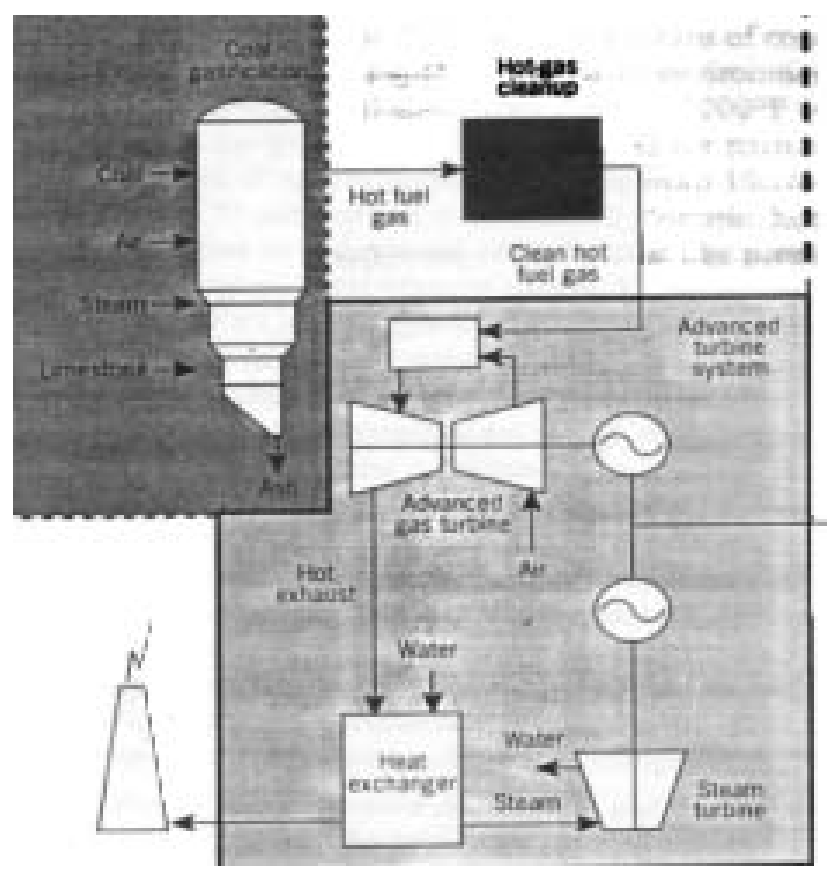

Figure 2.2.2. IGCC Power Plant flow Diagram

Coal is converted into gaseous fuel, which, when cleaned by removing more than 99 percent of the coal's sulfur and particulate contaminants, is comparable to natural gas in terms of energy content. 
For IGCC systems, hot-gas cleanup is a means of controlling particulate and gaseous species in an environment of high temperatures ( 800 to $1200 \mathrm{~F}$ for gases and up to $1200 \mathrm{~F}$ for particulate matter), and of system pressures ranging from 150 to $350 \mathrm{psi}$ [2]. In DCFT systems the operating temperature of the gas cleanup systems have to be in the $1000 \mathrm{C}$ to $1400 \mathrm{C}$ range.

Hot-gas cleanup represents a trade-off of the capital and operating costs of hightemperature and pressure equipment versus those of a cold cleanup system. Typical cold cleaning systems require an elaborate wastewater handling cycle and heat exchangers to cool the process gases and later reheat the same gases. Hot-gas cleanup improves the overall system efficiency by as much as three percentage points. This means that less coal can produce more power, while plant costs and pollutant emissions are lower. [2]

\subsection{Candle filter cleaning process}

To obtain a full understanding of the ceramic filter cleaning process, and specifically cake detachment, requires an understanding of the fluid mechanics of the gas flow and of the cake detachment mechanism. Experimental methods and facilities for investigating surface regeneration characteristics, like the one developed in this thesis, were essential to gain a better understanding of this technology. The basic filter operation process of a candle filter is shown in Figure

\subsection{1}



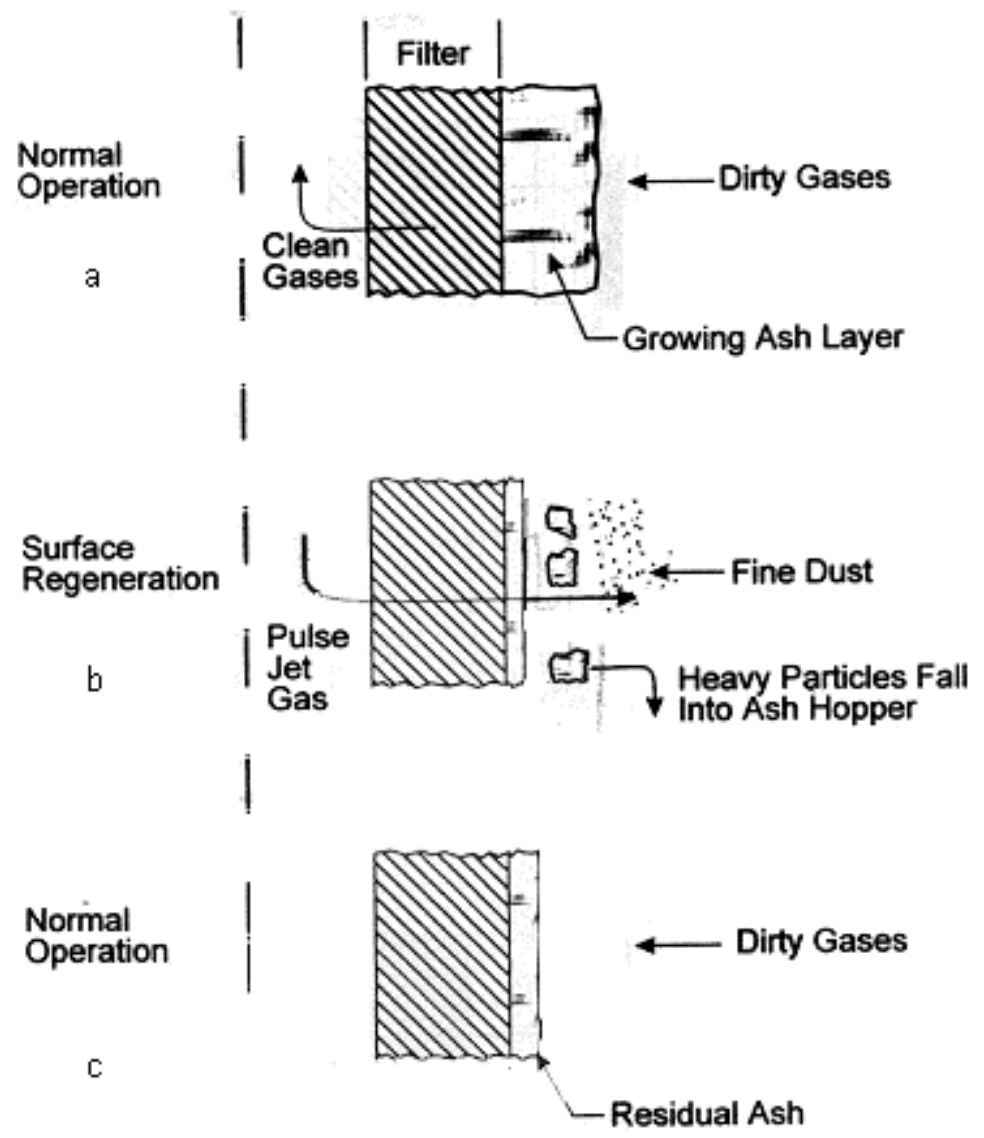

Figure 2.3.1 Basic Filter operation [13]

When the filtering process starts, a stream of dirty gases flows through the filter forming an ash deposit that builds up over time on the outer surface of the candle filter as it is shown in Figure 2.3.1 part a. After a specific filtering cycle period or a specific pressure drop across the filter is reached, a reverse pressure pulse is generated on the inner side of the filter. This action produces a flow of gases out through the filter, which ideally removes the ash layer as shown in Figure 2.3.1 part b. This process is known as surface regeneration and occurs in a short period of time, usually 0.3 seconds. 
During the detachment process, a portion of the initial cake may remain on the filter wall, which is known as residual ash, as is shown in Figure 2.3.1 part c.

When a reverse flow of cleaning gas is imposed, there will be a total pressure difference across the filter plus the cake, $\Delta \mathrm{P}_{\mathrm{T}}$, Figure 2.3.2. However, only part of this pressure difference, $\Delta \mathrm{P}_{\mathrm{C}}$, acts across the filter cake and it is shown that,

$$
\Delta \mathrm{P}_{\mathrm{C}}=\Delta \mathrm{PT}\left(\mathrm{R}_{\mathrm{C}} /\left(\mathrm{R}_{\mathrm{C}_{+}} \mathrm{R}_{\mathrm{F}}\right)\right)
$$

Where $R_{C}$ and $R_{F}$ are the resistance to flow (pressure difference divided by face velocity) of the cake and the filter, respectively.

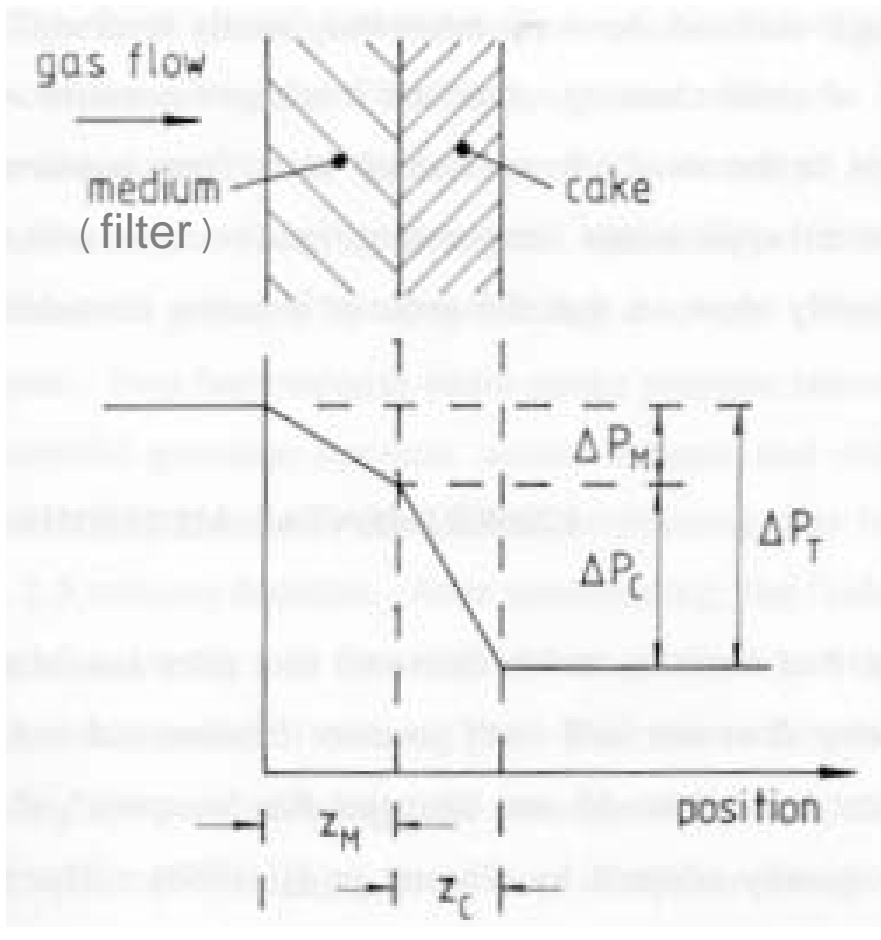

Figure 2.3.2

Pressure distribution in filter and cake during reverse flow [8]

The total resistance $\left(R_{C_{+}} R_{F}\right)$ can be obtained from the pressure drop at a given flow rate immediately prior to cleaning, while $R_{F}$ can be obtained from the pressure drop immediately after cleaning [8]. 
Laux et al observed that the dislodgment of the dust layer does not occur directly at the interface between the filter element surface and dust cake, but somewhere inside the dust layer itself. This leaves a thin layer of dust that remains on the surface (after cleaning) and is called the residual layer. The layer of ash that builds on top of the residual layer and dislodges when reverse pulse is applied is called the temporary layer. The sum of pressure drop due to the residual ash layer and the pressure drop of the filter is called the baseline pressure. This is the pressure drop after all the elements are cleaned and is dependent on a large set of parameters, mainly the interaction of the dust cake with the filter element surface and the residual dust layer permeability. [9]

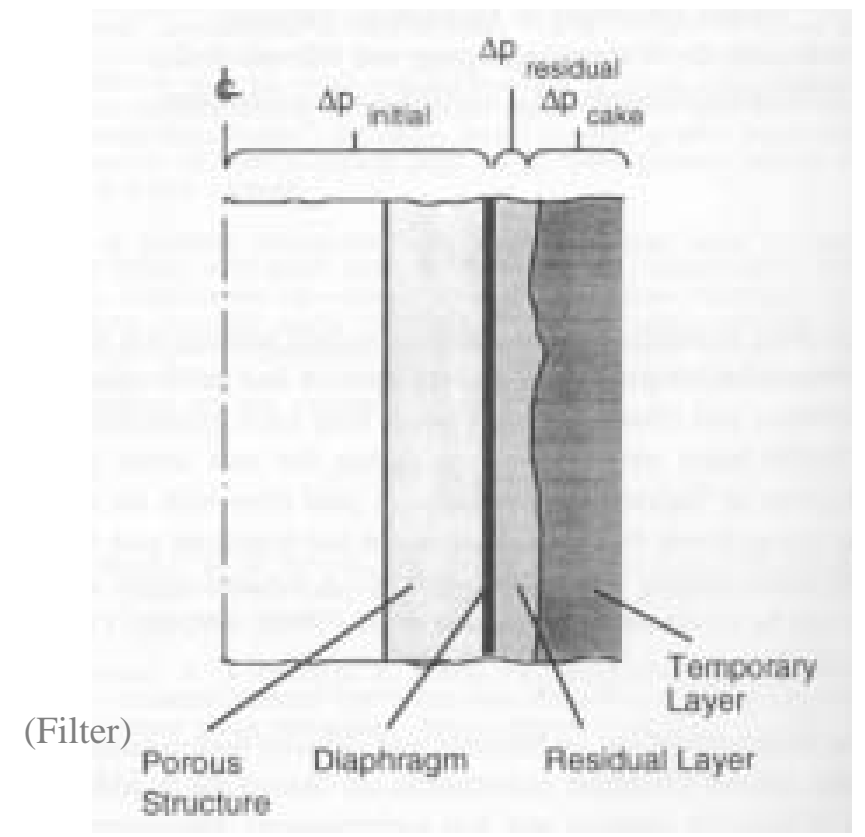

Figure 2.3.3

Filtration model [8] 
Three different kinds of filtration behavior can be identified. Stable filter cleaning occurs when the pressure drop during filtration, increases linearly as is shown in the left hand section of Figure 2.3.4. With a sufficiently strong pulse, the entire dust layer accumulated between two time-triggered pulses can be removed. Experiments show that a specific threshold pulse is necessary to achieve cleaning at certain operating conditions. Pulse pressures below this threshold fail to remove any dust cake. This results in a permanent building of the dust layer and subsequently in a shutdown of the facility. This condition is shown on the right hand side of the Figure 2.3.4. The pressure generated by a pulse inside the filter cavity must always exceed the pressure in the chamber to achieve a local flow reversal.

Pulse pressures slightly above the threshold pressure seem to provide sufficient cleaning over a short period of time. The threshold pressure is defined as the pulse pressure necessary to achieve cleaning at certain operating conditions. However, the amount of dust settling on the surface is larger than the amount of dust removed from the surface by cleaning pulse, leading to an unstable filter cleaning

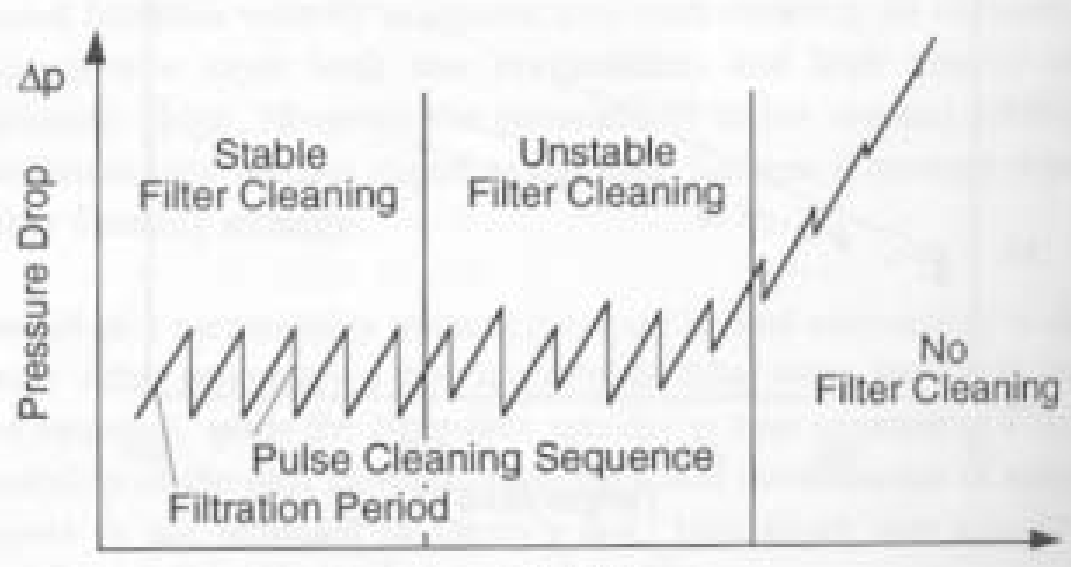

Time

Figure 2.3.4

Idealized Filter Pressure Drop [8] 
operation as can be seen in the middle section of Figure 2.3.4. [8]

Measurements of transient pressure differences in the candle filters have been identified as an important factor in the analysis of the cleaning process. The study of the pressure histories for the filter and chamber during surface regeneration has been carried out experimentally by a number of researchers.

Laux et al, at the Aachen University of Technology-Germany, tested different pulse pressures at room temperature. They observed an increase in the differential pressure across the filter element surface as the pulse pressure was increased as is shown in Figure 2.3.5.

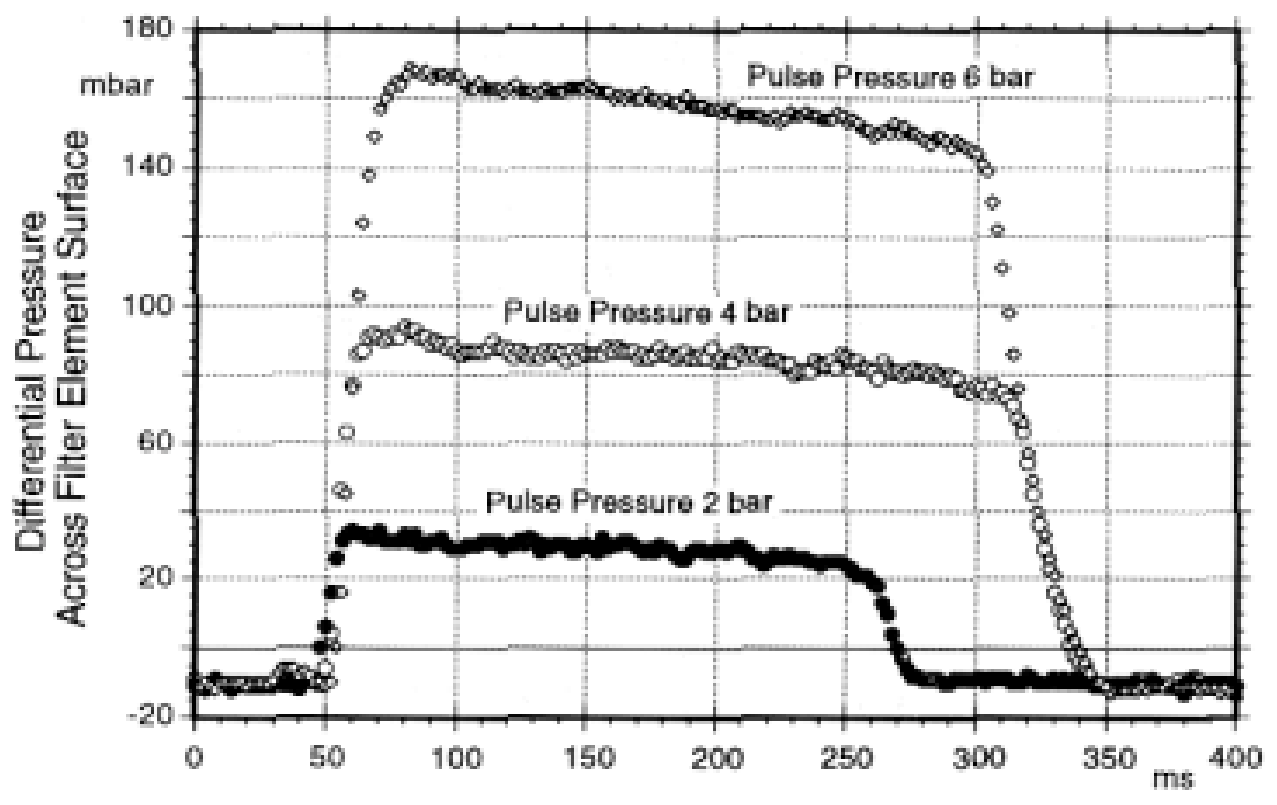

Time

Figure No. 2.3.5

Differential pressure across the filter element during pulse - for different pulse pressures[13] 
S.Berbner and F.Loffler investigated the influence of the pulse jet duration on the pressure peaks inside the filter element at elevated temperatures $(1000 \mathrm{C})$ at the University of Karlsruhe-Germany. They obtained pressure traces for different pulse durations as shown in Figure 2.3.6. It is shown that the pulse jet duration has no significant influence on the pressure peaks in the filter element.

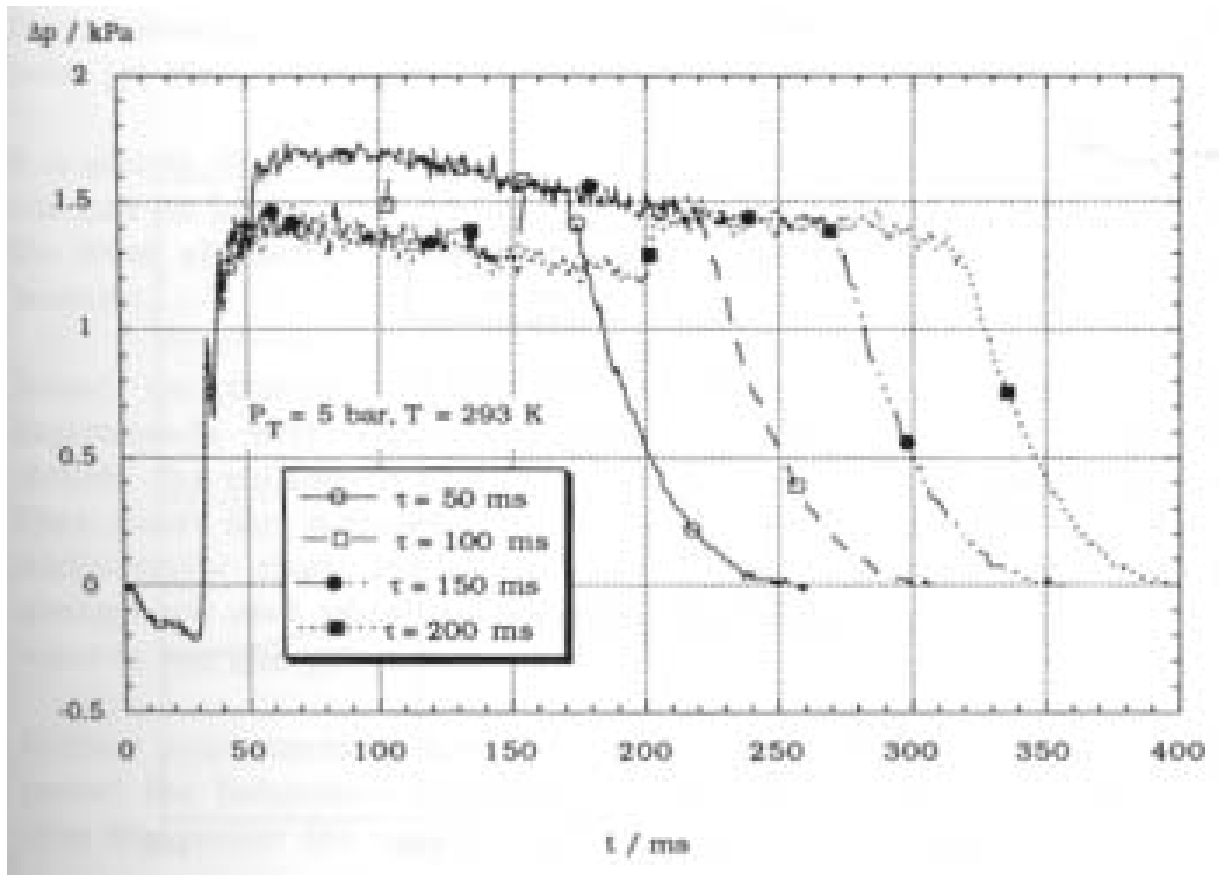

Figure 2.3.6

Transient pressure difference across the filter element during pulse - for different pulse duration [11] 


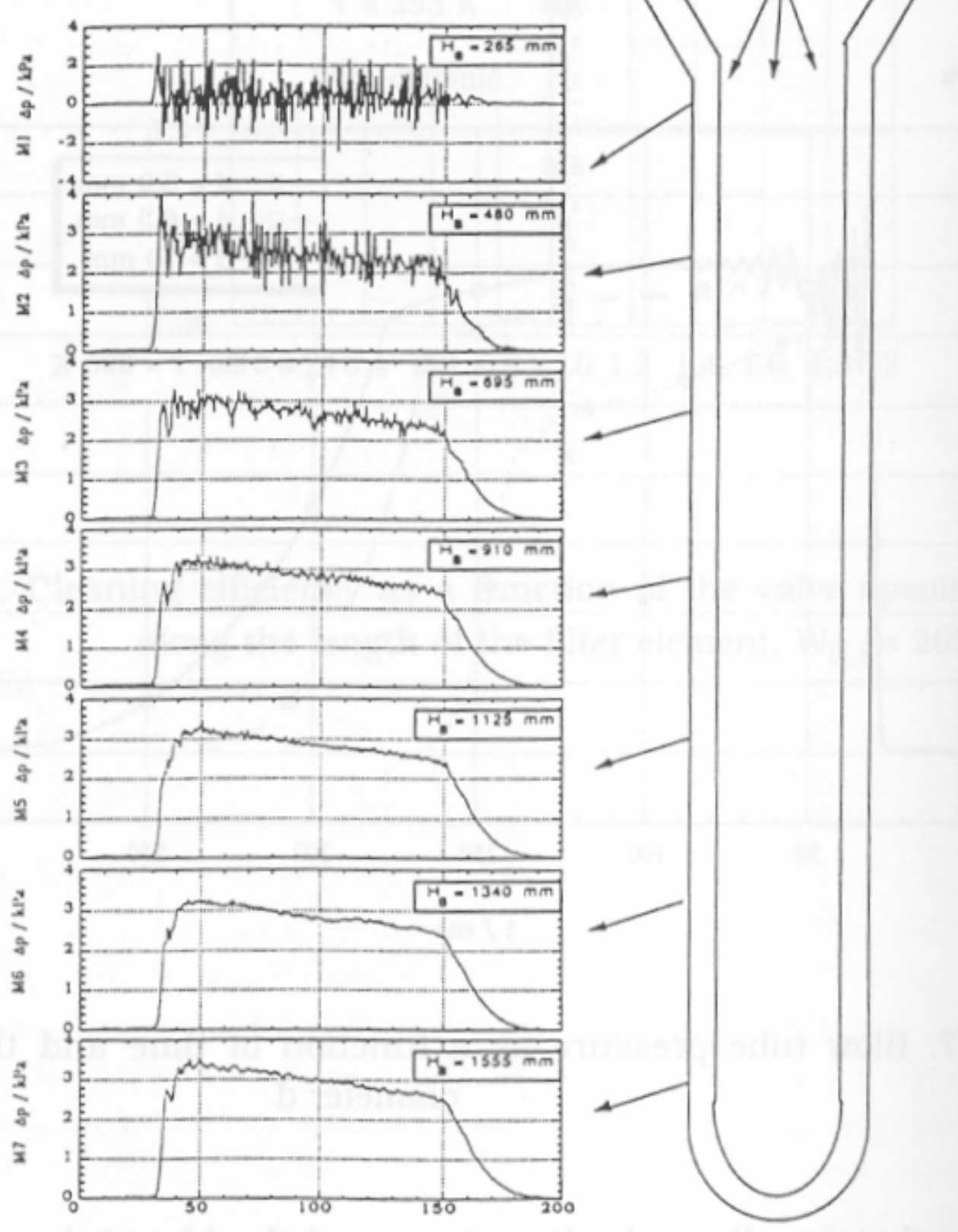

Figure 2.3.7

Transient pressure across the filter element during pulse, along the length of the filter[11] 
The same researches obtained typical pressure traces at various locations along the filter in a hot test. See Figure 2.3.7. Observing the measured pressure signals along the length of the candle filter, it can be seen that nearly the same peak pressure is reached at every position along the filter.

Zhongli Ji et al. at Tsinghua University, Beijing China observed the effects of reservoir pressure on the transient pressure in the filter element, Figure 2.3.8.

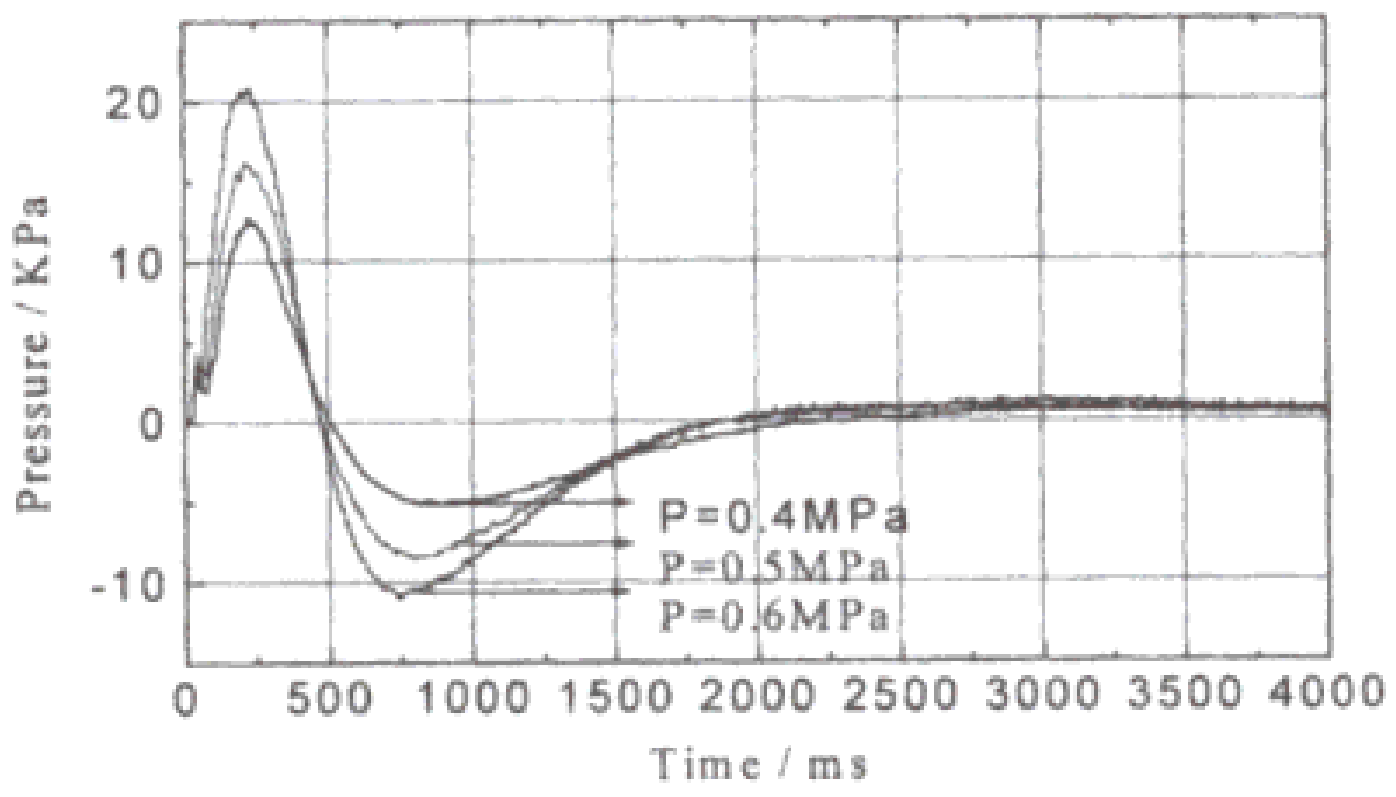

Figure 2.3.8

Transient pressure across the filter element during pulse, - for the different pulse pressures [10]

It is indicated that the absolute value of positive and negative peak pressure increase with the increase of reservoir pressure. The former is useful to pulse- 
jet cleaning, but the latter may cause a fraction of particles removed to redeposit on the candle surface. [10]

An important factor that describes how well the surface cleaning process has performed is the candle filter efficiency [7]. This was defined in terms of pressure drops across the filter as follows

$\eta=\left(\Delta \mathrm{P}_{\text {initial }}-\Delta \mathrm{P}_{\text {final }}\right) /\left(\Delta \mathrm{P}_{\text {initial }}-\Delta \mathrm{P}_{\text {clean }}\right)$

where $\Delta \mathrm{P}_{\text {initial }}=$ Pressure drop across the filter just before the cleaning process.

$\Delta \mathrm{P}_{\text {final }}=$ Pressure drop across the filter just after the cleaning process. $\Delta \mathrm{P}_{\text {clean }}=$ Pressure drop across the filter with no ash.

\subsection{Literature review of others HTTF's.}

Several HTTF's have been developed by researchers around the world. Significant developments are presented here for a better insight and awareness of the available technology.

S Berbner and F. Loffler [11] developed a hot gas experimental system to define the conditions for operation and cleanability of a filter working at high temperatures, see Figure 2.4.1. Also, the investigation concerns the influence of high temperatures on the time dependence of the residual pressure drop. 


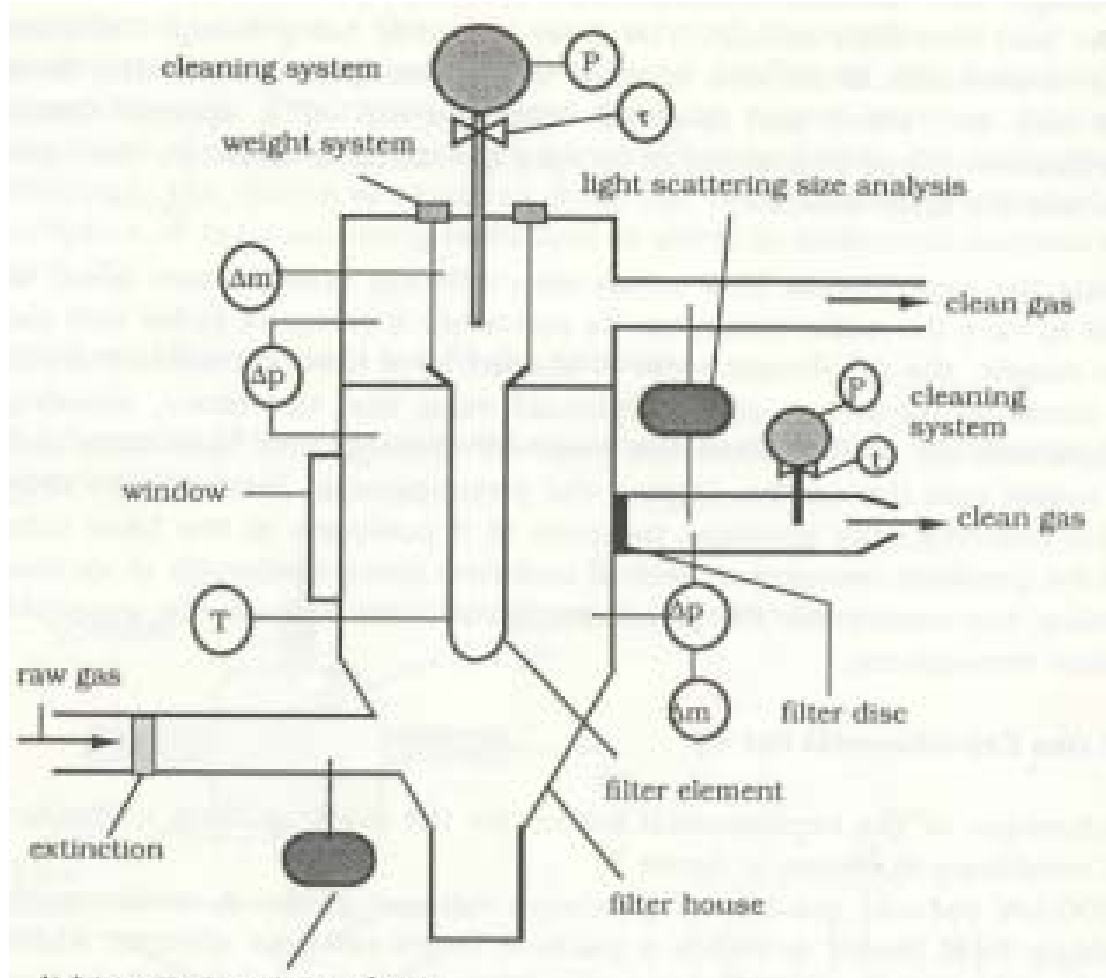

light scattering size analysis

Figure No. 2.4.1 Berbner and Loffler hot gas experimental set up [11]

A continuously working dust feeder provides particles for a raw gas stream, coming from a $300 \mathrm{~kW}$ natural gas burner. This particle laden stream enters the filter through the raw gas inlet. Directly up-stream of the raw gas inlet, the dust concentration is continuously monitored by a photometric device which measures the extinction laser beam. The filter housing itself is heated and contains two types of filters: In the center hangs a technical filter element as is used in many industrial applications of hot gas cleaning. A filter disc is attached on one wall of the filter housing. This filter disc is made out of the same material as the technical filter element in the center. Therefore, both filters are exposed 
to the same raw gas conditions. Both filters have their own pulse jet cleaning systems.

At the opposite side of the filter disc are high temperature resistant windows to enable high speed photographs to be taken during the cleaning process.

There is a system on top of the filter housing that uses force transducers to measure the weight of the center filter element before and after pulse jet cleaning. Hence together with the information from the pressure transducers (residual pressure drop) it is possible to estimate the success of the cleaning effort.

The filter house is built of SiC ceramic blocks. With the heating appliance a maximum temperature of about $1000 \mathrm{C}$ can be maintained during experiments.[11].

$\mathrm{J}-\mathrm{H}$. Choi at Gyeoungsang National U, Chinju Korea developed a hot test unit for investigation into the pulse cleaning of the ceramic candle filter. [12].

Six commercial silicon carbide candle filters of $1.5 \mathrm{~m}$ length were mounted on the left half of the tube sheet as shown in Figure 2.4.2. 


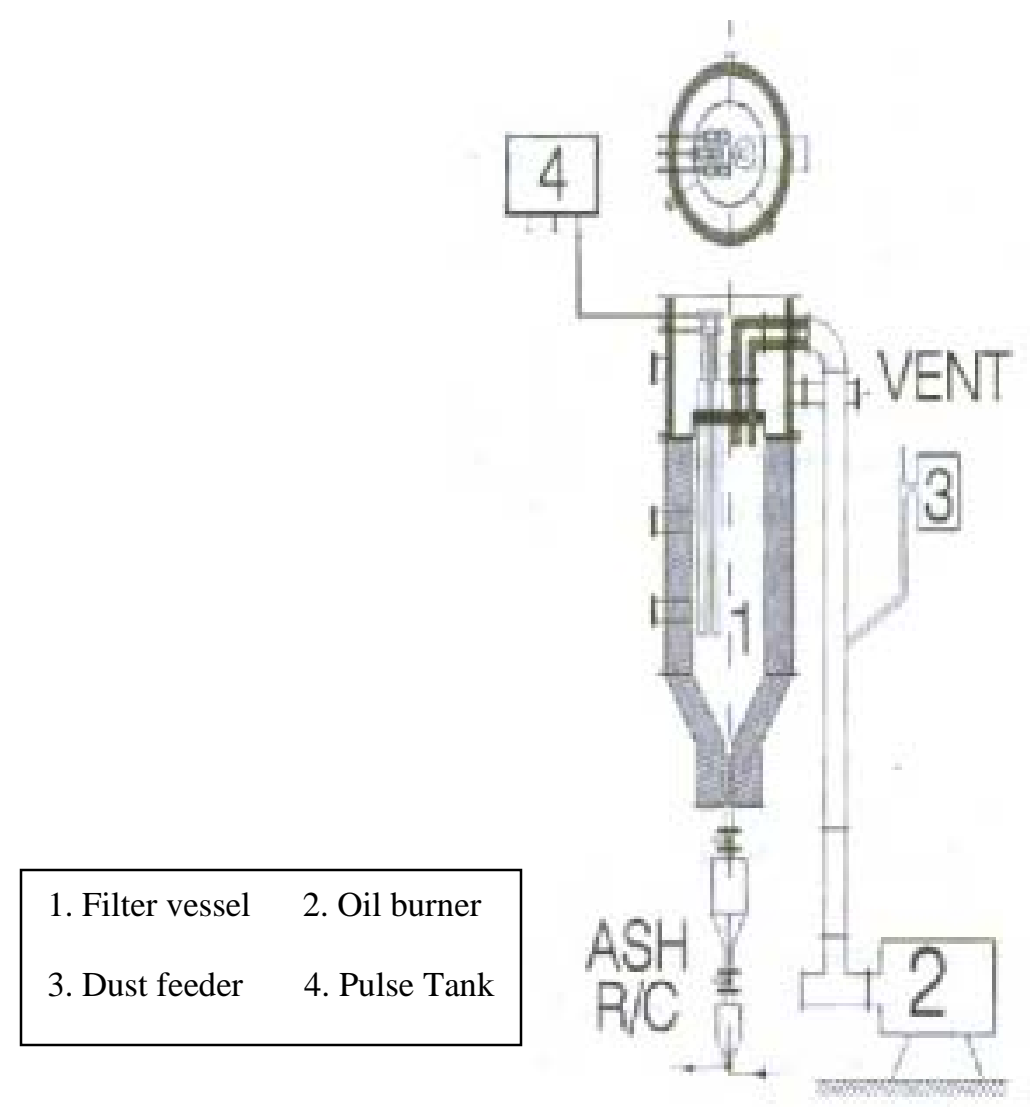

Figure 2.4.2 J.H. Choi Hot Test Unit [12]

The filter elements were concentrated at one side in order to investigate the characteristics of a group filter mounting. The inlet stream of dusty gas was introduced through the right half of the tube sheet in order to achieve the down flow injection of the inlet gas. The hot dusty stream was generated with the exhaust gas form an oil burner into which the fly ash was fed with a screw 
feeder. The filter element was arrayed in three groups with two elements per group. The pulse nozzle extended from the manifolds was located in the center of each filter element. The transient traces of temperature and pressure in the pulse system and in the candle filter cavity were recorded simultaneously with the operation of the pulse valve. Fly ash collected from an electric precipitator in a conventional coal power plant was used in order to prepare the hot gas stream. [12]

K. Hubner et al. at Universitat Essen, Germany investigated the advances in the use of ceramic candle filters for hot gas clean-up removing dust particles with sticking properties [14]. For the filter experiments, small cylindrical disks were used which were made of commercially available filter media consisting of rigid fleeces of alumina silica fibers with diameters of about $5 \mu \mathrm{m}$. A diagram of the unit for testing small ceramic fiber filter disks can be seen in Figure 2.4.3. 


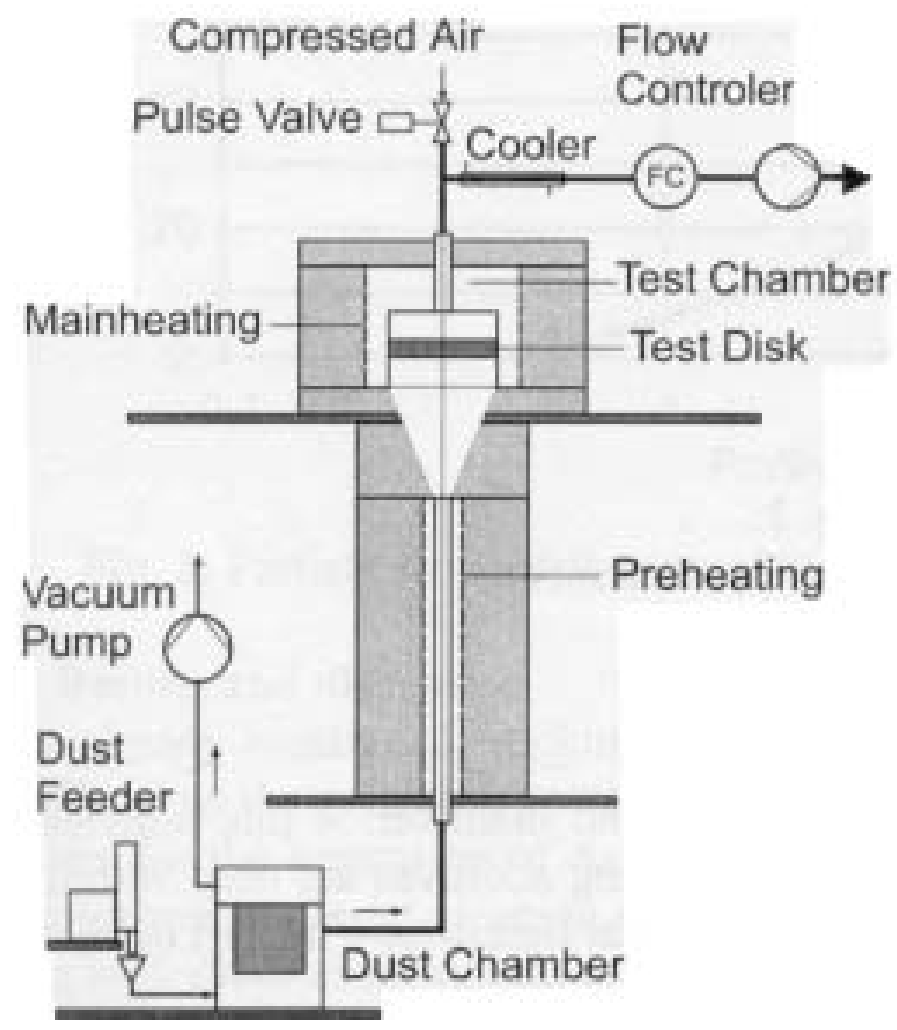

Figure 2.4.3 K. Hubner et al testing unit. [14]

The filter disk is fixed in a test chamber, which is heated electrically. Filter temperatures up to $800 \mathrm{C}$ can be realized in the test chamber. The filter gas stream was produced by an exhaust fan and controlled by a flow meter and a control valve. A mechanical dust feeder loads the filter gas stream with dust in the dust chamber. In this configuration the dust is added to a main stream and dispersed in the dust chamber. 
The main gas stream passes through a pocket filter element for precleaning and is then purified in a vacuum cleaner. A small side stream is taken from the raw gas side of the dust chamber and then passes through the test disk in the test chamber. The dust loaded side stream passing to the test chamber is preheated by an electric radiator.

Before entering the flow meter the filter gas stream is cooled down to ambient temperature by a convection cooler. For filter cleaning a pulse valve is arranged at the top of the test chamber which is controlled by an electronic pulse generator. The pulse pressure can be adjusted by a reducing regulator between 0.5 and 9 bar. The temperatures of the preheating and the test chamber are measured by thermocouples and controlled by electronic regulators.

The pressure drop is measured by an electric transmitter and plotted on line recorder.

The filter disks have a diameter of $45 \mathrm{~mm}$, and the open filter area is $8 \mathrm{~cm}^{2}$. The thickness of the disks can be varied up to $20 \mathrm{~mm}$ by using an adjustable screw clamp. The gas inlet and outlet tubes have diameter of $8 \mathrm{~mm}$, and the pressure pipes have a diameter of $4 \mathrm{~mm}$.

The HTTF's described up to this point use similar technology. All of them use the back pulse mechanism as a cleaning system and they all have dust feeders. Some of them have instrumentation sensing pressure drops, dust cake weight and dust concentration. 
The HTTF proposed in this thesis, has an ash fluidization system instead of a dust feeder, a pressure sensing system and an image capturing system. The ash fluidization system used in the new HTTF makes it much more simple and unique among all the others. 


\section{Chapter 3. The Test facility}

\subsection{The System}

\subsubsection{General description}

The HTTF system, based on the RTTF design [6], consists of a electrically heated chamber, an air preheater, a gas control panel, a water cooling system for the pressure sensors, a temperature control unit for the electrical heating units, a data acquisition system to collect pressure data and an image capturing optical system, as shown in Figure 3.1.1.1.

The air preheater is a Pebble Bedded Heat Exchanger (PBHE), which can raise the gas (air) to the desired temperature. The PBHE consists of a forty-inch long stainless steel pipe (diameter: 4.25 inch, thickness: 0.135 inch) which is filled with 1/4" diameter alumina-silica balls (for the purpose of increasing total surface area for heat transfer as well as mixing the air for a more uniform temperature distribution). The unit is thermally insulated with a three inch thick layer of a softhard combination of alumina-silica from Zircar Ceramics ${ }^{\mathrm{R}}$. 


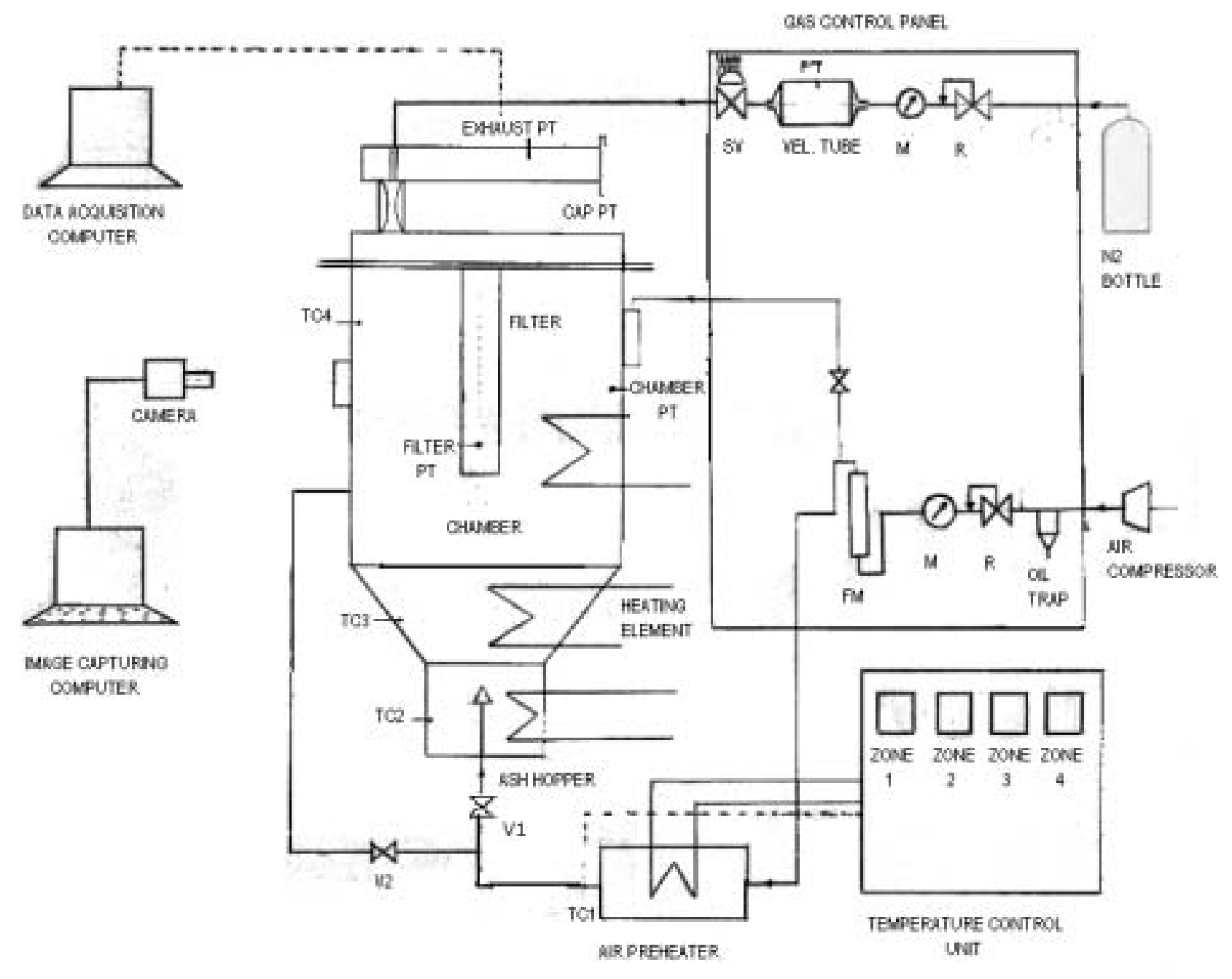

Figure 3.1.1.1 The High Temperature Testing Facility 
The gas (air) from the preheater enters the chamber at two points (see Figure 3.1.1.1). The $\mathrm{V} 1$ valve controls the air going to the ash hopper, while the $\mathrm{V} 2$ valve controls air going to the side port, thus bypassing the ash hopper. In this way the system can simulate the actual regeneration process in an IGCC or PFBC power plant, i.e., keeping the flow of gas (air) through the filter when a regeneration is taking place. Specifically, when V1 is opened with V2 closed, the ash is being fluidized and filtration occurs at a specified face velocity. When V2 is opened with V1 closed, the fluidization of ash is stopped, the concentration of particles near the ash layer is significantly reduced while the face velocity is maintained.

The HTTF chamber is essentially an electrically heated oven which was constructed of stainless steel with heating elements mounted on the walls and then covered by a 1.5 inches thick thermal insulation layer of alumina silica. A single filtration element (candle filter) was mounted inside the chamber where the hot gas filtration process took place.

For a typical hot ash particle upstream operation, a continuous stream of hot air flows through a nozzle in the ash hopper at the bottom of the HTTF. The hot air flow disperses the particles in the ash hopper. The fluidized stream of particles then flow through the chamber and to the candle filter. The gases then flow through the filter and the ash particles are trapped on the filter surface. 
The HTTF system had pressure sensors placed inside the chamber, filter, cap of the chamber, and exhaust tube of the chamber. Each pressure sensor had proper water cooling protection to prevent overheating damage. Also, an uncooled pressure sensor was placed in the velocity tube for measuring the back pulse pressure. The data acquisition system was used to record all the pressure information from the pressure sensors.

The image capturing system was capable of recording sequential high resolution pictures (1024 x 512 pixels) of the regeneration process at 60 frames per second for 20 seconds. The imaging acquisition was triggered by a signal coming from the solenoid valve in the nitrogen line. A long distance microscope was attached to the CCD camera and was capable of measuring resolution down to 25 micron at a distance of one meter from the object.

\subsubsection{Measureable variables}

The following variables can be measured with the instrumentation implemented into the facility. 
- Pressure and volumetric flow of air flow used for the filter cake build up. These variables could be read on the gas control panel, Figure 3.1.1.2

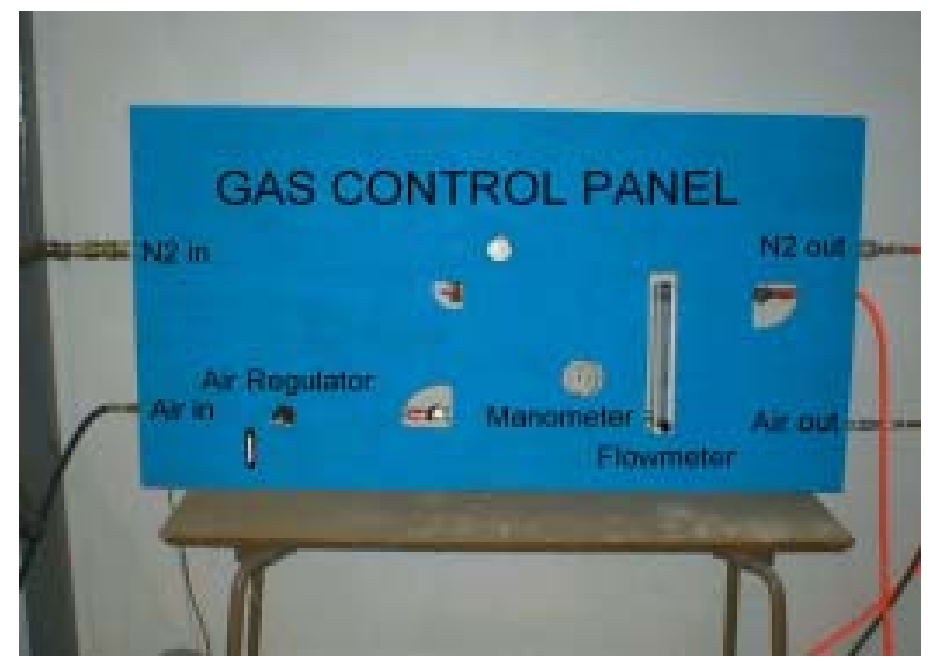

Figure 3.1.1.2 The Gas Control Panel

- Pressures in the system were measured in four different locations: exhaust, cap, filter and chamber. The locations are noted in Figure 3.1.1.1. These readings were generated by the pressure sensors and converted to digital information which was processed by the data acquisition system.

- Temperatures were measured at five different locations of the system: air preheater outlet, ash hopper wall, wall at the bottom part of the chamber, wall of the chamber near one of the windows and air temperature inside the chamber as shown by marked points in Figure 3.1.1.1. These readings could be taken from the temperature control unit and also from a separate temperature display which was installed. 
- The pressure of the nitrogen used for surface regeneration cycle was also measured. This reading was obtained from the pressure regulator installed in the nitrogen tank, Figure 3.1.1.3

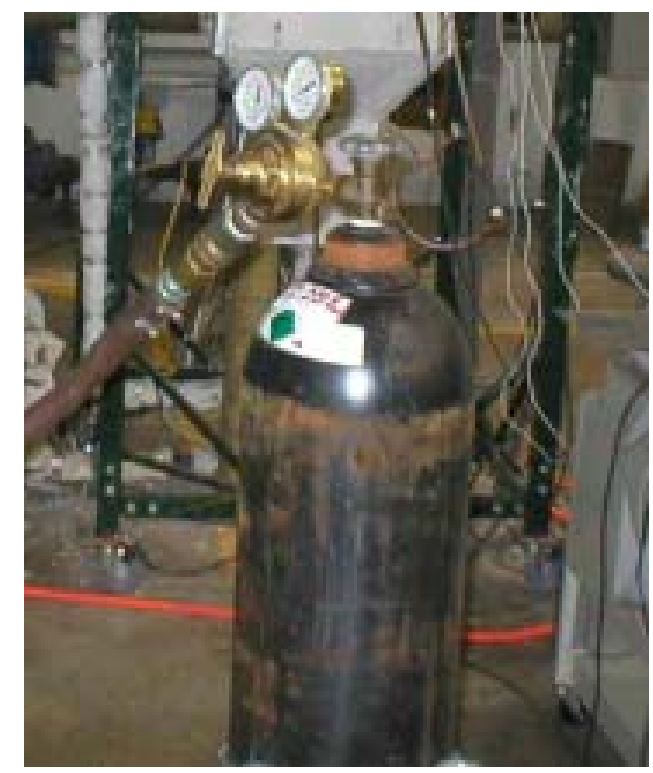

Figure 3.1.1.3 Nitrogen pressure regulator

The proof of concept and design evaluation was based on the following independent variables.

- Face velocity

- Build up time

- Regeneration pressure

- Temperature filtration process

Because there was no direct instrument reading for the face velocity of the air approaching the candle filter, an analytical derivation based on the measurements of pressure and volumetric flow of air was established. 


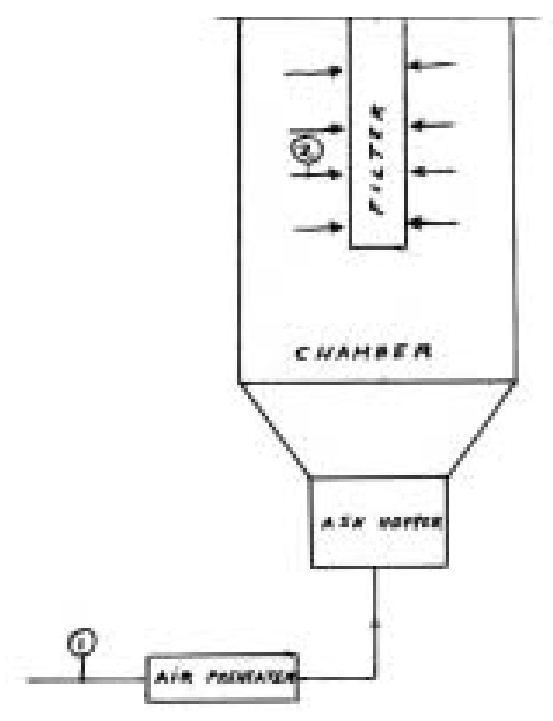

Figure 3.1.1.4 Air flow model for face velocity derivation

Assuming that all the air flowing through the filter flows only through the vertical filter walls and considering stations \# 1 and 2 on Figure 3.1.1.4, it follows from continuity equation that

$$
\begin{aligned}
& \rho_{1} Q_{1}=\rho_{2} Q_{2} \\
& \text { where } \\
& Q_{2}=V_{2} A_{2} \text {, and } \\
& A_{2}=\text { filter surface area } \\
& V_{2}=\text { face velocity }
\end{aligned}
$$

$Q_{1}$ can be easily determined from the gas control panel measurements (pressure and volumetric flow). The densities $\rho_{1}$ and $\rho_{2}$ are the air densities at state 1 (room 
temperature and panel pressure) and state 2 (high temperature being tested and chamber pressure during ash layer formation period). This was the chamber pressure and was usually very close to atmospheric pressure.

From equation [3.1.2.1], it can concluded that

$$
V_{2}=\rho_{1} Q_{1} / \rho_{2} A_{2}
$$

Performing the computations in the last equation for a test a $1300 \mathrm{~F}$, we have $\mathrm{A}_{2}=0.094 \mathrm{~m} 2$, for a filter $50 \mathrm{~cm}$ long with an external diameter of $6 \mathrm{~cm}$, resulting in a face velocity of $5 \mathrm{~cm} / \mathrm{s}$.

\subsubsection{Development and Construction details of the HTTF.}

\subsubsection{The Gas Control Panel}

An improved version of the old gas control panel used in the RTTF was designed and constructed. The improved gas control panel had two separate gas lines, one for air and the other for nitrogen, Figure 3.1.1.2. The air line supplied air at the desired flow rate and pressure to the air preheater. An oil trap was installed before the air regulator to ensure an oil free air for the experiments, thereby avoiding potential problems at high temperatures.

The nitrogen line had a pressure regulator to set up a suitable reservoir pressure for the back pulse. A velocity tube was installed with a pressure sensor attached to it. This configuration provided additional pulse pressure information during the 
regeneration period. A normally closed solenoid valve was installed in the nitrogen line, to be triggered by the data acquisition system for the start of the surface regeneration process. An opening time of 0.3 seconds was used.

\subsubsection{The Air Preheater}

An air preheater was constructed in order to heat the air to the desired test temperature. Initially a 40" length ASME SAE 178 grade A pipe, 4 "O.D with a wall thickness of 0.135 " was used for this purpose. After several test were performed it was concluded that a different material should be used for this purpose due to severe deterioration observed in the pipe caused by the high temperature, Figure

\subsubsection{1}

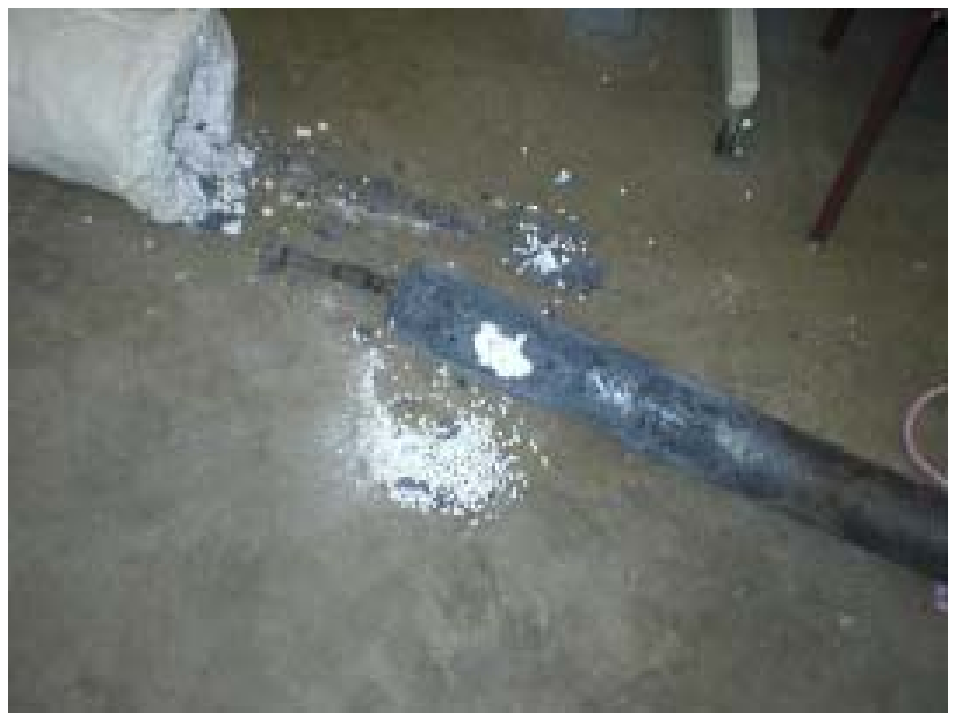

Figure 3.1.3.2.1 First damaged air preheater 
A second air preheater was built, using 304 SS pipe with a 4.5 " O.D and a wall thickness of 0.237 ". This preheater had the same length as the first one, and was also filled with $1 / 4$ " diameter alumina silica balls. A larger diameter for the second air preheater increased the total surface area for heat transfer and, along with additional alumina silica balls, produced a more uniform temperature distribution at the exit. In spite of this new material selected, the pipe melted in one of the tests due to too a high heating rate. It was necessary to change the heat up procedure of the unit, to allow for a slower safer rise in temperature.

\subsubsection{The Chamber}

The chamber design was developed from the experience acquired with the RTTF system. The crucial issue addressed was how to simulate the actual filtration process at elevated temperatures (up to $1500 \mathrm{~F}$ ) inside the chamber while the filtration and surface regeneration processes were occurring.

A 304 stainless steel sheet $1 / 4$ " thick was chosen as the material to build the chamber. This selection was made based on the acceptable behavior of the material at elevated temperatures. The main body of the chamber is a rectangular parallelepiped with $2 \mathrm{ft}^{3}$ volume, the half bottom part is an inverted frustum of a pyramid with of $0.04 \mathrm{ft}^{3}$ volume as shown in Figure 3.1.3.3.1. 


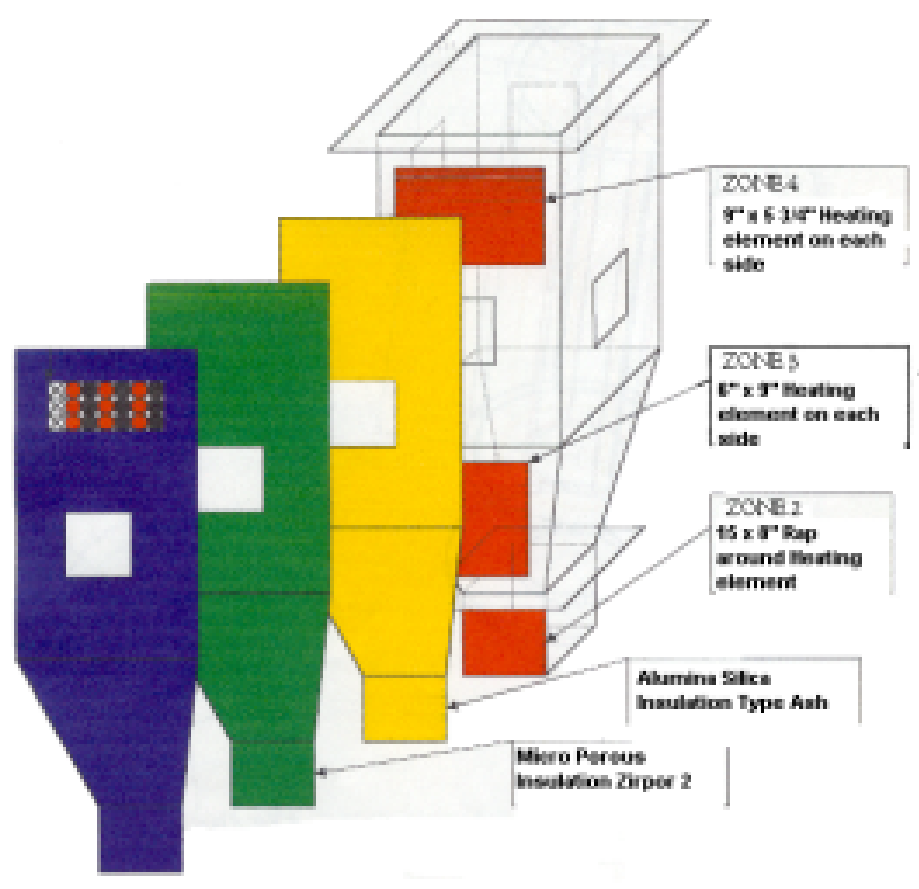

Figure 3.1.3.3.1 Chamber construction detail

A removable cap that supports an exhaust port was attached to the upper half of the chamber. The cap formed a plenum for the injection of the high pressure nitrogen back pulse used in the surface regeneration process. An injector was welded to the cap. 
All the details regarding the fluidization of the ashes were learned from experience with the RTTF, so an ash hopper with its fluidizing air tube was again employed into the system, Figure 3.1.3.3.2.
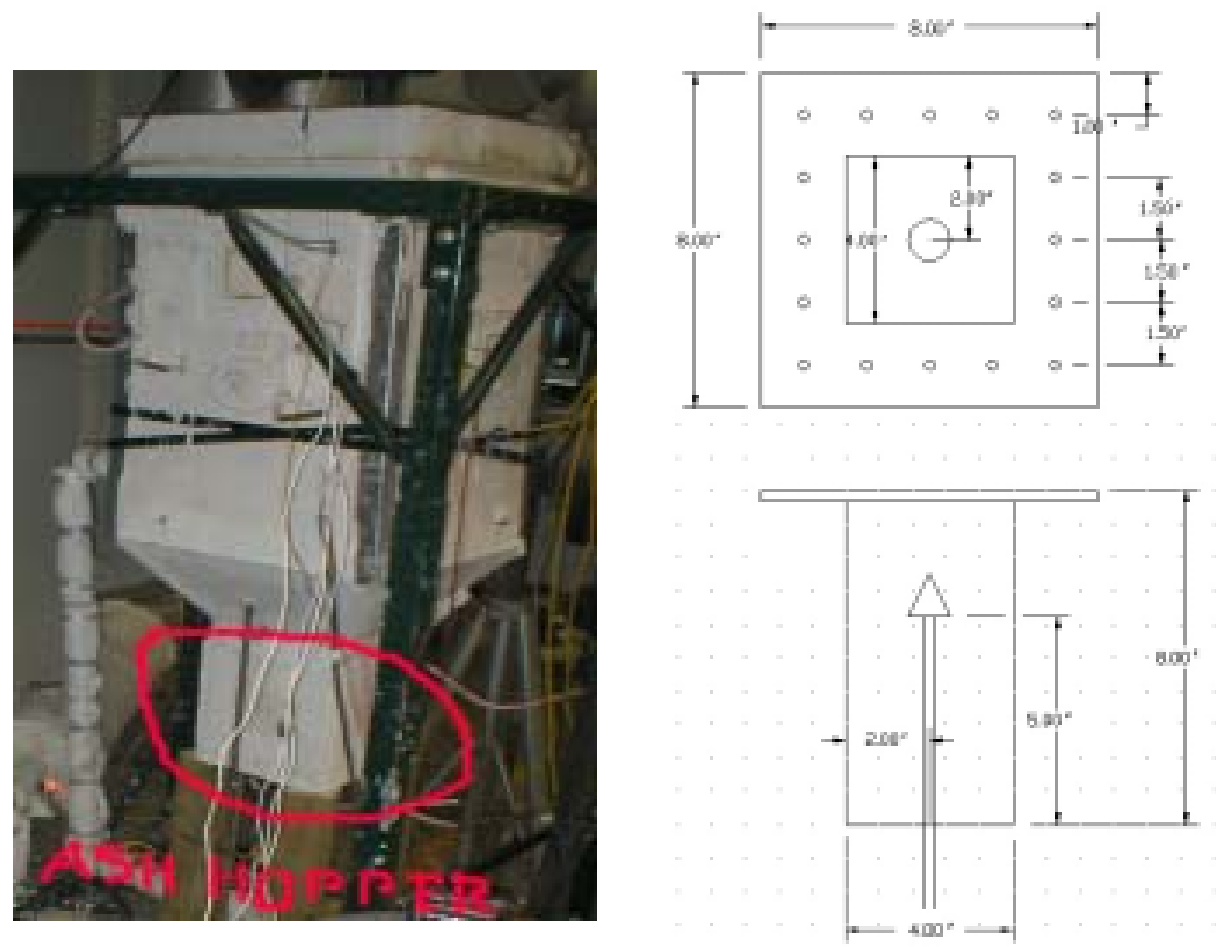

Figure 3.1.3.3.2 Ash Hopper detail

A critical issue was the temperature in the support beams of the chamber, attached to the frame. In spite of the thermal insulation installed between the chamber and the supporting beams, in some preliminary heating tests, it was noticed that excessive temperatures were developing in the supporting beams. This was 
identified as a safety concern for the supporting frame, because heat was transferred to all the supporting structure. An Inconel steel with high tensile strength at high temperature was chosen and then installed. At this stage of the construction, with no pressure sensors installed yet, several preliminary tests were conducted, to check the capability of the system to reach temperatures up to 1500 F. A typical heating profile curve is shown in Figure 3.1.3.3.3

HTTF heating curve for $1300 \mathrm{~F}$ test

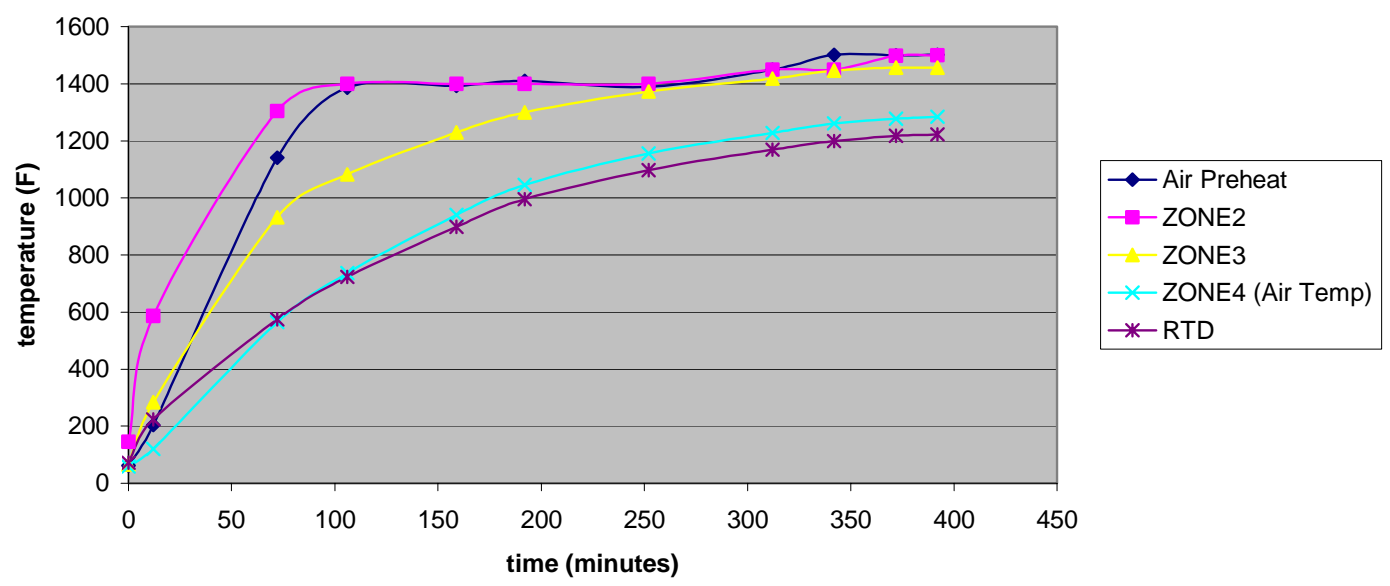

Figure 3.1.3.3.3 Typical heating profile curve for a $1300 \mathrm{~F}$ test

Improvements in the heat insulation were necessary to reach the maximum temperatures in a heating time dictated by thermal stress and distortion. 


\subsubsection{The Temperature Control System}

A temperature control unit was used to keep the air inside the chamber at the desired temperature level during the filtration test. The temperature was controlled through four independent heating zones with a total power rating of $28.8 \mathrm{Kw}$.

Each zone controls the temperature independently of the others, having its own temperature display as shown in Figure 3.1.3.4.1.

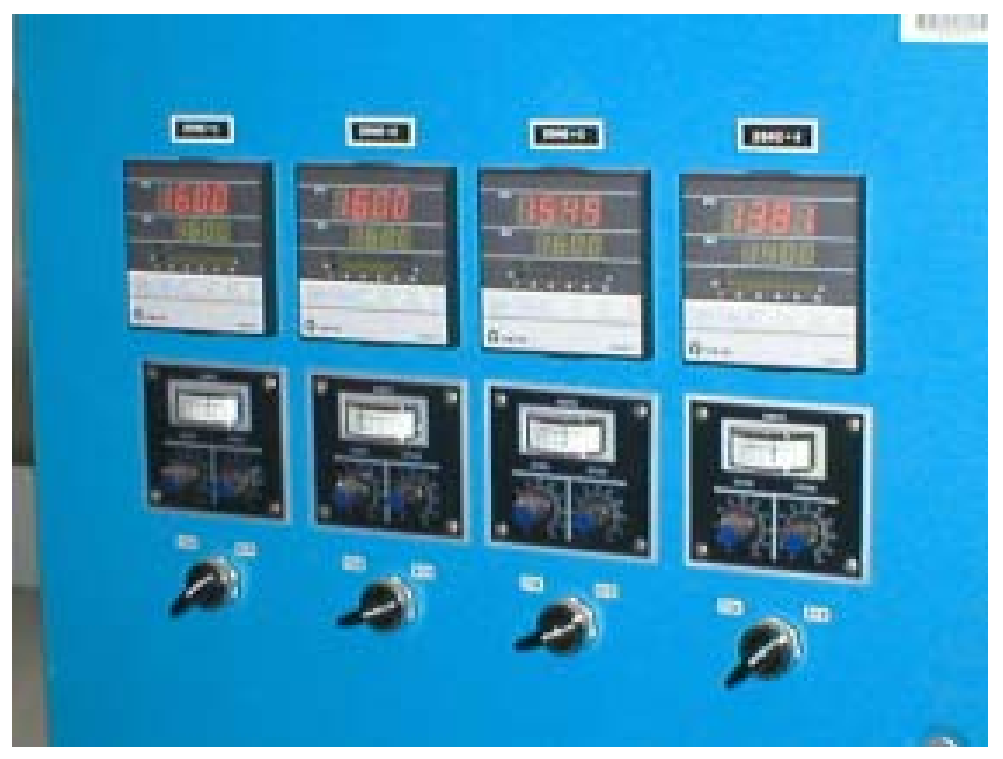

Figure 3.1.3.4.1 Temperature Controller

Custom made ceramic heating pads having the right dimensions to fit in each part of the system were ordered from Zircar Ceramics ${ }^{\mathrm{R}}$, Figure 3.1.3.4.2. 


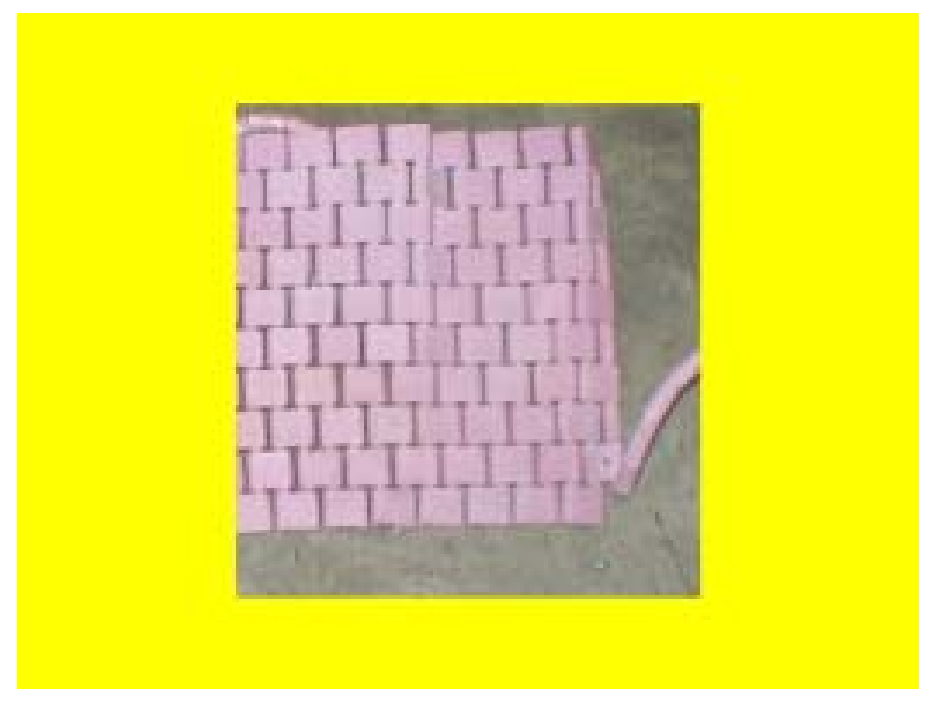

Figure 3.1.3.4.2 Ceramic heating pad

These were wrapped around each heating zone. The first zone is the air preheater with a power rating of $10.8 \mathrm{Kw}$. Zone two is the ash hopper section with a $3.6 \mathrm{Kw}$ heating element. Zone three is the middle part of the chamber with a heating element of $7.2 \mathrm{kw}$. Zone four is the upper portion of the chamber with a $7.2 \mathrm{Kw}$ heating element. Each zone has its own thermocouple connected to the temperature controller.

\subsubsection{The Pressure Sensors and Cooling System.}

One of the most challenging parts of the system was to assure the reliability of the pressure sensors at working condition temperatures. Commercially available miniature pressure transducers for high temperature application were purchased from Kulite ${ }^{r}$ Products for the HTTF, Figure 3.1.3.5.1 
HIGH TEMPERATURE ULTRAMINIATURE HIGH TEMPERATURE ULTRAMINIATURE IS PRESSURE TRANSDUCER

XCE-062 SERIES

- $1 / 10^{*}$ Diamoter
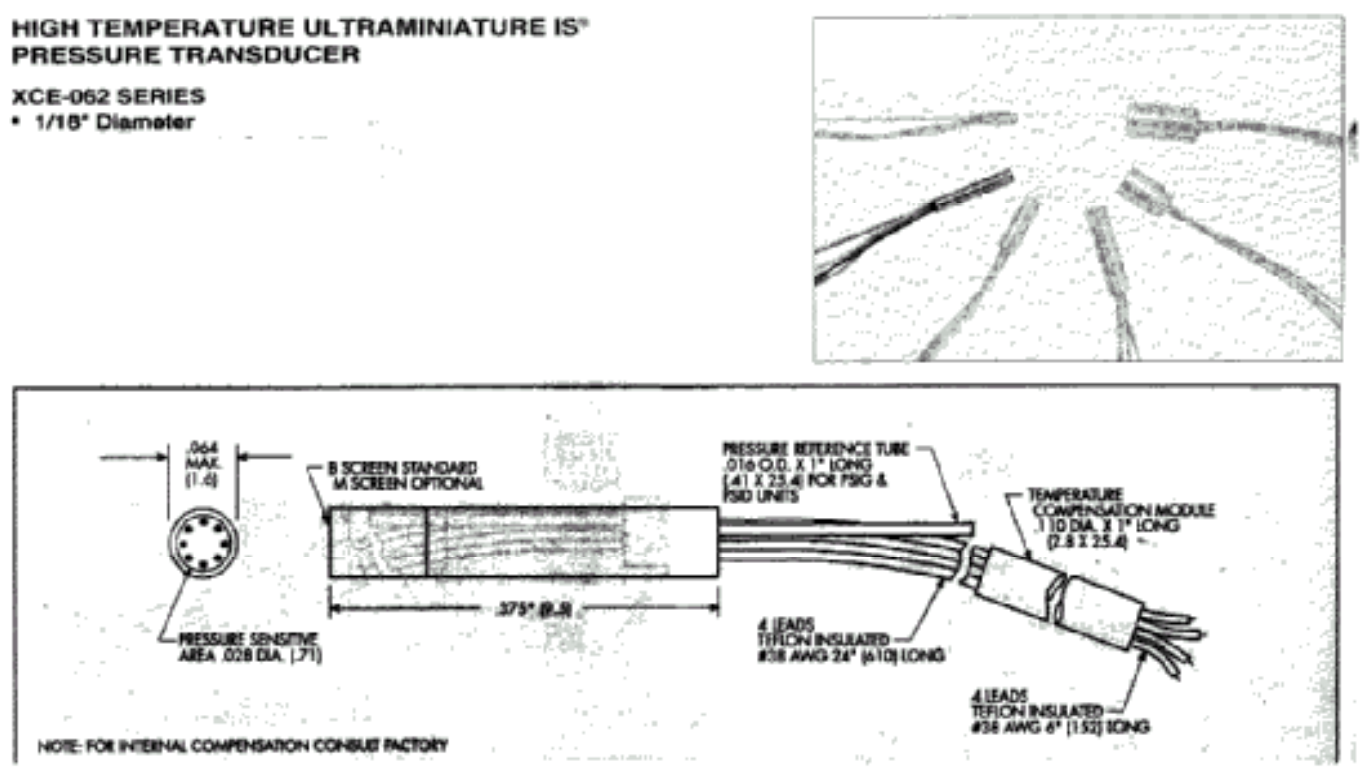

Figure 3.1.3.5.1 Miniature pressure transducer

Two kinds of water cooling protection systems were used for the sensors. One of the systems was used for the larger sensors that were installed on the chamber, cap and exhaust. These unites were acquired from the sensor supplier, Figure 3.1.3.5.2. 


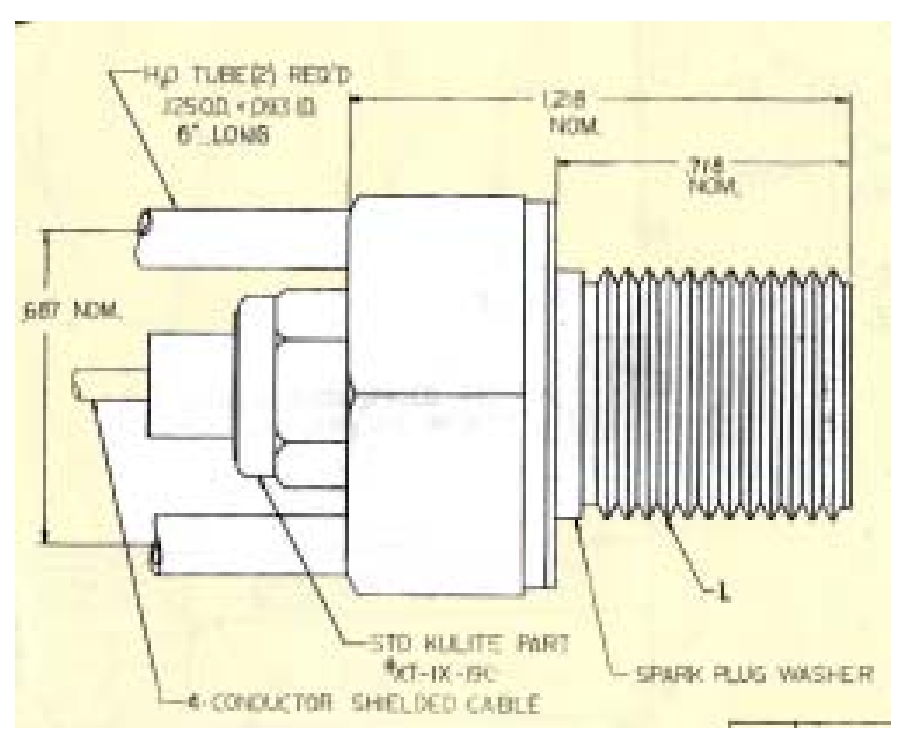

Figure 3.1.3.5.2 Water cooling jacket device

They consisted of a stainless steel water cooling jacket around the body of the sensor with inlet and outlet tubing for the water. The other water cooling protection system was used for the tiny filter pressure sensor. This sensor was a special design made to fit into the filter where the maximum temperatures occurred. The sensor cooling device consists of a 3/8" diameter. stainless steel T pipe assembly, as shown in Figure 3.1.3.5.3 


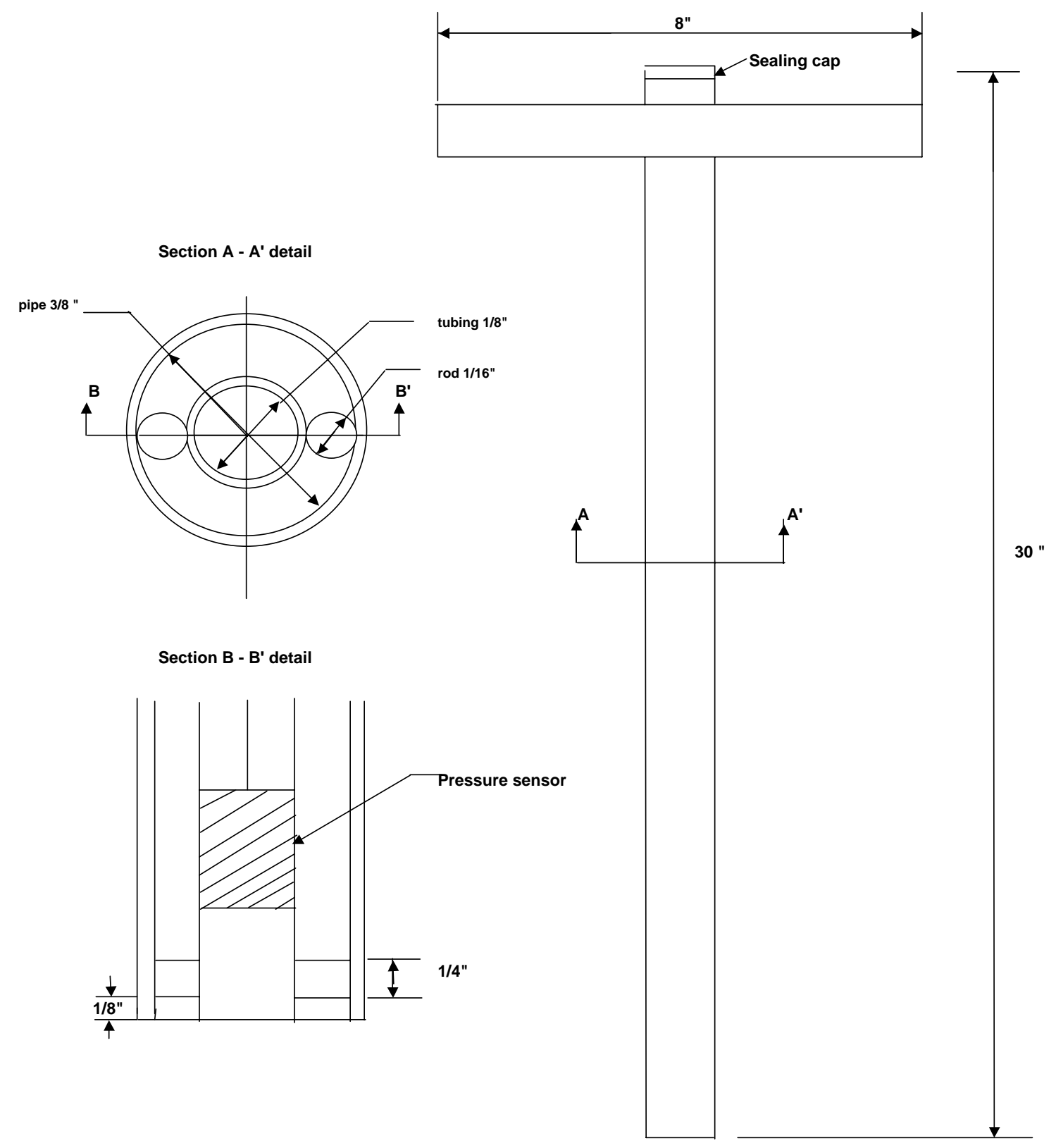

Figure 3.1.3.5.3 Miniature sensor cooling device 
The vertical portion of the T pipe has a 1/8" diameter tubing inside, forming a cylindrical space for water to flow around the tubing. Two 1/16" diameter cylindrical rods were welded 180 degrees apart along the tubing, forming two corridors along the $T$ pipe. The miniature pressure sensor was embedded in the $1 / 8$ " diameter tubing, as shown in Figure 3.1.3.5.4.

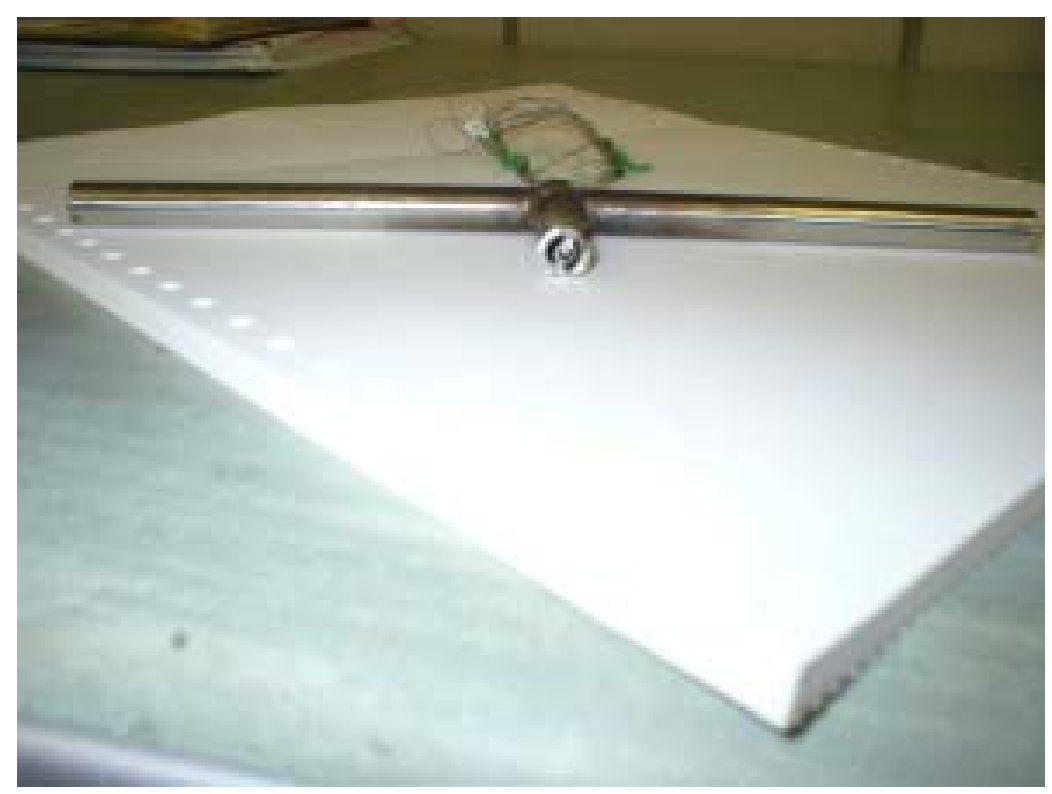

Figure 3.1.3.5.4 Internal view of the $\mathrm{T}$ pipe cooling device.

Cold water enters in one side of the T pipe. Then it flows to the center vertical pipe and goes down to the bottom through one half of the surface tubing. After the water has absorbed the heat, it goes up through the other half of the surface tubing and out through the other end of the T pipe. 
Because the filter pressure sensor was embedded in the filter, Figure 3.1.1.1, it encountered the most severe high temperature condition, it was necessary to change the soldering material used originally in the first tested unit. After several preliminary tests, this first unit melted inside, letting water vapor touch the sensor and damaged it. The silver soldering material used in the first design was changed by stainless steel TIG welding in the second design. After several trial and error tests, an appropriate design of the lines providing water to the sensor cooling devices was installed. A water filter, to avoid any clogging in the small $1 / 8$ " diameter tubing lines, was also installed with flow indicators to make sure that all lines were running water at all time. See Figure 3.1.3.5.5.

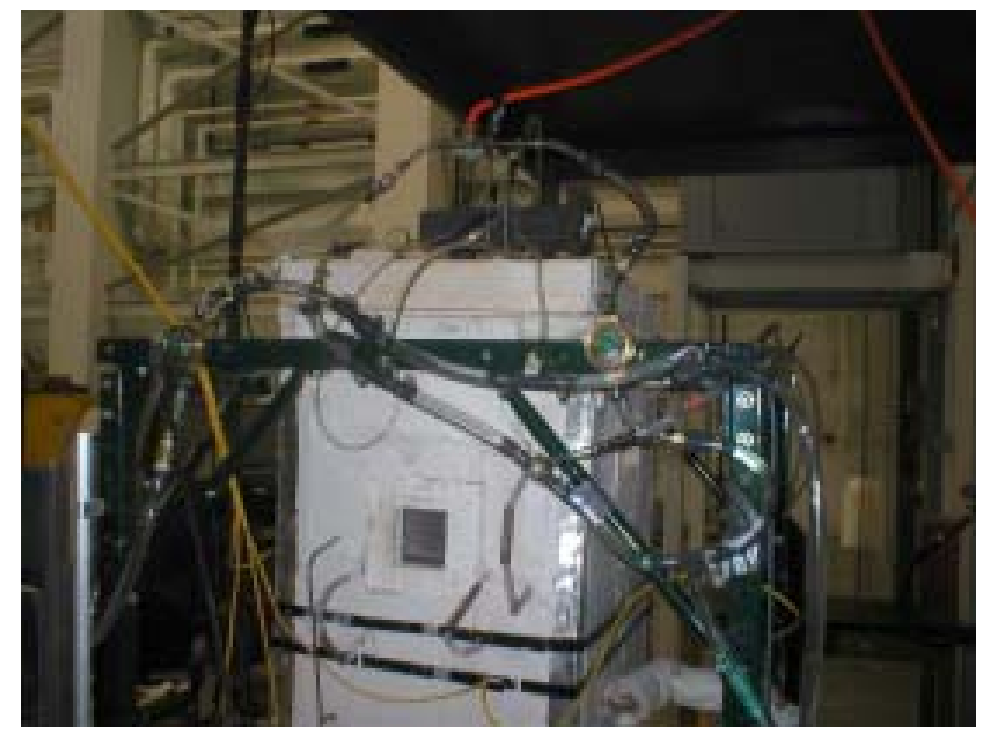

Figure 3.1.3.5.5 Pressure sensor cooling system

After several preliminary tests were performed, an optimum inlet flow of cold tap water of 2 gallons per minute was choose for the operation of the system. 


\subsubsection{The Data Acquisition System}

The same system successfully developed in the RTTF was used with the HTTF system, as show in Figure 3.1.3.5.6

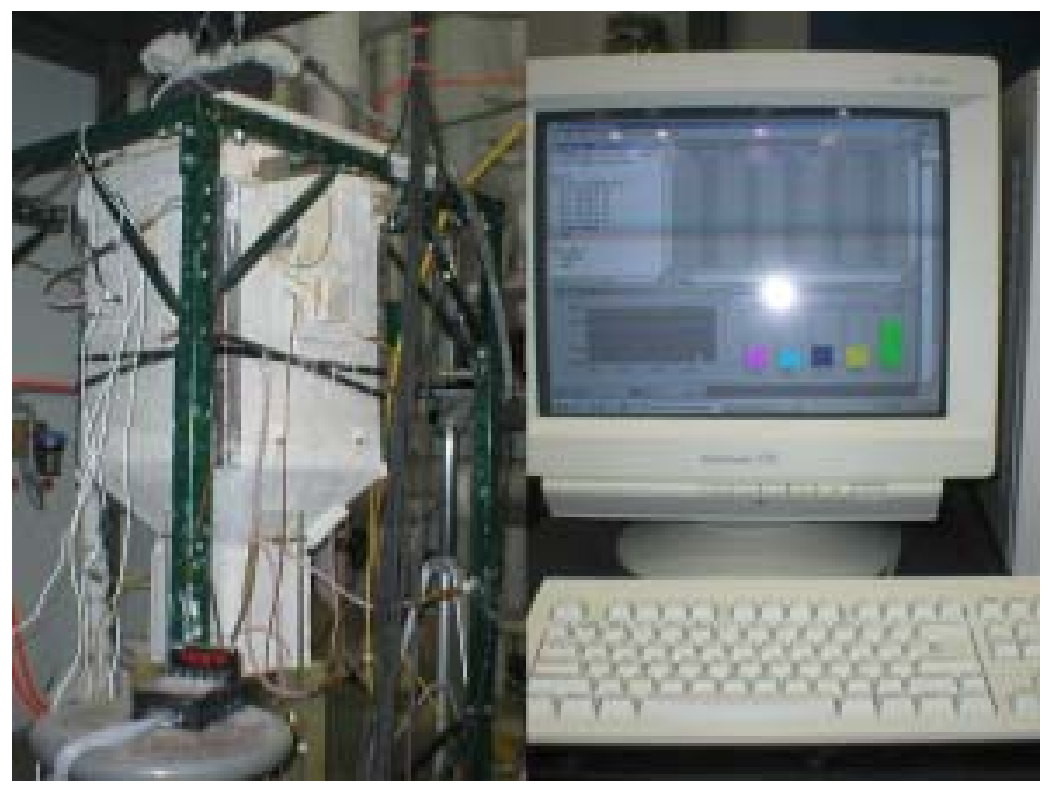

Figure 3.1.3.5.6 Data acquisition system

A full and detailed description of the electronics and software involved in it can be found in reference [7]. An initial room temperature calibration procedure was performed for all new high temperature sensors, and a high temperature correction was required in reducing the raw data.

Two acquisition programs were used. The first one, called here "calib.dap" was the one for the build up process, taking four readings of pressure each second. The other program, called "fastak.dap", was used for the surface regeneration process. It had the capability of recording one hundred readings per second. A list of the Matlab ${ }^{R}$ programs that were used is found in reference [7]. Many more 
readings were taken per second with the "fastak.dap" program than with the other program. This was because the significant pressure changes occurred during the surface regeneration process before the first second passed. The raw data was converted to spreadsheet files for data reduction and analysis purposes.

3.1.3.7 The Image Capturing System

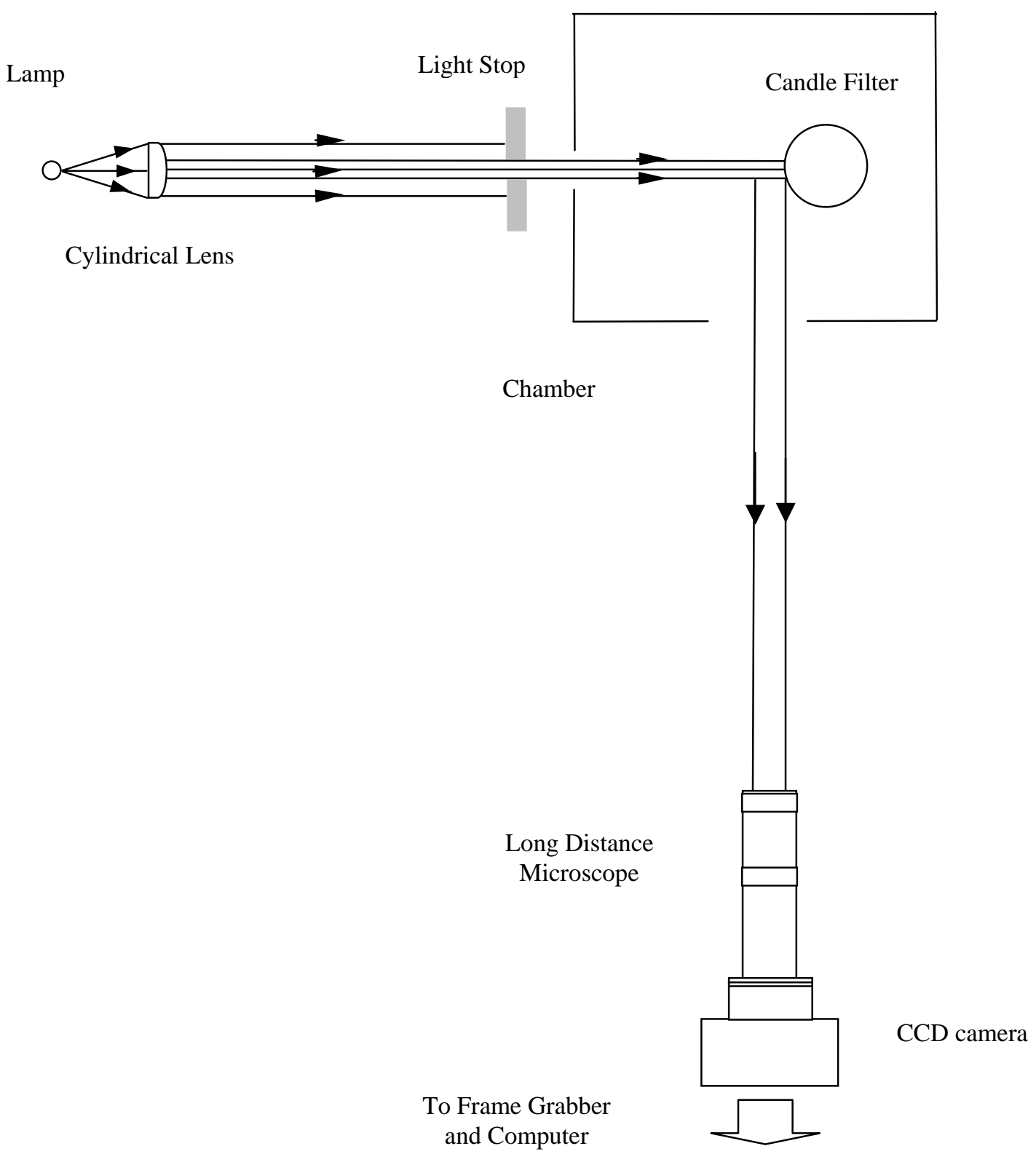

Figure 3.1.3.5.6 The image capturing system [6] 
The system developed for the RTTF was used in the HTTF, Figure 3.1.3.7.1.

Details about the illumination, long distance microscope, high resolution \& high speed camera and image acquisition board can be found on reference [6].

\subsubsection{Window design}

The chamber has been built with a quartz window in each wall. The image capturing system takes pictures through one of them while a light source system projects a sheet of intense light through the adjacent window. The windows were positioned in sets of two at two different elevations. They enabled image acquisition of surface regeneration at two locations of the candle filter. The selection of quartz windows was necessary for its high temperature resistance as well as its low thermal expansion coefficient. This selection avoided breakdowns in the cooling down period after each test.

All the windows had internal metallic shields which could be opened or closed depending on whether regeneration pictures were to be taken. Continuous gas (air) injection was provided between the shield and the quartz window in order to keep the window clean, which was crucial for obtaining good quality images. 


\subsection{Operation procedure}

The procedure consisted of three main steps. In the first step, ash was loaded into the ash hopper through one of the windows in the chamber. Sufficient volume of ash was loaded reaching a level of one inch below the tip of the fluidizing air tube in the ash hopper, Figure 3.1.3.3.2. The filter inside the chamber, the internal walls of the chamber and windows should be properly cleaned of any ash before starting a new test. In the second step the chamber is brought up to operating temperature. Initially valve V1 was closed and valve V2 was opened, Figure 3.1.1.1. This avoided any ash fluidization during the heating up process. The desired target air temperature for the test was set in zone 4 of the temperature control unit. Temperature readings were recorded every half hour during the heating process. The heating rate was specified in the temperature controller in order to achieve at least 5 to 6 hours of heating time.

In the third step, when the air inside the chamber had reached a stable temperature condition, the filtration process was now commenced. The data acquisition system is activated, and valve V1 was opened and valve V2 was closed.

After the filtration period has been completed, valve V1 was closed and valve V2 was opened in order to let the free particles settle while maintaining a face velocity on the ash layer. Then two windows at the selected level were opened for the 
image-capturing event of filter surface regeneration. The onset of the image capturing process for the surface regeneration event was triggered by the signal coming from the solenoid valve. This step was repeated for each cycle at a specified temperature condition.

A detailed operation procedure for the facility follows, describing all information needed to perform a test.

\subsubsection{Start Up}

1. Clean the filter, the internal walls of the chamber and the windows of any ash.

2. Change the alumina silica paper gaskets of the windows in use.

3. Install the windows and close the chamber, making sure is free of air leaks.

4. Turn on the ventilation fan up in the hood.

5. Open the air supply valve to the gas control panel.

6. Set the water flow for pressure transducer cooling system (2 gallons per minute)

7. Set the airflow conditions in the gas control panel, making sure that the needle control valve for the air supply to the windows is open.

8. Activate the data acquisition system (DAS) and check that the pressure transducers are reading data. 
9. Set the temperatures in the temperature controller. Set zone 4 at $1000^{\circ} \mathrm{F}$, set zone 2 and 3 at $100 \mathrm{~F}$ degrees above zone 4, and set zone $1200 \mathrm{~F}$ below zone 4 .

10. Turn on all four knobs in the temperature control panel to initiate the heating up period.

11. Wait until zone 4 has reached the target temperature, then increase zone 4 temperature control, setting $100 \mathrm{~F}$ higher, then do the same with zones 1,2 and 3.

12. Wait again until zone 4 has reached the target temperature and repeat step 11 as many times as necessary until the target temperature is reached in zone 4.

13. Make sure that during the whole heating up period, valve $\mathrm{V} 1$ is closed and valve $\mathrm{V} 2$ is open.

14. Track the system as it is heated to the test temperature, recording temperature data from all four zones. Record pressure and flow data from both the gas control panel and the water cooling system. All recordings should be taken every 30 minutes.

15. Once the test temperature has been reached and the system is stable, name the first build-up file in the DAS. 


\subsubsection{Cycling Operation}

1. Make sure the metallic windows shields are properly closed and the needle control valve for cleaning air flow is open $1 \frac{1}{4}$ turns.

2. Open valve V1 and close valve V2.

3. Start to record data with DAS using the program "calib.dap"

4. Once the required build up time (ash deposition time or filtration time) has been reached, close valve V1 and open valve V2.

5. Close the main air supply valve in the gas control panel (the blue one)

6. Wait at least for two minutes to allow the ashes to settle down inside the chamber. (4POINTS= 1 SEC)

7. Open the metallic window shields, making sure that the chamber is not shaken, in order to avoid damage to the existing ash cake.

8. Open the air supply valve in the gas control panel.

9. Stop taking data with program"calib.dap".

10. Create a new file by changing the name of the old file in the DAS.

11. Open the program "fastak2.dap"

12. Make sure the image capturing system is ready to take pictures (awaiting 
trigger condition). This is done once the optical initialization procedure has been completed. [6]

13. Turn on the light source to check if the image is clear. Set the proper gain and integration time, looking for the better quality of the image. Turn the light source off again.

14. Set the desired regeneration pressure in the N2 regulator and open the cylinder valve.

15. Turn the light on and initiate the DAS.

16. Once the sequence of pictures has been taken, turn the light off and close the N2 cylinder valve.

17. Stop the "fastak2.dap" program in the DAS.

18. Change the file name for the next build up period.

19. Open the "calib.dap" program in DAS.

20. Close the metallic window shields without shaking the chamber and make sure them are totally closed.

21. Open valve V1 and close valve V2.

22. Start to acquire data with "calib.dap" program at DAS.

23. Go to step 4 and repeat the process for each cycle in the test. 


\subsubsection{Shut down}

1. Turn off all four knobs in the Temperature control Panel, making sure temperatures still can be read from the display.

2. Make copies of all pressure data and image data files in a different magnetic media than the hard drive of the computer. A CD is suggested.

3. Turn off the DAS and the Image Capturing System.

4. Make sure valve V1 is closed and V2 is open.

5. Let the system cool down, and inspect for water leaks in the sensor cooling systems until zone 4 has reach $400 \mathrm{~F}$.

6. Turn off the air supply to the system

7. Turn off the ventilation fan up in the hood.

8. Turn off the water supply of the system.

9. Turn off the Temperature display in the temperature controller.

It is very important for a complete test that the water supply to the cooling sensor system keeps running at the right flow ( 2 GPM at 25 psi) at all times. If any water leaks were detected while running a test, the water supply should never be shutdown in order to avoid damaging the pressure sensors. A complete long term test, involved recording data for 21 regeneration cycles and required approximately 24 continuous hours of operation. 


\section{Chapter 4. Test Results}

\subsection{Test matrix}

Many preliminary tests were conducted on the HTTF system from room temperature up to $1500{ }^{\circ} \mathrm{F}$ to ensure the integrity and performance of all its components. After these preliminary tests, ash was added to the system. A test matrix was formulated to establish the performance of the HTTF, table 4.1.1. The test conditions selected correspond to those of room temperature tests which were done in the first stage of this project. A coal ash sample obtained from the Power System Development Facility (PSDF) at Wilsonville, AL was used in both the room and the elevated temperature regeneration tests.

The basic test conditions were (1) face velocity: $5 \mathrm{~cm} / \mathrm{s}$, (2) regeneration pressure: 6,596 Kpa (95 psi), and (3) build-up time: 20 minutes. To improve the evaluation of the HTTF system for temperatures above $1300 \mathrm{~F}$, an additional test condition of a face velocity of $7 \mathrm{~cm} / \mathrm{s}$ was included in the last set of long term tests.

Pressure history data for the pressure drop across the filter (filter pressure chamber pressure) was obtained at the five test temperatures. The results are shown in Figures 4.2.2, 4.2.8, 4.2.17, 4.2.24, 4.2.35, 4.2.40 and 4.2.57. 


\begin{tabular}{|c|c|c|c|c|c|}
\hline Test \# & Temperature & $\begin{array}{c}\text { Face Velocity } \\
(\mathrm{cm} / \mathbf{s})\end{array}$ & $\begin{array}{c}\text { Regeneration } \\
\text { Pressure ( psi) }\end{array}$ & $\begin{array}{c}\text { Build up time } \\
\text { (minutes) }\end{array}$ & $\begin{array}{c}\text { \# of regeneration } \\
\text { cycles }\end{array}$ \\
\hline 1 & 1100 & 5 & 95 & 20 & 8 \\
\hline 2 & 1200 & 5 & 95 & 20 & 7 \\
\hline 3 & 1300 & 5 & 95 & 20 & 8 \\
\hline 4 & 1300 & 5 & 95 & 20 & 21 \\
\hline 5 & 1300 & 7 & 95 & 20 & 21 \\
\hline 6 & 1400 & 5 & 95 & 20 & 21 \\
\hline 7 & 1400 & 7 & 95 & 20 & 16 \\
\hline 8 & 1500 & 7 & 95 & 20 & 21 \\
\hline
\end{tabular}

Table 4.1.1 Test Matrix

Several representative surface regeneration images at different temperature tests are shown in the following Figures. The term "successful regeneration" refers to observed cake detachment in the images taken. It can be thick ash regeneration as shown typically in Figure 4.2.50, where an initial vertical crack is noticed on the cake before detaching (frame at $t=0.16 \mathrm{sec}$ ), then forming chunks of material falling down. It can also be thin ash regeneration, when the cake is detached by an 
explosion of small particles shooting out from the filter wall and then either falling down or re-entraining as is shown in Figure 4.2.51.

Figure 4.2.6 shows a thick ash regeneration at $1100{ }^{\circ} \mathrm{F}$ for the first cycle. A thin ash regeneration at $1100{ }^{\circ} \mathrm{F}$ for the second cycle is shown in Figure 4.2.7. Figure 4.2.12 shows a thin ash regeneration at $1200^{\circ} \mathrm{F}$ for the first regeneration cycle. Figure 4.2.13 shows a thick ash regeneration at $1200{ }^{\circ} \mathrm{F}$ at the fourth regeneration cycle. Figures 4.2.14 to 4.2.16 show different regeneration characteristics at $1300 \mathrm{~F}, 5 \mathrm{~cm} / \mathrm{s}$. Figure 4.2 .14 shows small chunks of ashes falling down. Figure 4.2.15 shows a thin ash regeneration and Figure 4.2.16 shows no regeneration at all. Figures 4.2 .48 and 4.2 .49 show thick and thin ash regeneration respectively at $1400 \mathrm{~F}, 5 \mathrm{~cm} / \mathrm{s}$. Figures 4.2 .50 and 4.2 .51 show thick and thin regenerations at $1400 \mathrm{~F}, 7 \mathrm{~cm} / \mathrm{s}$. Figures 4.2 .62 and 4.2 .63 show thick ash regeneration in cyles one and four respectively at $1500 \mathrm{~F}, 7 \mathrm{~cm} / \mathrm{s}$.

\subsection{Analysis of data obtained in the test}

Due to the amount of data obtained from the test performed and the scope of this thesis, a preliminary analysis of some specific observations is presented in this section. Since all the analysis was derived from the pressure history curves, a definition of the terms involved is presented in advance. See Figure 4.2.1 
$\Delta P_{i}=$ resistance offered by the filter, residual and ash layer accumulated in last filtration.

$\Delta P_{f}=$ resistance offered by the filter and the residual ash, after regeneration.

$\Delta \mathrm{P}_{\max }=$ maximum pressure difference.

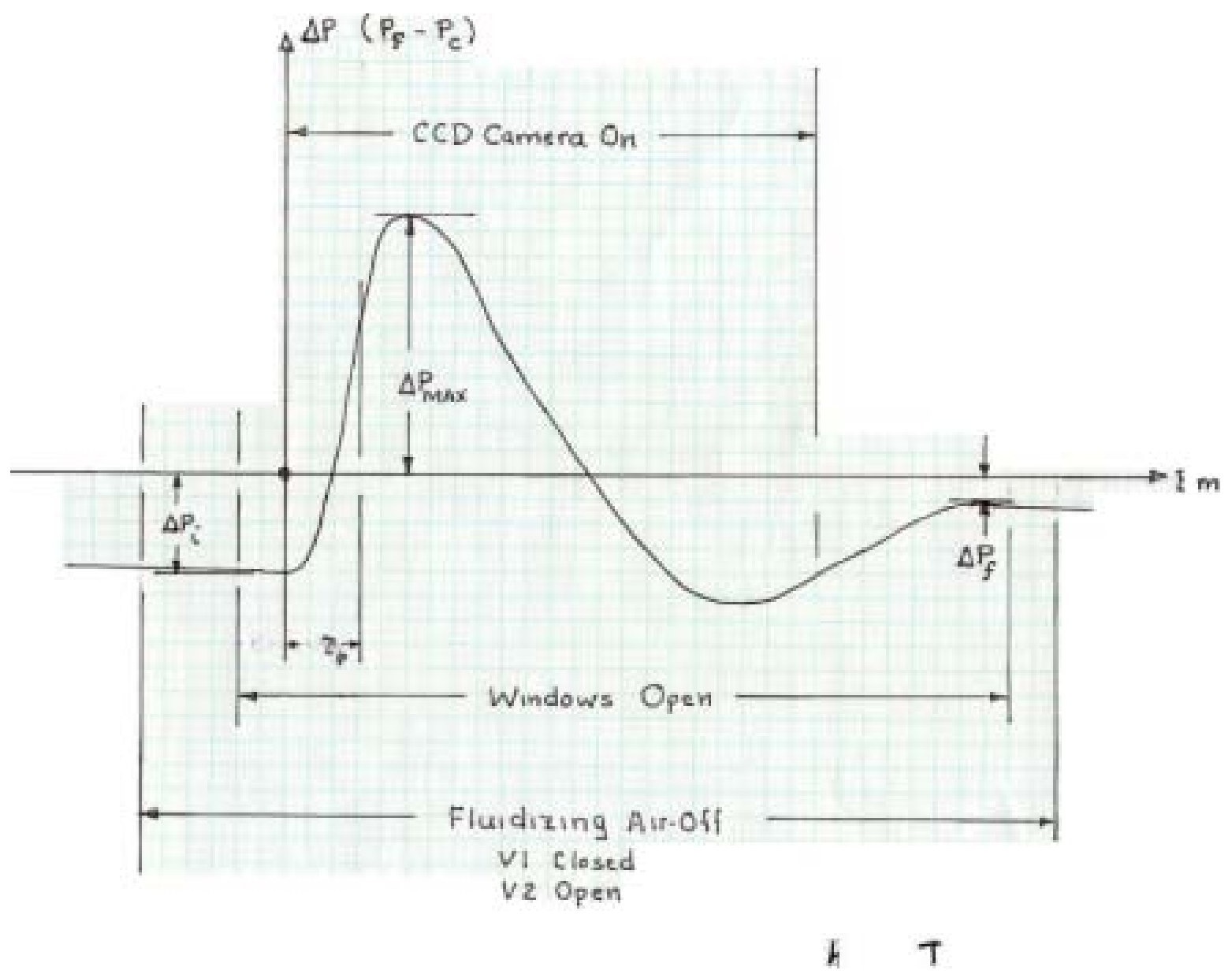

Figure 4.2.1 Analysis variable definition for a typical pressure drop curve in a regeneration cycle. [15] 
Comparing the high temperature test results up to $1200{ }^{\circ} \mathrm{F}$ with the room temperature results previously taken from the RTTF, see reference [6], the ash surface regeneration characteristics are about the same, except that it is conducive for residual ash to form at elevated temperatures. However, when testing at 1300 ${ }^{\circ} \mathrm{F}$, a different ash surface regeneration behavior has been observed. Figures 4.2.14 to 4.2.16 show ash regeneration observations at $1300^{\circ} \mathrm{F}$ at cycles 4,5 , and 6. It was noted that no ash regeneration was observed for cycles 1 to 4 , as typically shown in Figure 4.2.14. The ash layer thickness just simply built up and at cycle 5 a partially successful ash regeneration was observed, as shown in Figure 4.2.15. There is evidence of residual ash layer formation after cycle 5, as shown in Figure 4.2.15 $(\mathrm{t}=0.83$ seconds image). After cycle 5 , no ash regeneration was observed, as typically shown in Figure 4.1.16.

The HTTF was tested with more filtration cycles at elevated temperatures. This was done in order to obtain a more complete set of data at the higher temperatures of $1300 \mathrm{~F}$ and above.

Table 4.2.1 shows the general observations for the long term tests. 


\begin{tabular}{|c|c|c|c|c|c|}
\hline Temperature & Face velocity & $\begin{array}{l}\text { initial pressure } \\
\text { drop range } \\
\text { (psi) }\end{array}$ & $\begin{array}{l}\text { maximum } \\
\text { pressure drop } \\
\text { range (psi) }\end{array}$ & $\begin{array}{l}\text { final pressure } \\
\text { drop range } \\
\text { (psi) }\end{array}$ & Observations \\
\hline $1300 \mathrm{~F}$ & $5 \mathrm{~cm} / \mathrm{s}$ & -0.41 to -0.01 & 1.54 to 1.91 & -0.42 to 0.005 & $\begin{array}{l}\text { Sucessful thick ash } \\
\text { regeneration at first } \\
\text { cycle. No } \\
\text { regeneration } \\
\text { between cycles } 2 \\
\text { and 21, with } \\
\text { different amount of } \\
\text { particles flying out. }\end{array}$ \\
\hline $1300 \mathrm{~F}$ & $7 \mathrm{~cm} / \mathrm{s}$ & -0.62 to -0.38 & 1.33 to 1.59 & -0.60 to -0.37 & $\begin{array}{l}\text { Succesful thick ash } \\
\text { regeneration at first } \\
\text { cycle, sucessful } \\
\text { thin ash } \\
\text { regeneration at } \\
\text { second cycle. No } \\
\text { regeneration } \\
\text { between cycles } 3 \\
\text { and } 21 \text { with } \\
\text { different amount of } \\
\text { particles flying out }\end{array}$ \\
\hline $1400 \mathrm{~F}$ & $5 \mathrm{~cm} / \mathrm{s}$ & -0.43 to -0.2 & 1.53 to 1.70 & -0.41 to -0.18 & $\begin{array}{l}\text { Thick ash } \\
\text { regeneration at first } \\
\text { cycle. Thin ash } \\
\text { regeneration at } 2^{\text {nd }} \\
\text { and fifth cycles. No } \\
\text { regeneration in } \\
\text { other cycles with } \\
\text { different amount of } \\
\text { particles flying out. }\end{array}$ \\
\hline $1400 \mathrm{~F}$ & $7 \mathrm{~cm} / \mathrm{s}$ & -0.52 to -0.36 & 1.51 to 1.63 & -0.48 to -0.36 & $\begin{array}{l}\text { Thick ash } \\
\text { regeneration at first } \\
\text { cycle. Thin ash } \\
\text { regeneration at } \\
\text { second cycle. No } \\
\text { regeneration in } \\
\text { other cycles with } \\
\text { different amount of } \\
\text { particles flying out. }\end{array}$ \\
\hline $1500 \mathrm{~F}$ & $7 \mathrm{~cm} / \mathrm{s}$ & -0.52 to -0.29 & 1.49 to 1.68 & -0.55 to -0.33 & $\begin{array}{l}\text { Thick ash } \\
\text { regeneration at } \\
\text { cycles \# 1, \#2, and } \\
\# 4 \text {. No } \\
\text { regeneration in } \\
\text { other cycles with } \\
\text { different amount of } \\
\text { particles flying out. }\end{array}$ \\
\hline
\end{tabular}

Table 4.2.1 General results for Long term test at 1300, 1400 and $1500 \mathrm{~F}$. 
All the tests showed few successful regenerations in the first cycles of operation. The test at $1300 \mathrm{~F}, 5 \mathrm{~cm} / \mathrm{s}$, showed successful regeneration at first cycle. The test at $1300 \mathrm{~F}, 7 \mathrm{~cm} / \mathrm{s}$, showed successful regeneration at first and second cycles. The test at $1400 \mathrm{~F}, 5 \mathrm{~cm} / \mathrm{s}$, showed successful regeneration in first, second and fifth cycle. The test at $1400 \mathrm{~F}, 7 \mathrm{~cm} / \mathrm{s}$ showed successful regeneration at first and second cycles. The test at $1500 \mathrm{~F}, 7 \mathrm{~cm} / \mathrm{s}$, showed a successful regeneration in the first, second and fourth cycles.

The pressure profiles shown in Figure 4.2.17 for the $1300{ }^{\circ} \mathrm{F}$ test case, have the opposite trend (upwards) when compared to Figures 4.2.2 and 4.2.8. The same trend is shown in the tests at $1400 \mathrm{~F}$ and $1500 \mathrm{~F}$, see Figures 4.2.35, 4.2 .40 and 4.2.57. It can be explained due to the chemical/physical property changes of coal ash, i.e. the coal ash was more likely to attach to the filter at temperatures above $1300^{\circ} \mathrm{F}$. Therefore, the ash surface regeneration characteristics differ substantially with those of lower temperature tests. It is possible that residual ash can be built up on candle filter while maintaining filter surface porosity [16].

The most common mechanism of particle cleaning observed in this set of tests was particles flying out from the cake in varying amounts, depending on the conditions of each test. This phenomenon is shown in Figures 4.2.52 and 4.2.53, frames 
corresponding at time $0.25 \mathrm{sec}$. This event is not considered to be a successful surface regeneration.

As the number of cycles increased, the maximum pressure drop across the filter increased during regeneration in four of the five tests. This is shown in Figures 4.2.26, 4.2.37, 4.2.42 and 4.2.59. In the particular case of the test at $1300 \mathrm{~F}, 7$ $\mathrm{cm} / \mathrm{s}$, and comparing regenerations at cycles 3 and 18 , it can be seen that the pressure drop has increased due to a double effect. These two effects are an increase in the filter pressure from $16.86 \mathrm{psi}$ to $16.95 \mathrm{psi}$ and a decrease in the chamber pressure from 15.75 psi to 15.63 psi, respectively, as it is shown in Figures 4.2.33 and 4.2.34.

Other important observations were noticed regarding the influence of face velocity on particle reintrainment for tests at $1300 \mathrm{~F}$ and $1400 \mathrm{~F}$. The minimum values of the pressure drop across the filter are all above -0.6 psi for a face velocity of 5 $\mathrm{cm} / \mathrm{s}$ as seen in Figures 4.2.17 and 4.2.35. In Figures 4.2.24 and 4.22.40, all the minimum values of the pressure drop across the filter corresponding to a face velocity of $7 \mathrm{~cm} / \mathrm{s}$ went below $-0.58 \mathrm{psi}$. This means that higher face velocities caused more negative pressure drops and the reintrainment of the particles back to the filter becomes more probable. Evidence of reintrainment can be seen in the sequence of images presented in Figure 4.2.54.

It was also observed that the face velocity affects the maximum pressure drop across the filter during the surface regeneration. All values for $1300 \mathrm{~F}, 5 \mathrm{~cm} / \mathrm{s}$ are located between 1.54 and $1.91 \mathrm{psi}$ as seen in Figure 4.2.19. For $1300 \mathrm{~F}, 7 \mathrm{~cm} / \mathrm{s}$ 
lower values (1.33 to $1.59 \mathrm{psi}$ ) are seen in Figure 4.2.26. The same behavior was found at $1400 \mathrm{~F}$, where for $5 \mathrm{~cm} / \mathrm{s}, 94 \%$ of the values of maximum pressure drop ranged between 1.57 and $1.7 \mathrm{psi}$, as seen in Figure 4.2.37. At $7 \mathrm{~cm} / \mathrm{s}$, all the values ranged between 1.51 and $1.64 \mathrm{psi}$, as seen in Figure 4.2.42.

An increase in face velocity from $5 \mathrm{~cm} / \mathrm{s}$ to $7 \mathrm{~cm} / \mathrm{s}$ creates a higher chamber pressure, which in turn causes a lower maximum pressure drop across the filter. A typical case is shown in Figure 4.2.32, where a comparison between first cycles in test at $1300 \mathrm{~F}, 5 \mathrm{~cm} / \mathrm{s}$ and test at $1300 \mathrm{~F}, 7 \mathrm{~cm} / \mathrm{s}$ has been done.

Additional Figures are presented below, showing the behavior of the initial, maximum and final pressures drops for all the temperatures tested. 


\section{Sequence of regenerations at $1100 \mathrm{~F}$ basic conditions}

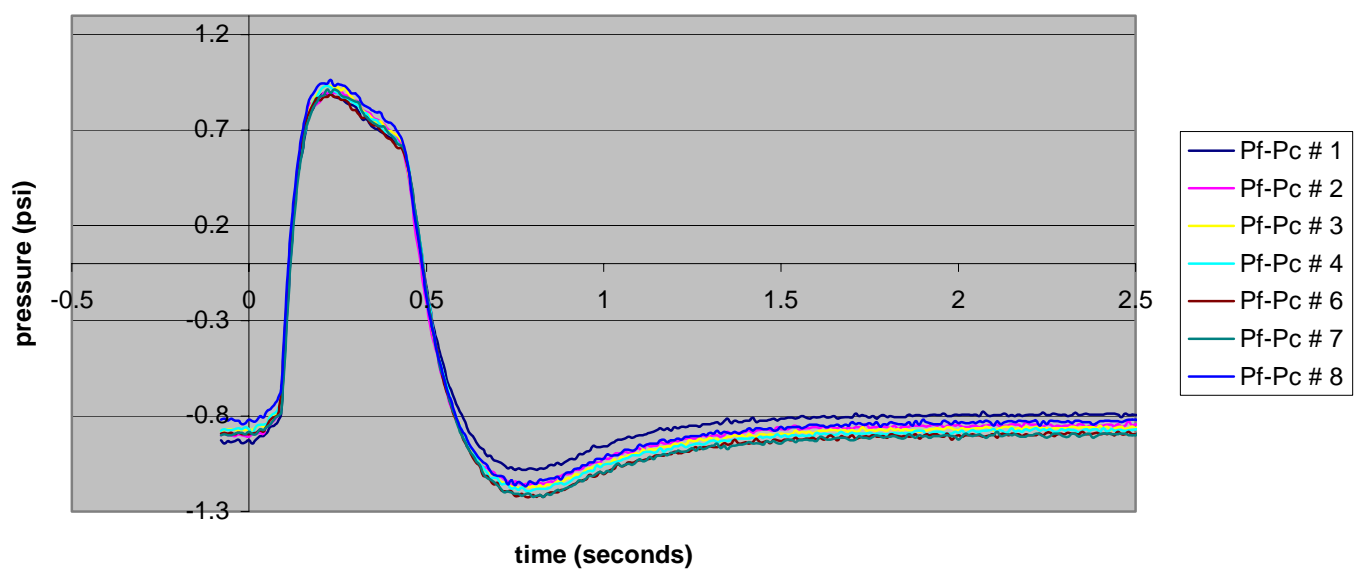

Figure 4.2.2 Pressure profiles during surface regeneration at $1100^{\circ} \mathrm{F}$.

** ( $\mathrm{Pf}-\mathrm{Pc}$ ) stands for the pressure drop across the filter (filter pressure minus chamber pressure). The number to the right refers to the regeneration cycle.

$\Delta P_{\mathrm{i}}$ vs cycle $1100 \mathrm{~F}, 5 \mathrm{~cm} / \mathrm{s}$

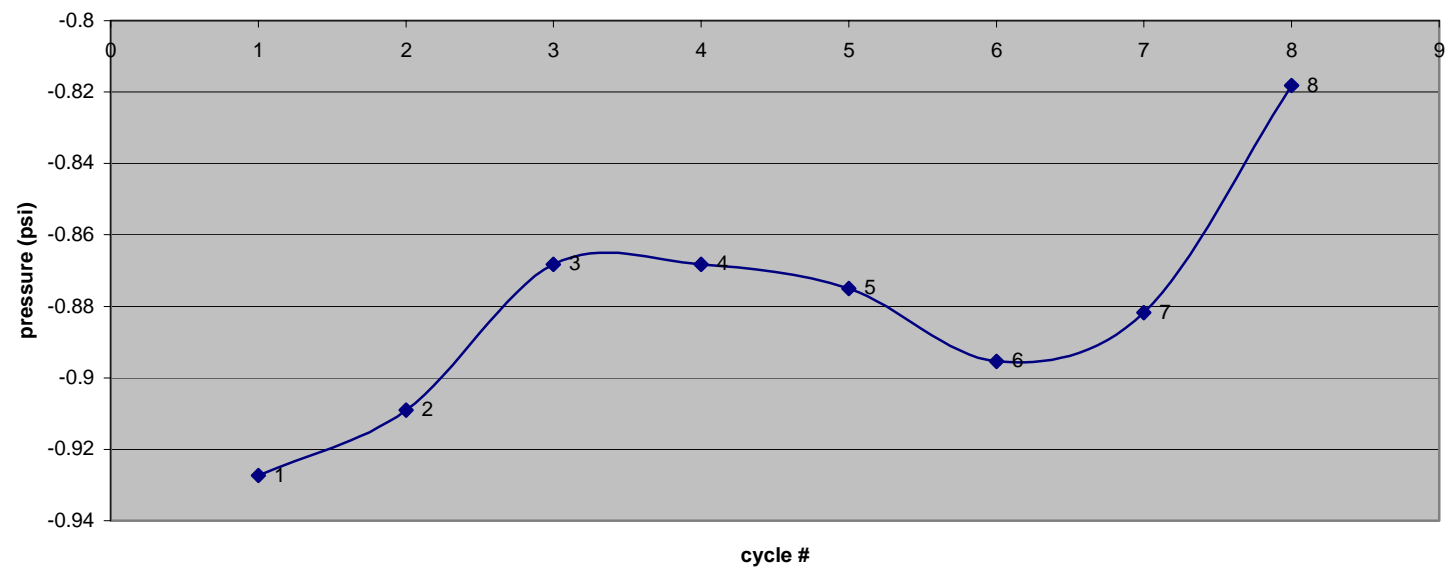

Figure 4.2.3 Initial pressure drop at $1100 \mathrm{~F}$ 
$\Delta \mathrm{P}$ max vs cycle $1100 \mathrm{~F}, 5 \mathrm{~cm} / \mathrm{s}$

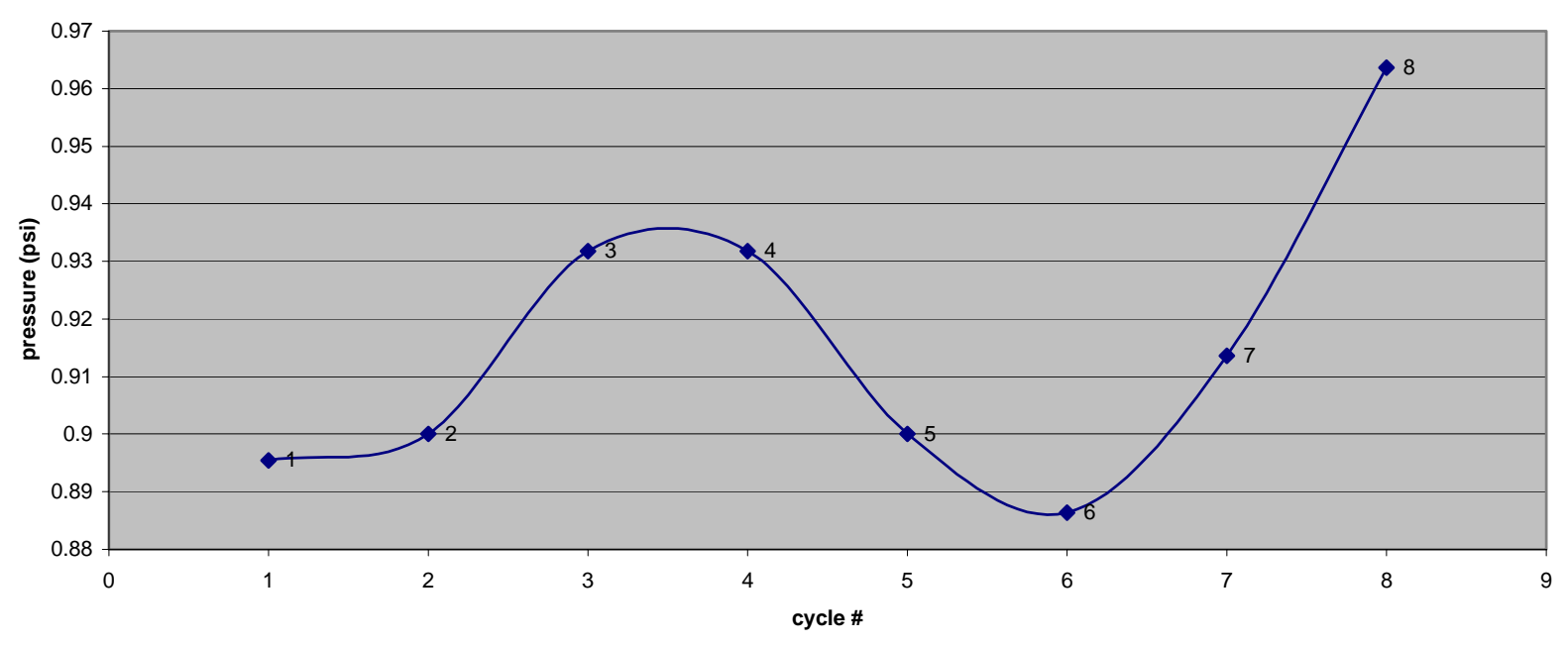

Figure 4.2.4 Maximum pressure drop at $1100 \mathrm{~F}$

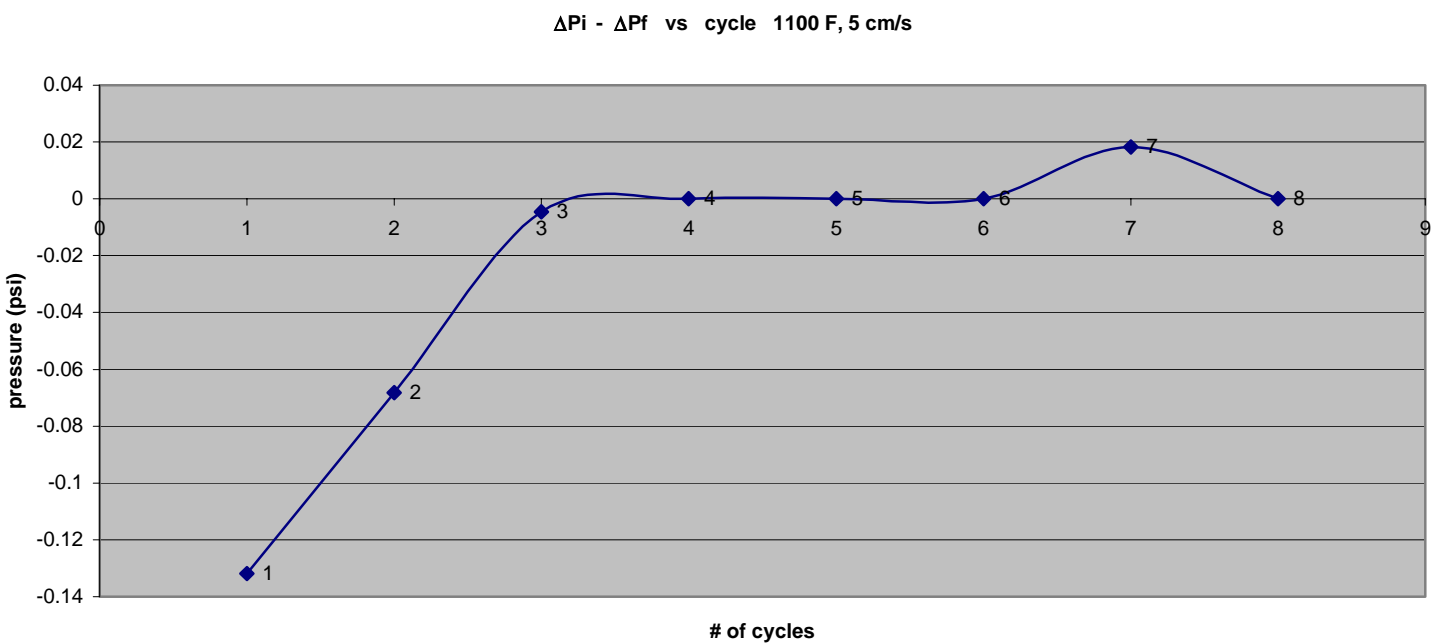

Figure 4.2.5 Initial - final pressure drop difference at $1100 \mathrm{~F}$ 


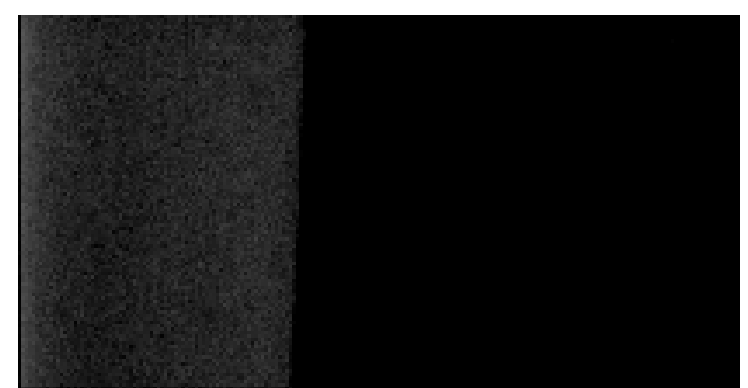

$\mathrm{t}=0 \mathrm{sec}$

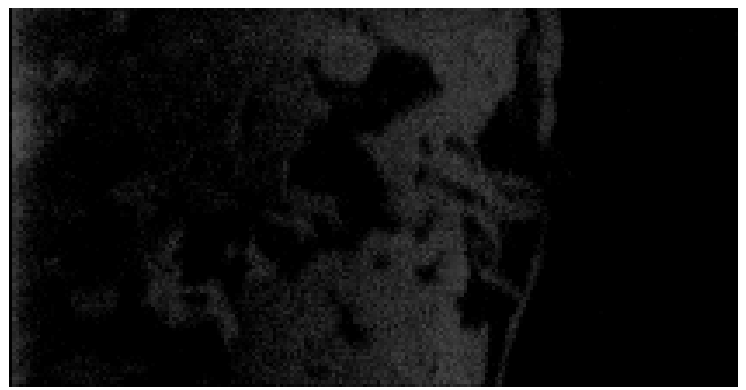

$\mathrm{t}=0.28 \mathrm{sec}$

Figure 4.2.6 First cycle Regeneration (Thick ash) at $1100^{\circ} \mathrm{F}$

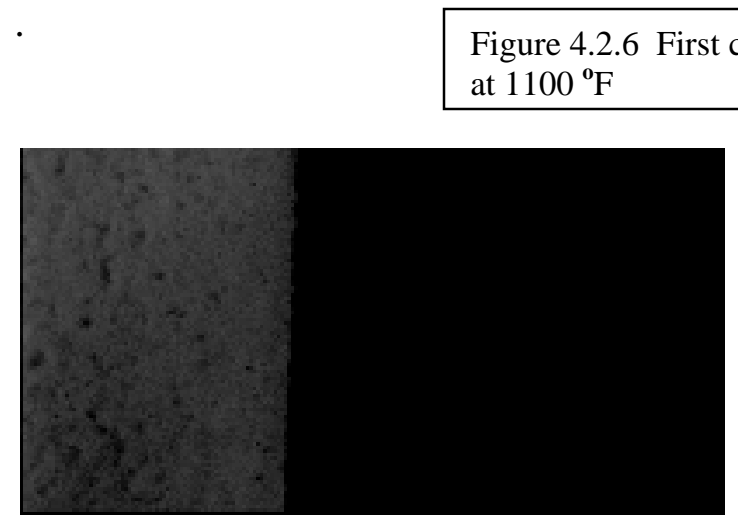

$\mathrm{t}=0 \mathrm{sec}$

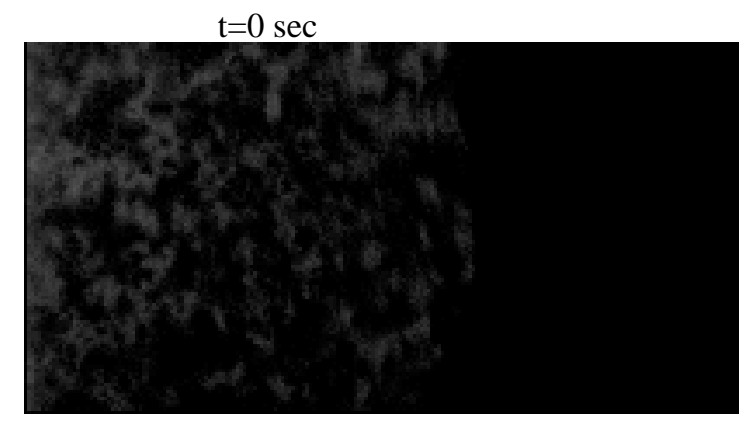

$\mathrm{t}=0.25 \mathrm{sec}$

$0.25 \mathrm{sec}$

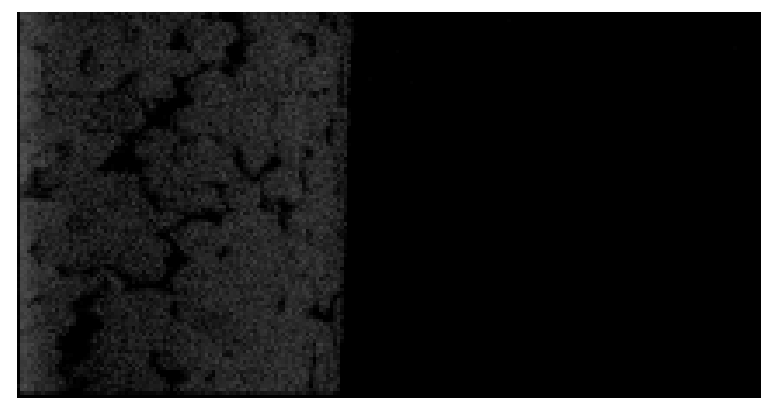

$\mathrm{t}=0.17 \mathrm{sec}$

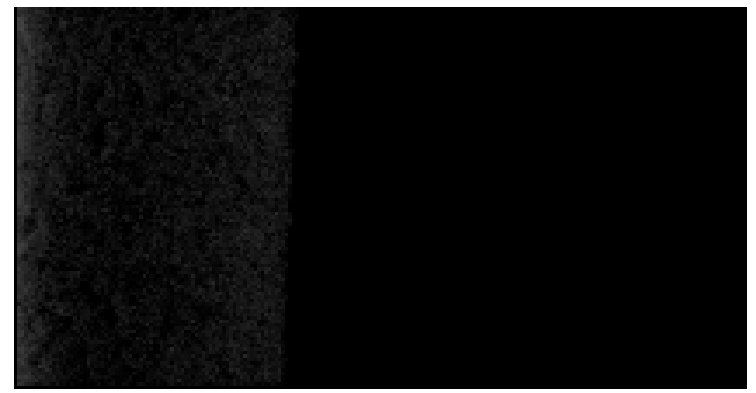

$\mathrm{t}=0.5 \mathrm{sec}$

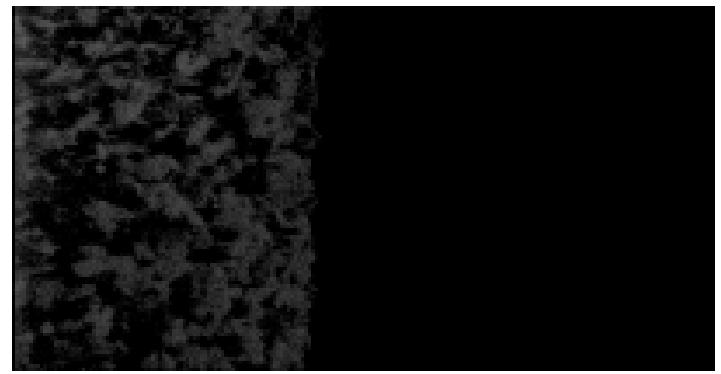

$\mathrm{t}=0.17 \mathrm{sec}$

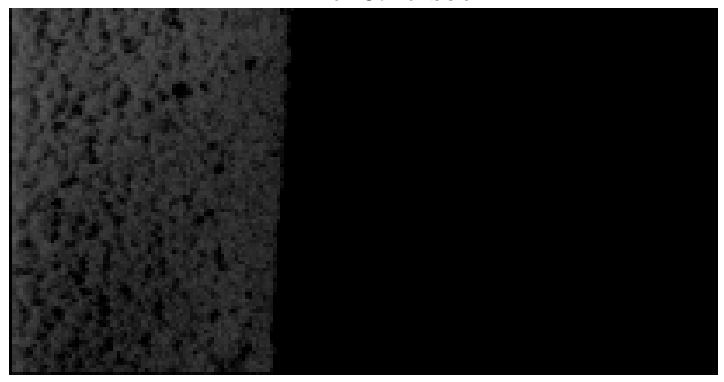

$\mathrm{t}=0.5 \mathrm{sec}$

Figure 4.2.7. Second cycle

Regeneration (Thin ash) at $1100 \mathrm{~F}$ 


\section{Sequence of regenerations at $1200 \mathrm{~F}$}

basic conditions

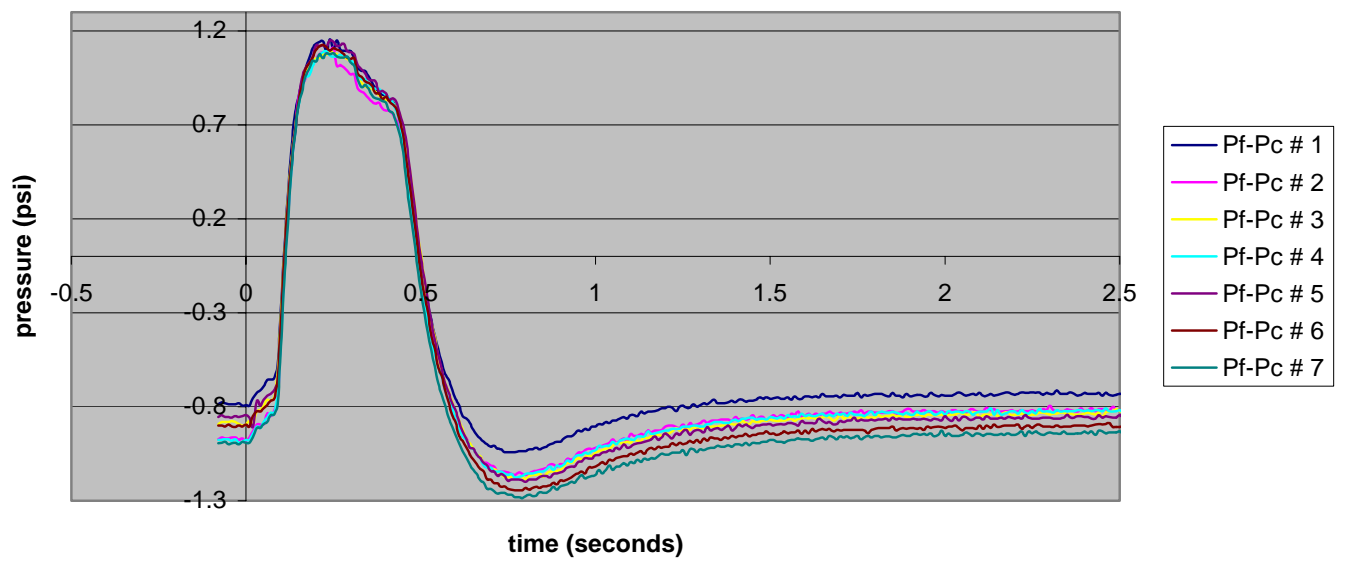

Figure 4.2.8 Pressure profiles during surface regeneration at $1200{ }^{\circ} \mathrm{F}$.

$\Delta P_{\mathrm{i}}$ vs cycle $1200 \mathrm{~F}, 5 \mathrm{~cm} / \mathrm{s}$

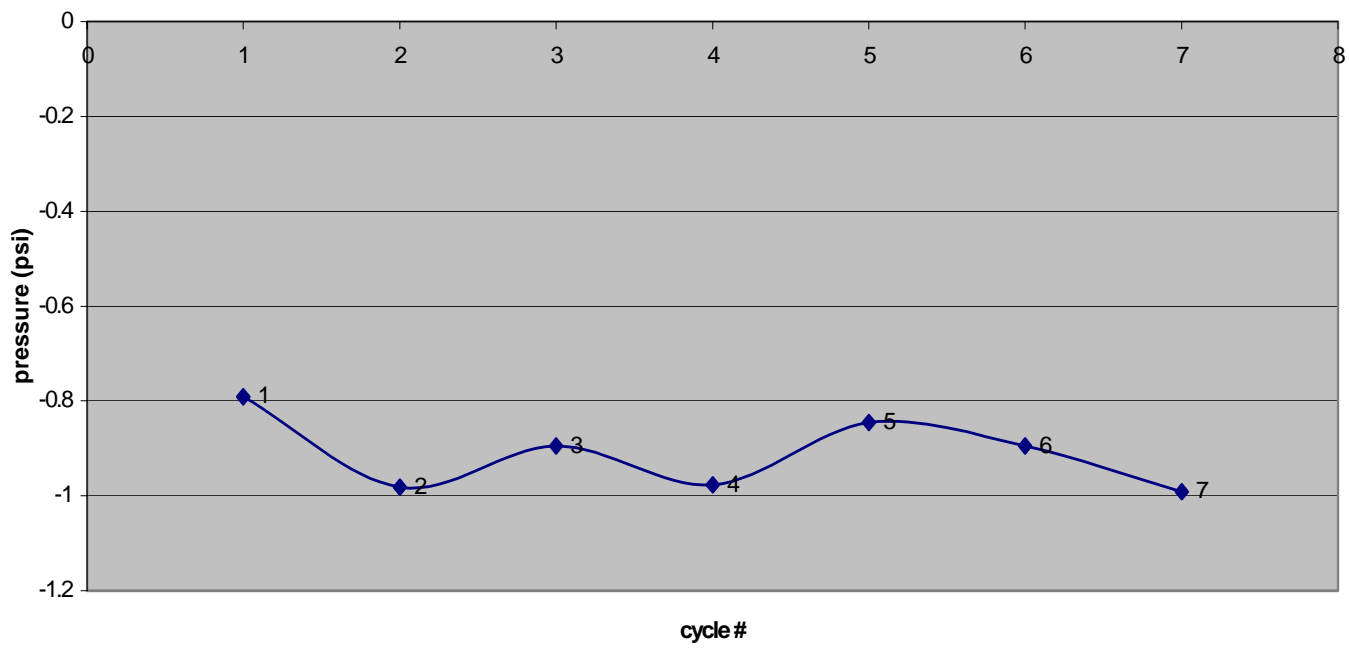

Figure 4.2.9 Initial pressure drop at $1200 \mathrm{~F}$ 
$\Delta \mathrm{P}$ max vs cycle $1200 \mathrm{~F}, 5 \mathrm{~cm} / \mathrm{s}$

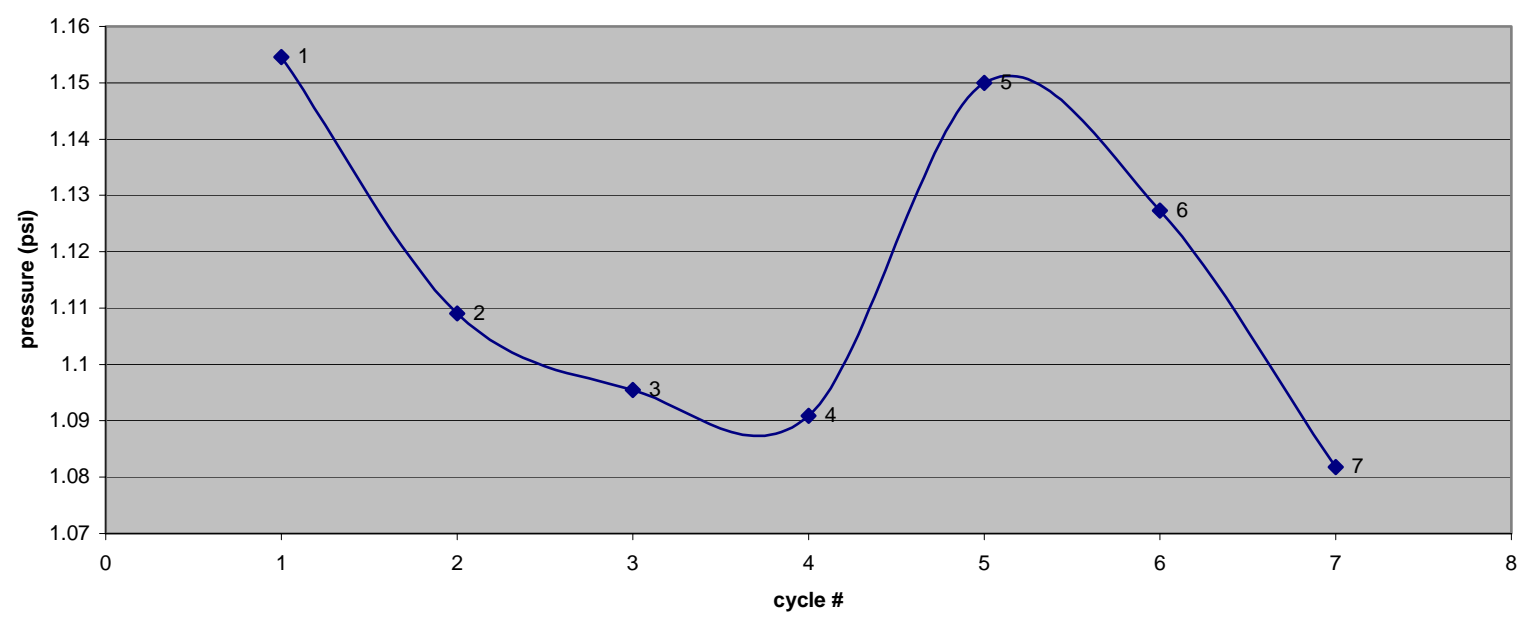

Figure 4.2.10 Maximum pressure drop at $1200 \mathrm{~F}$

$\Delta \mathrm{Pi}-\Delta \mathrm{Pf}$ vs cycle $1200 \mathrm{~F}, 5 \mathrm{~cm} / \mathrm{s}$

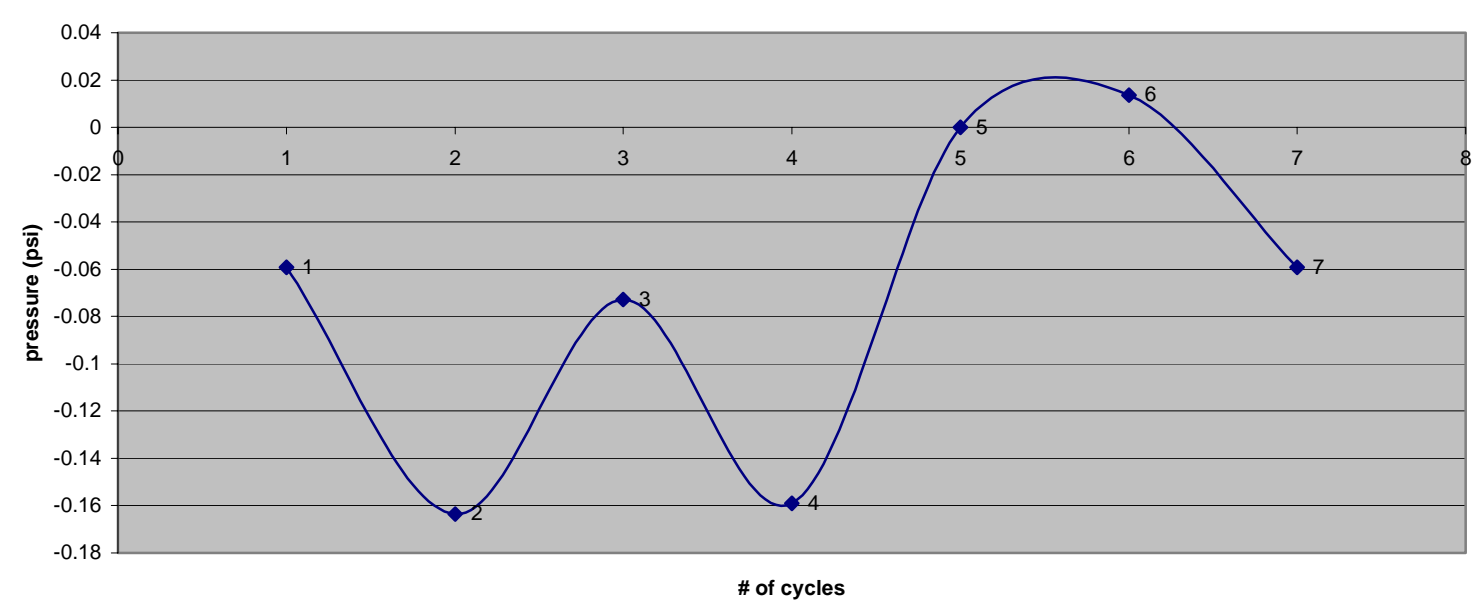

Figure 4.2.11 Initial - final pressure drop difference at $1200 \mathrm{~F}$ 


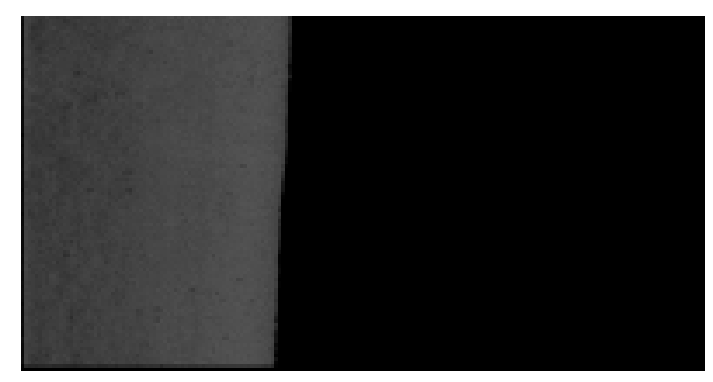

$\mathrm{t}=0 \mathrm{sec}$

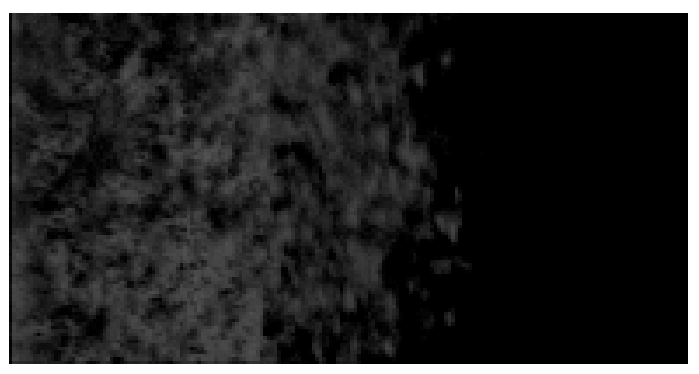

$\mathrm{t}=0.25 \mathrm{sec}$

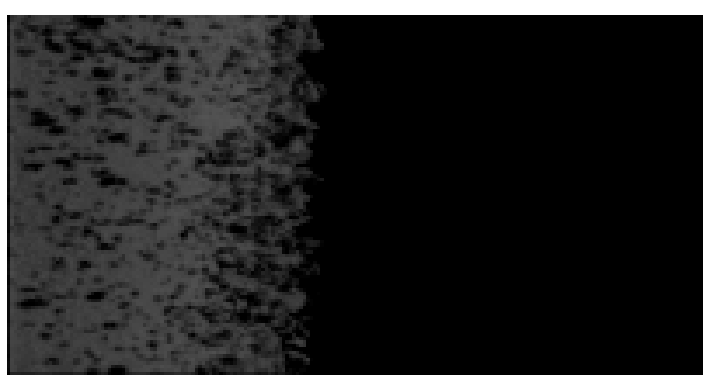

$\mathrm{t}=0.17 \mathrm{sec}$

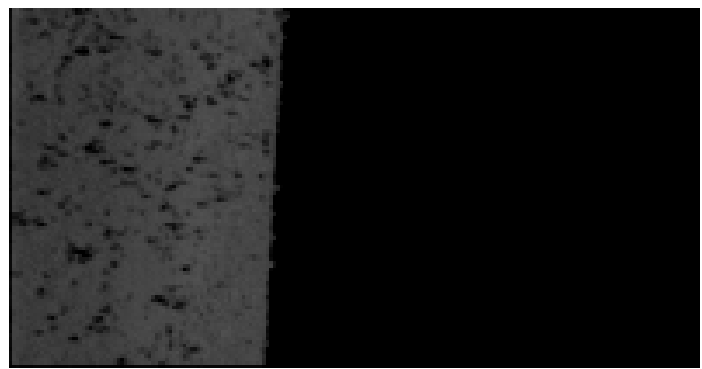

$\mathrm{t}=0.5 \mathrm{sec}$

Figure 4.2.12 Thin ash Regeneration at $1200 \mathrm{~F}$. Cycle \# 1 at $1200^{\circ} \mathrm{F}$.

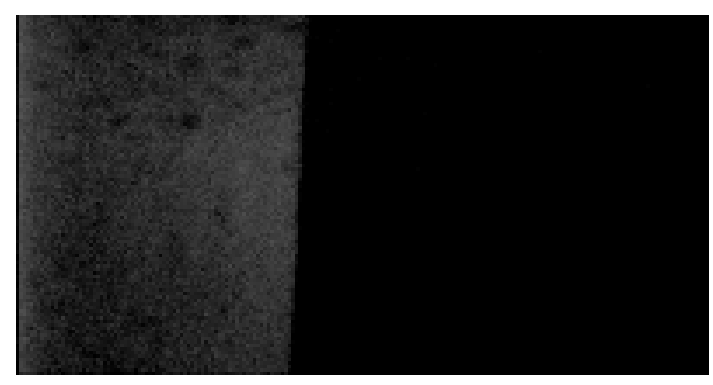

$\mathrm{t}=0 \mathrm{sec}$

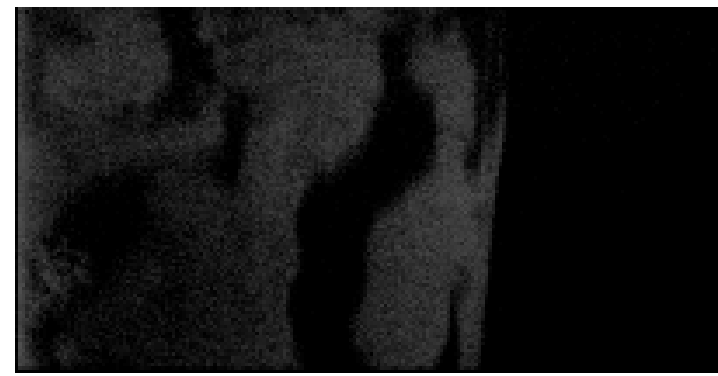

$\mathrm{t}=0.25 \mathrm{sec}$

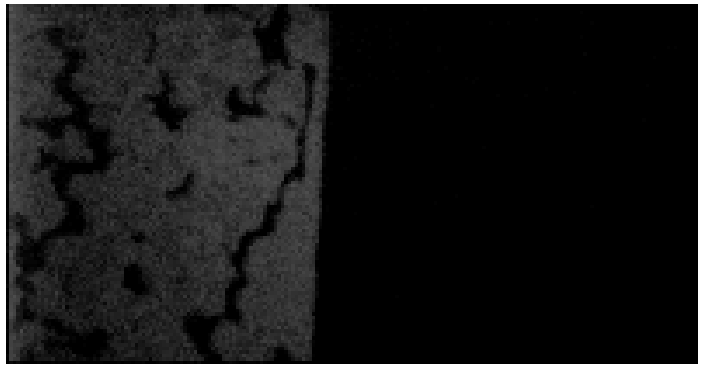

$\mathrm{t}=0.17 \mathrm{sec}$

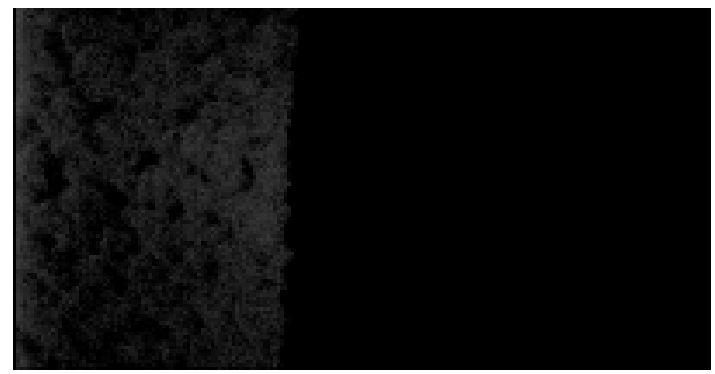

$\mathrm{t}=0.5 \mathrm{sec}$

Figure 4.2.13. Thick ash regeneration at $1200 \mathrm{~F}$. Cycle \# 4. 


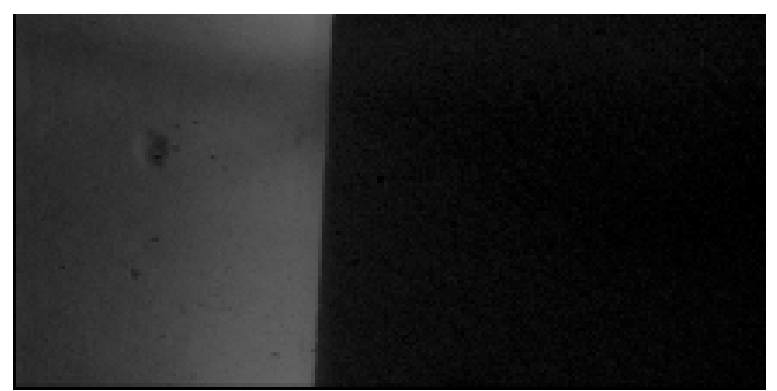

$\mathrm{t}=0 \mathrm{sec}$

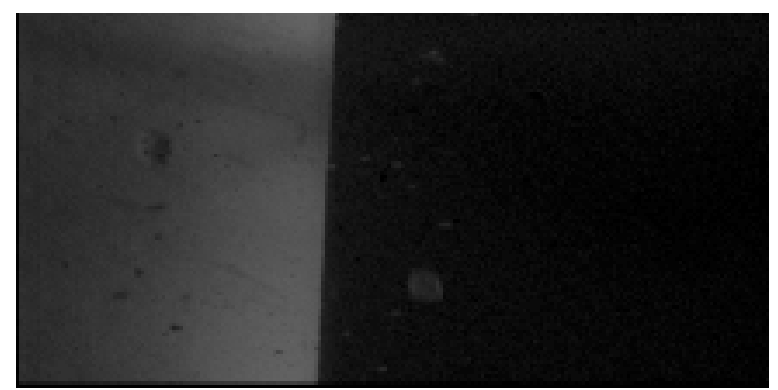

$\mathrm{t}=0.25 \mathrm{sec}$

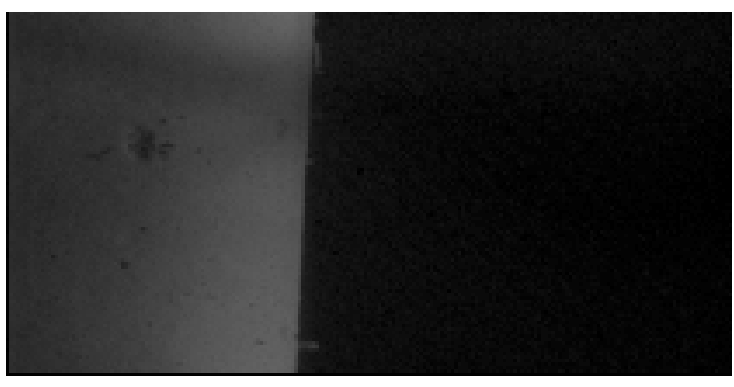

$\mathrm{t}=0.21 \mathrm{sec}$

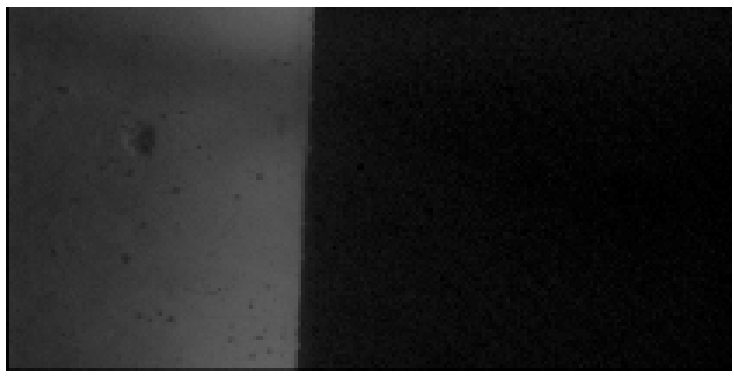

$\mathrm{t}=0.83 \mathrm{sec}$

Figure 4.2.14 Regeneration at $1300 \mathrm{~F}$. $5 \mathrm{~cm} / \mathrm{s}$ face velocity, Cycle \# 4 .

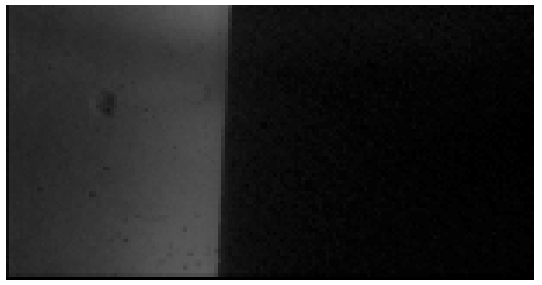

$\mathrm{t}=0 \mathrm{sec}$

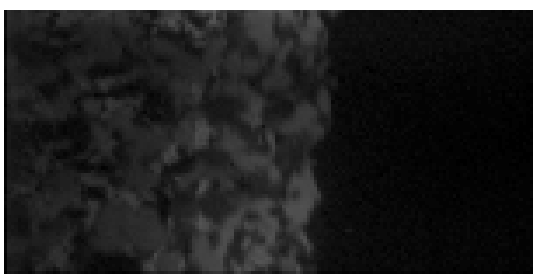

$\mathrm{t}=0.23 \mathrm{sec}$

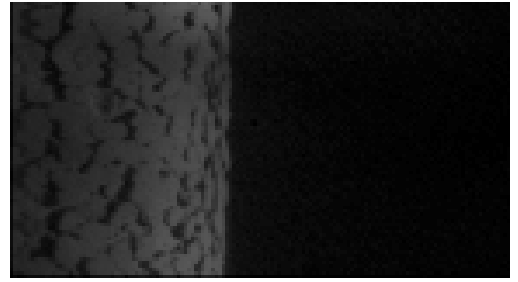

$\mathrm{t}=0.16 \mathrm{sec}$

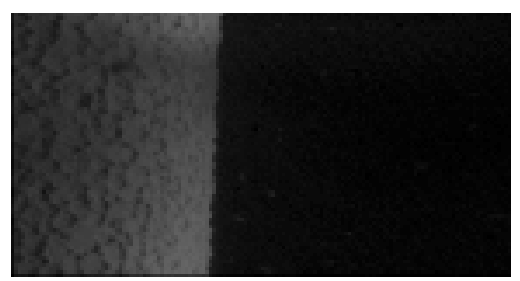

$\mathrm{t}=0.41 \mathrm{sec}$

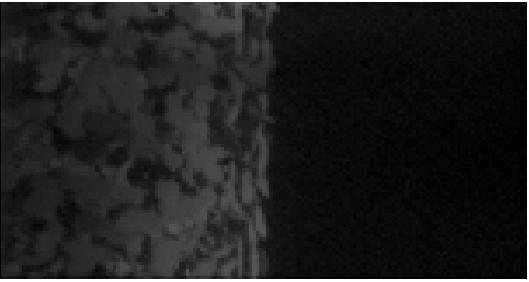

$\mathrm{t}=0.20 \mathrm{sec}$

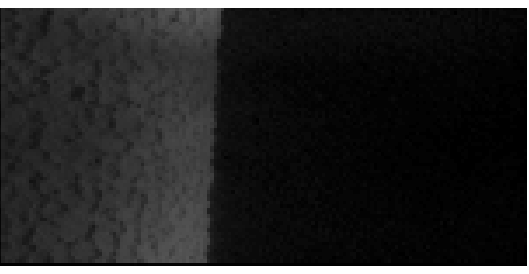

$\mathrm{t}=0.83 \mathrm{sec}$

Figure 4.2.15 Regeneration at $1300 \mathrm{~F}$.

$5 \mathrm{~cm} / \mathrm{s}$ face velocity Cycle \# 5 . 


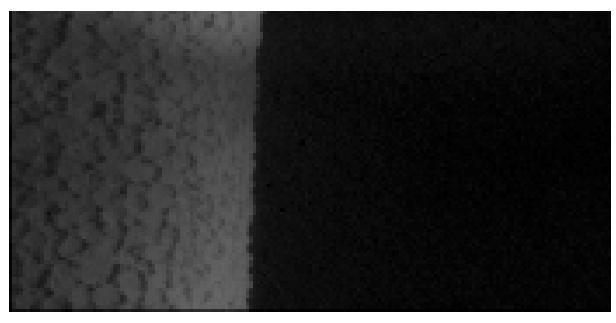

$\mathrm{t}=0 \mathrm{sec}$

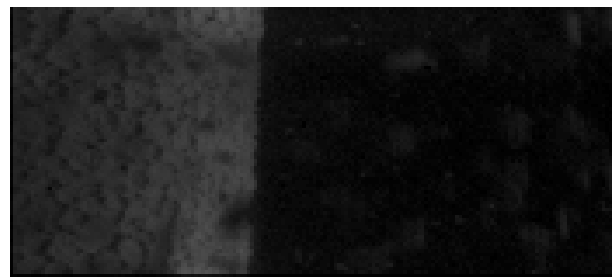

$\mathrm{t}=0.25 \mathrm{sec}$

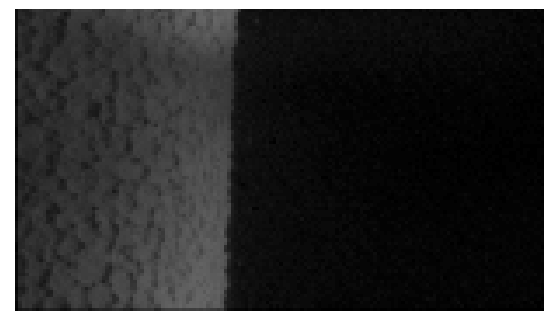

$\mathrm{t}=0.21 \mathrm{sec}$

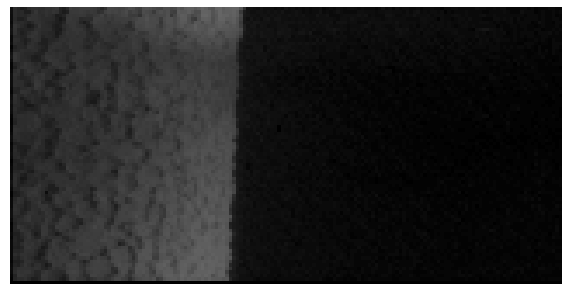

$\mathrm{t}=0.83 \mathrm{sec}$

Figure 4.2.16 Regeneration at $1300 \mathrm{~F}$. $5 \mathrm{~cm} / \mathrm{s}$ face velocity, Cycle \# 6 .

Sequence of regenerations at $1300 \mathrm{~F}, 5 \mathrm{~cm} / \mathrm{s}$

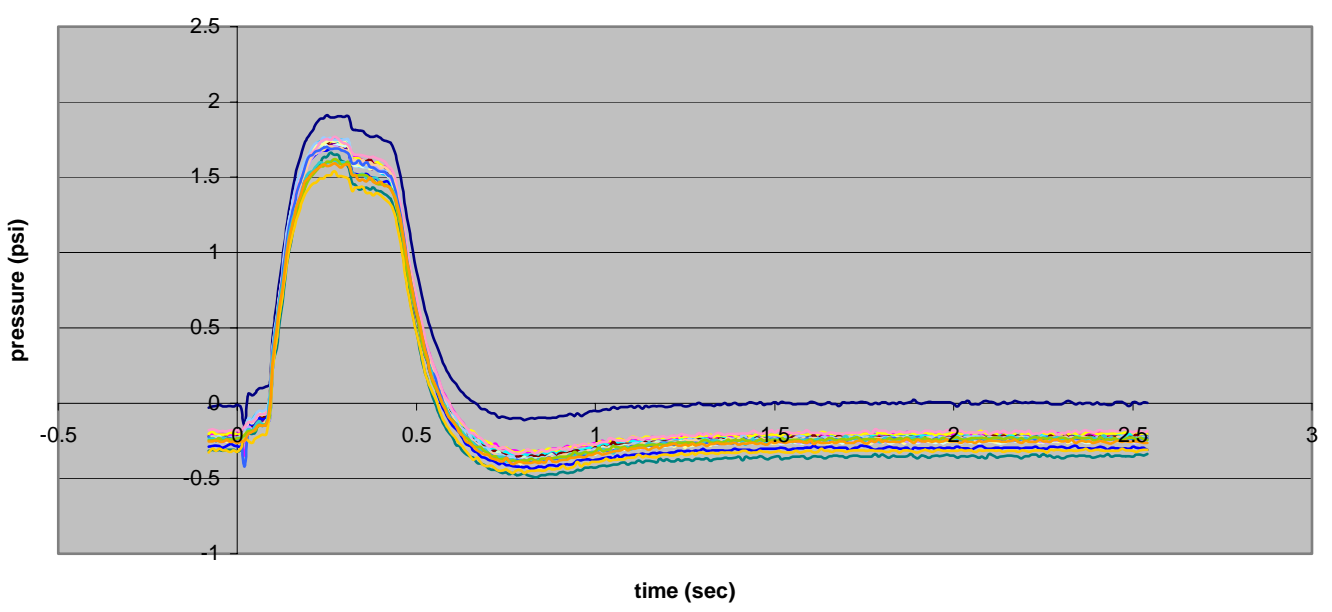

Figure 4.2.17 Pressure profiles during surface regeneration at $1300 \mathrm{~F}, 5 \mathrm{~cm} / \mathrm{s}$. Long term test. 
$\Delta \mathrm{Pi}$ vs cycle $1300 \mathrm{~F}, 5 \mathrm{~cm} / \mathrm{s}$

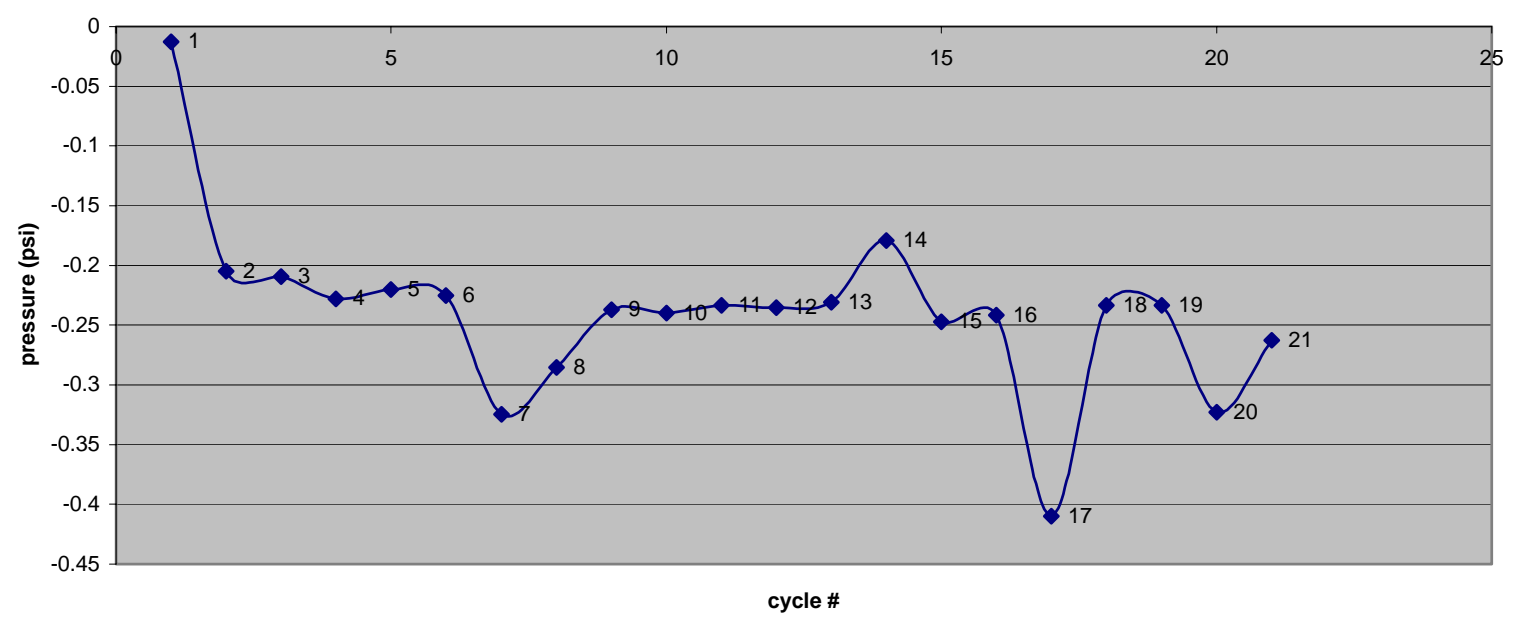

Figure 4.2.18 Initial pressure drop at $1300 \mathrm{~F}, 5 \mathrm{~cm} / \mathrm{s}$

$\Delta \mathrm{P} \max$ vs cycle $1300 \mathrm{~F}, 5 \mathrm{~cm} / \mathrm{s}$

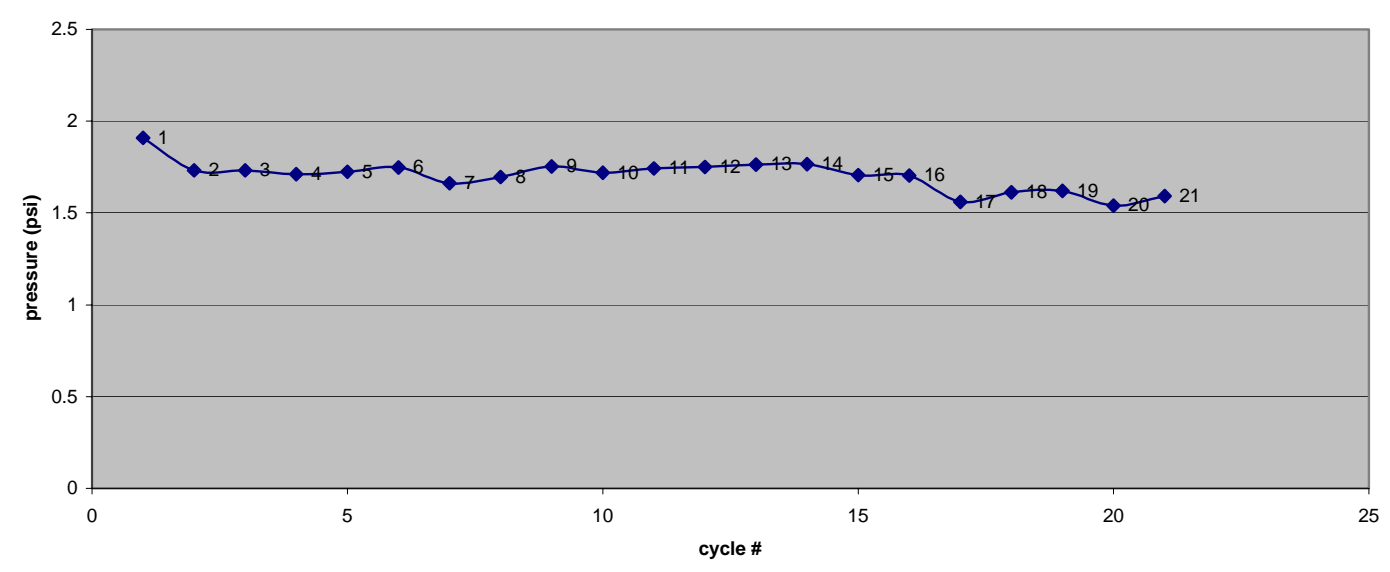

Figure 4.2.19 Maximum pressure drop at 1300 F, $5 \mathrm{~cm} / \mathrm{s}$ 
$\Delta \mathrm{Pf}$ vs cycle $1300 \mathrm{~F}, 5 \mathrm{~cm} / \mathrm{s}$

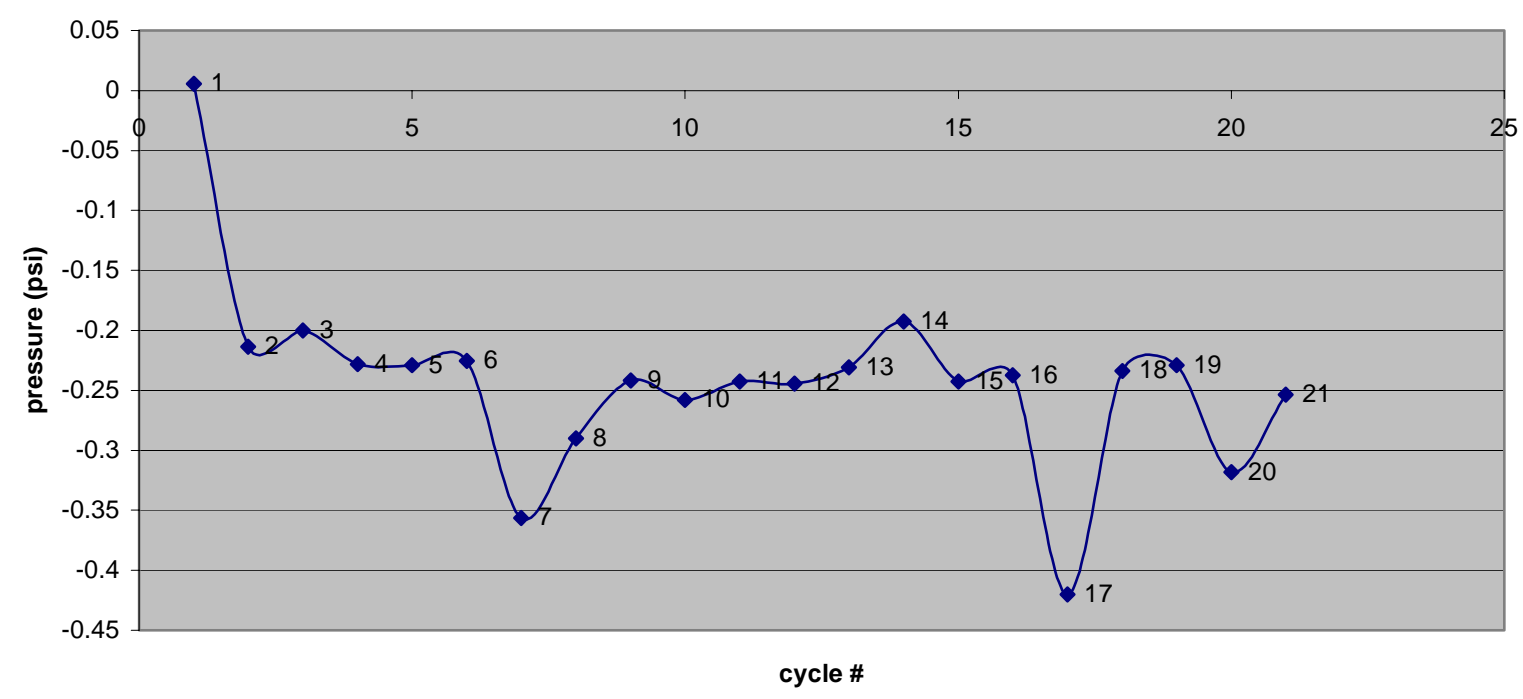

Figure 4.2.20 Final pressure drop at $1300 \mathrm{~F}, 5 \mathrm{~cm} / \mathrm{s}$

$\Delta \mathrm{Pi}-\Delta \mathrm{Pf}$ vs cycle $1300 \mathrm{~F}, 5 \mathrm{~cm} / \mathrm{s}$

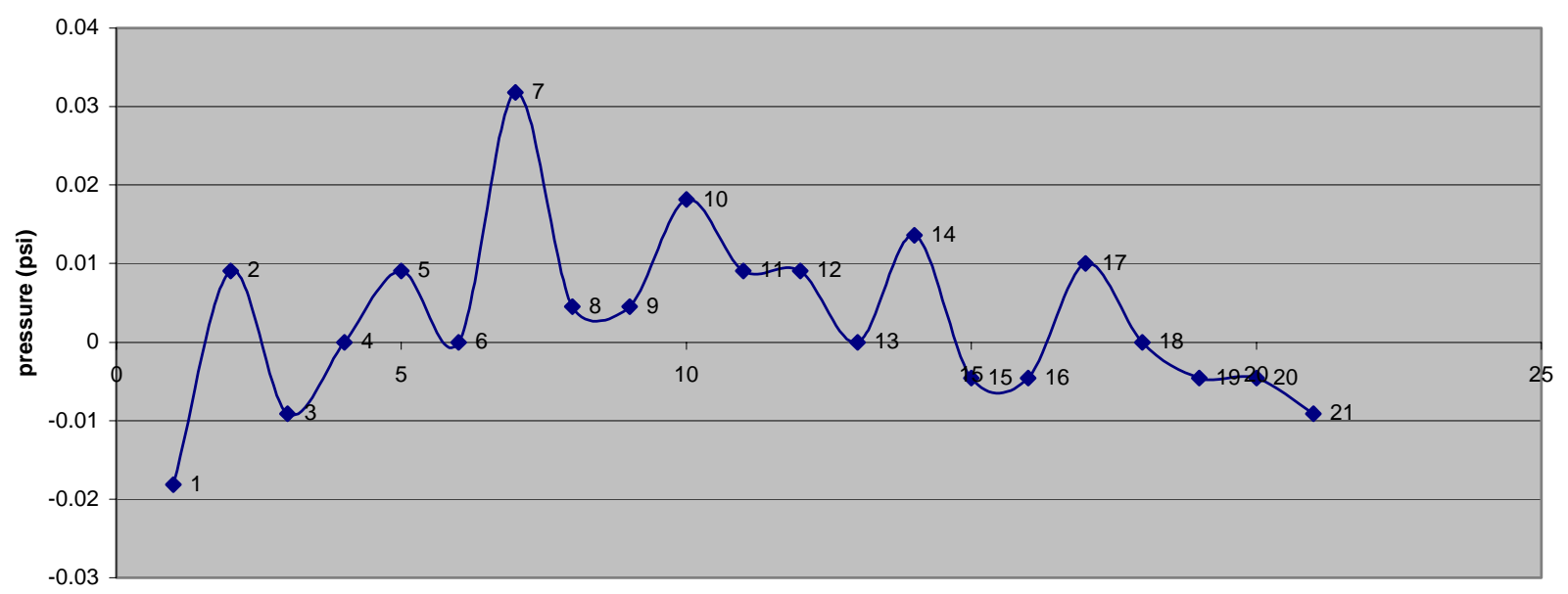

\# of cycles

Figure 4.2.21 Initial - final pressure drop difference at $1300 \mathrm{~F}, 5 \mathrm{~cm} / \mathrm{s}$ 

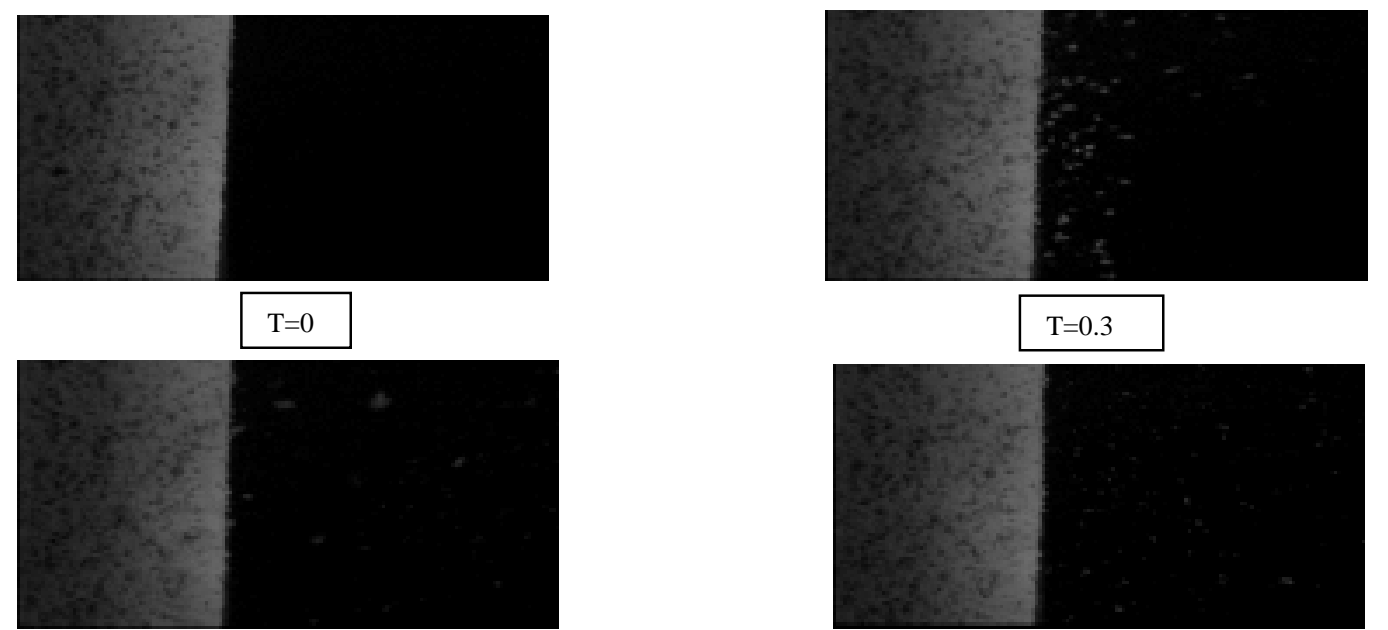

$\mathrm{T}=0.68$

$\mathrm{T}=0.83$

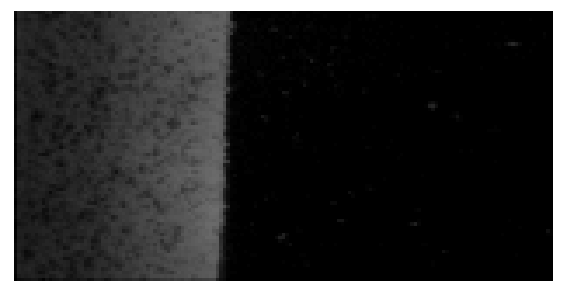

$\mathrm{T}=1.05$

\section{$\mathrm{T}=1.5$}

Figure 4.2.22 Regeneration \# 4 at test $1300 \mathrm{~F}, 5 \mathrm{~cm} / \mathrm{s}$ 

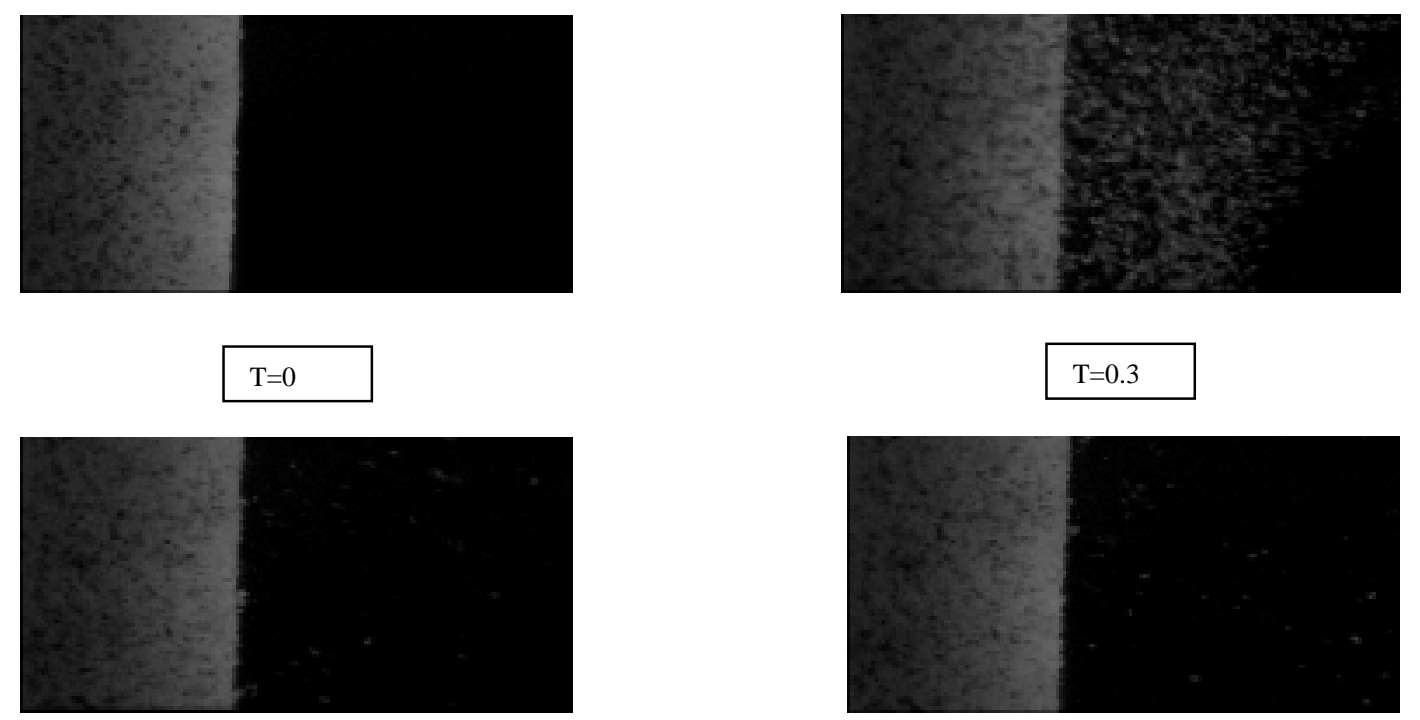

$\mathrm{T}=0.68$

$\mathrm{T}=0.83$

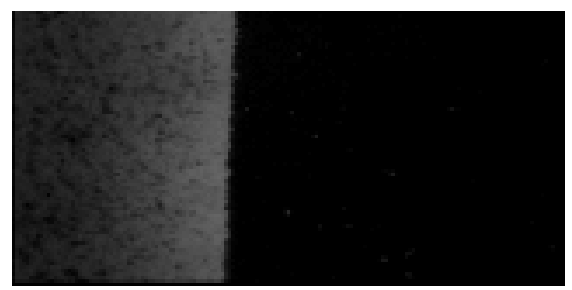

$\mathrm{T}=1.05$

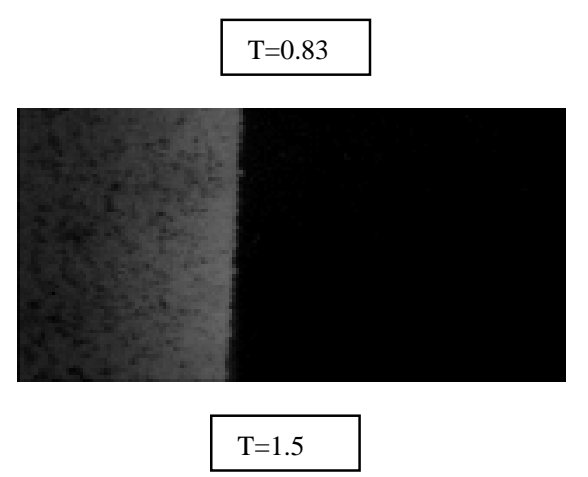

Figure 4.2.23 Regeneration \# 5 at test 1300 F, $5 \mathrm{~cm} / \mathrm{s}$ 
sequence of regenerations at $1300 \mathrm{~F}, 7 \mathrm{~cm} / \mathrm{s}$
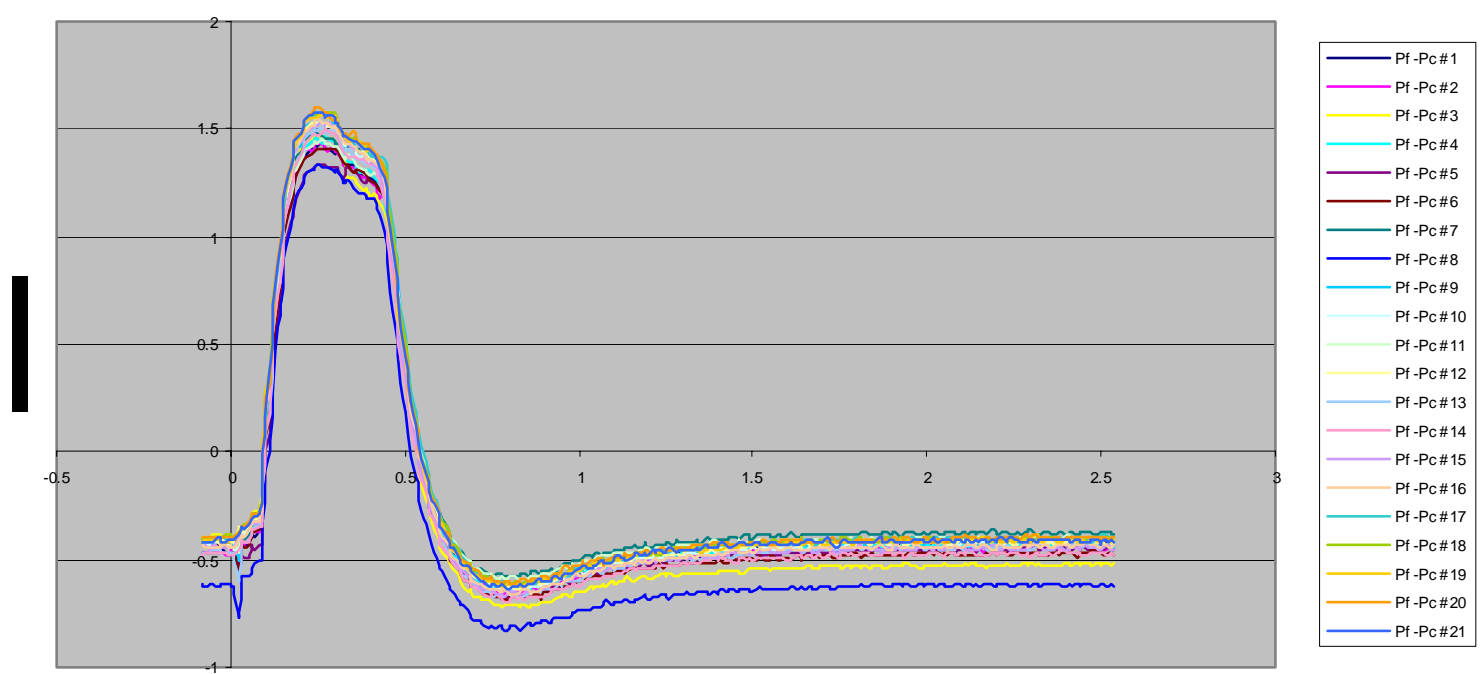

time (sec)

Figure 4.2.24. Pressure profiles during surface regeneration at $1300 \mathrm{~F}, 7 \mathrm{~cm} / \mathrm{s}$. Long term test

$\Delta \mathrm{Pi}$ vs cycle $1300 \mathrm{~F}, 7 \mathrm{~cm} / \mathrm{s}$

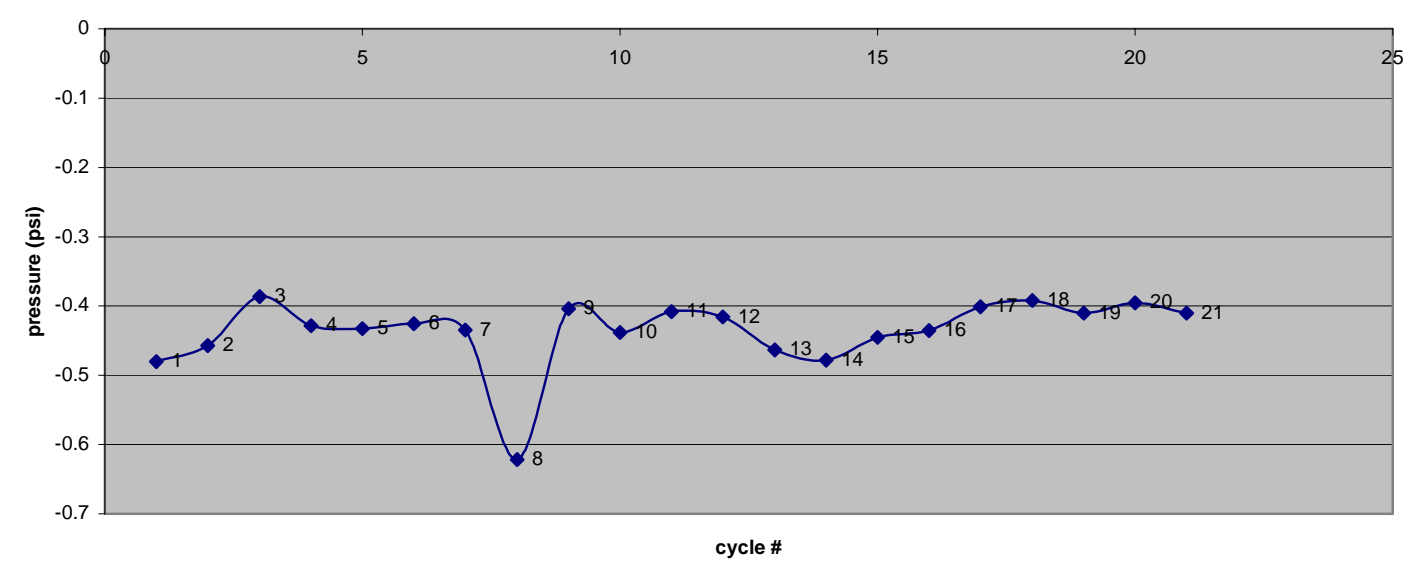

Figure 4.2.25 Initial pressure drop at $1300 \mathrm{~F}, 7 \mathrm{~cm} / \mathrm{s}$ 
$\Delta \mathrm{P}$ max vs cycle $1300 \mathrm{~F}, 7 \mathrm{~cm} / \mathrm{s}$

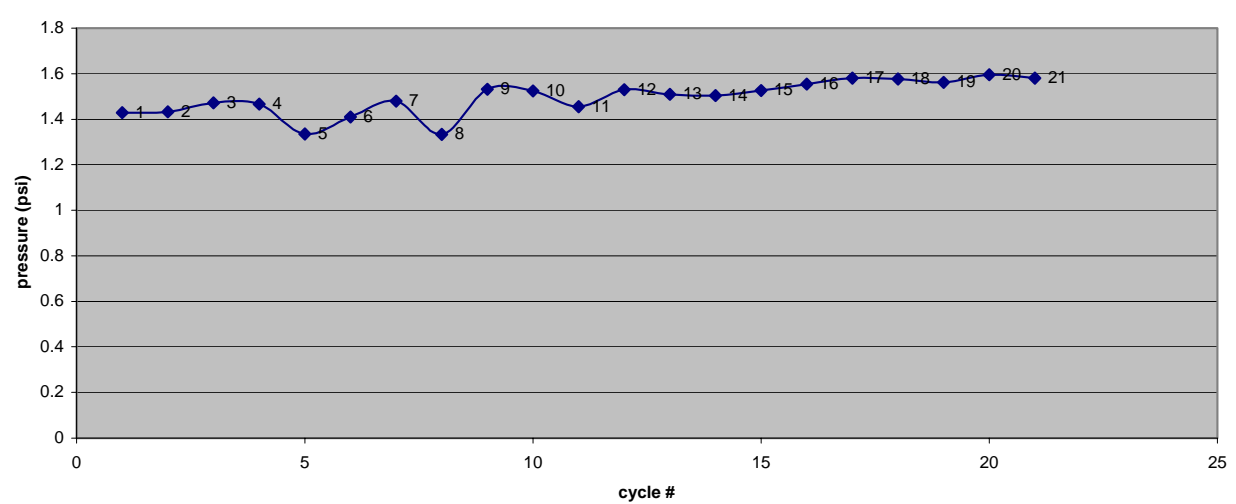

Figure 4.2.26 Maximum pressure drop at $1300 \mathrm{~F}, 7 \mathrm{~cm} / \mathrm{s}$

\section{$\Delta P_{f}$ vs time \\ $1300 \mathrm{~F}, 7 \mathrm{~cm} / \mathrm{s}$}

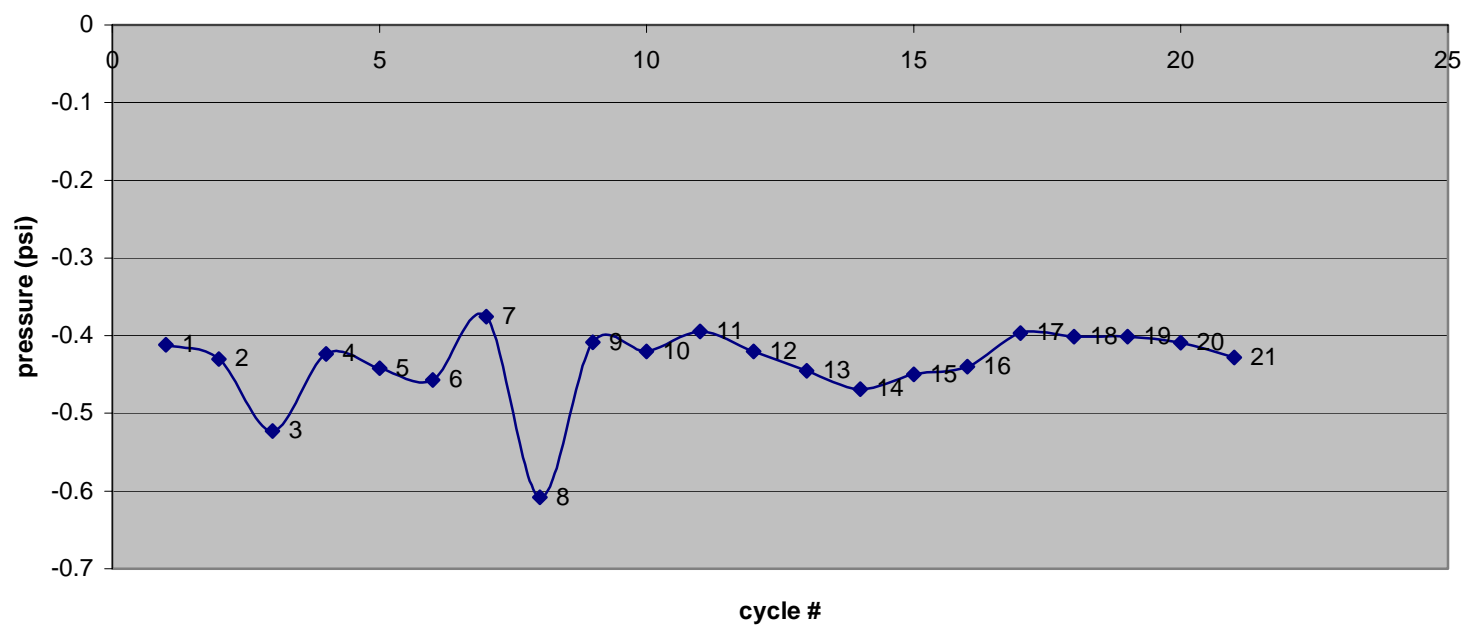

Figure 4.2.27 Final pressure drop at 1300 F, 7 cm/s 
$\Delta \mathrm{Pi}-\Delta \mathrm{Pf}$ vs cycle $1300 \mathrm{~F}, 7 \mathrm{~cm} / \mathrm{s}$

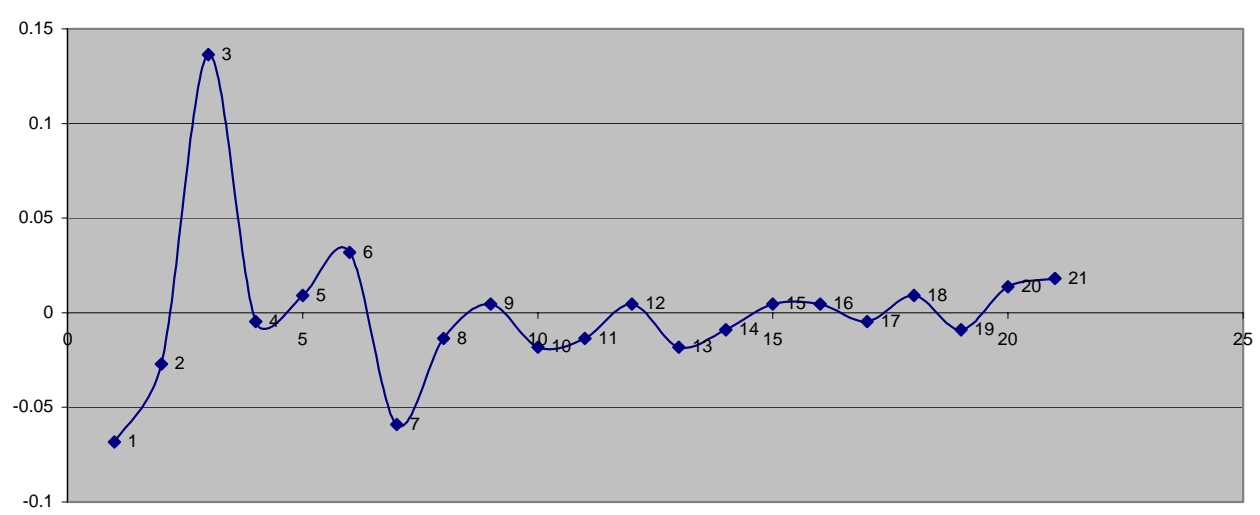

Figure 4.2.28 Initial - final pressure drop at 1300

$\mathrm{F}, 7 \mathrm{~cm} / \mathrm{s}$ 


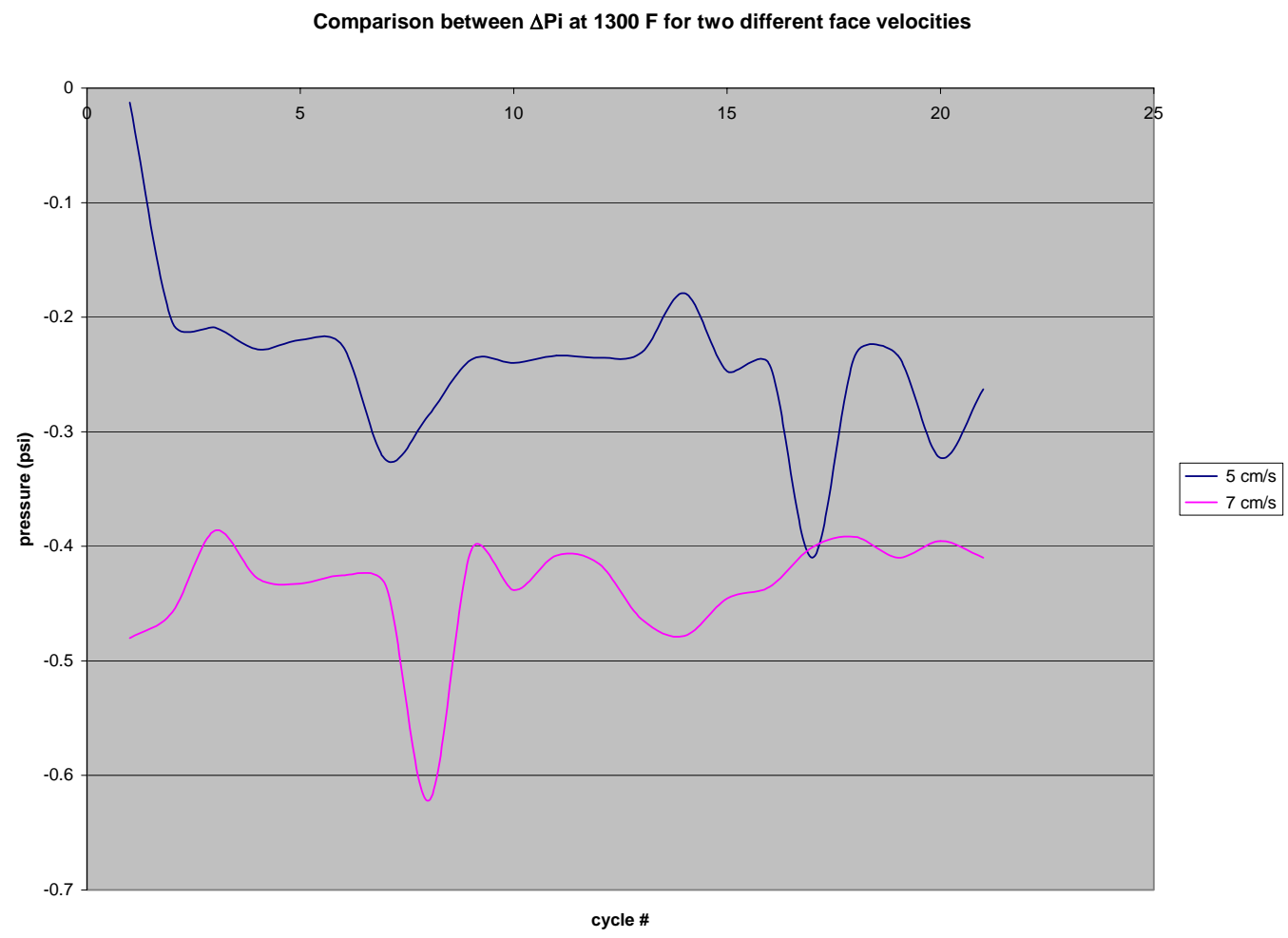

Figure 4.2.29 Comparison between initial pressure drop at $1300 \mathrm{~F}$ for two diferent face velocities

Comparison between $\triangle \mathrm{Pmax}$ at $1300 \mathrm{~F}$ for two different face velocities

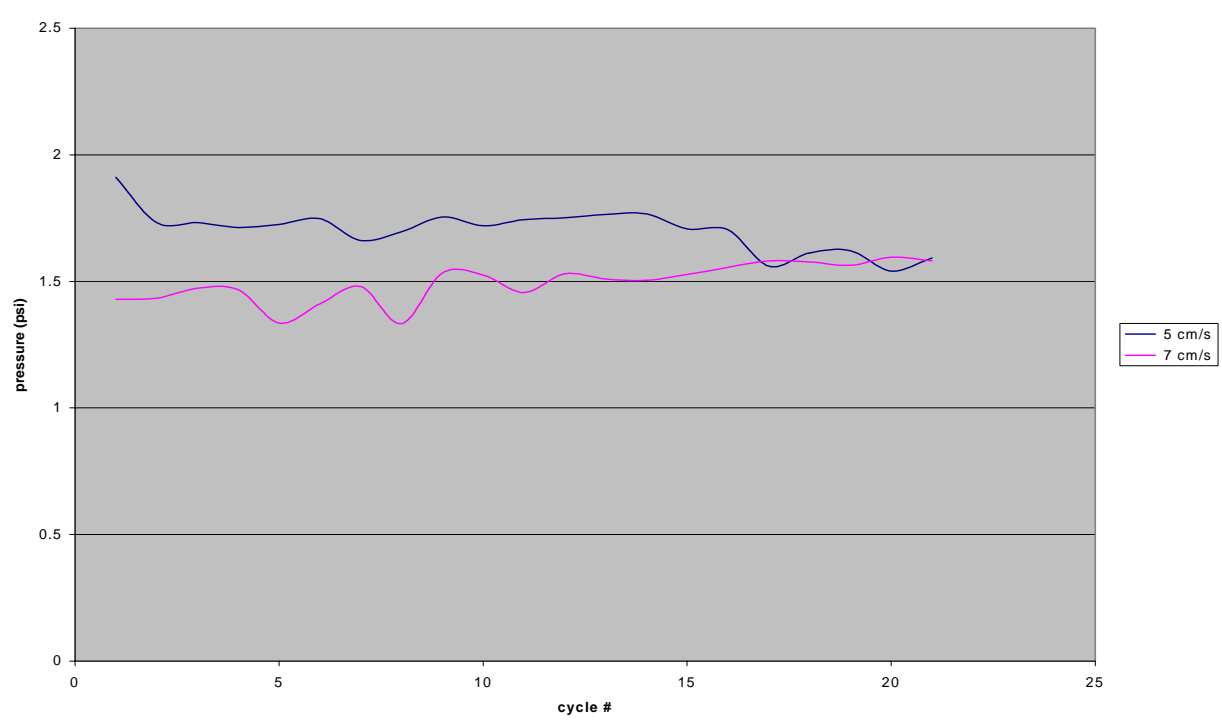

Figure 4.2.30 Comparison between maximum pressure drop at $1300 \mathrm{~F}$ for two different velocities. 


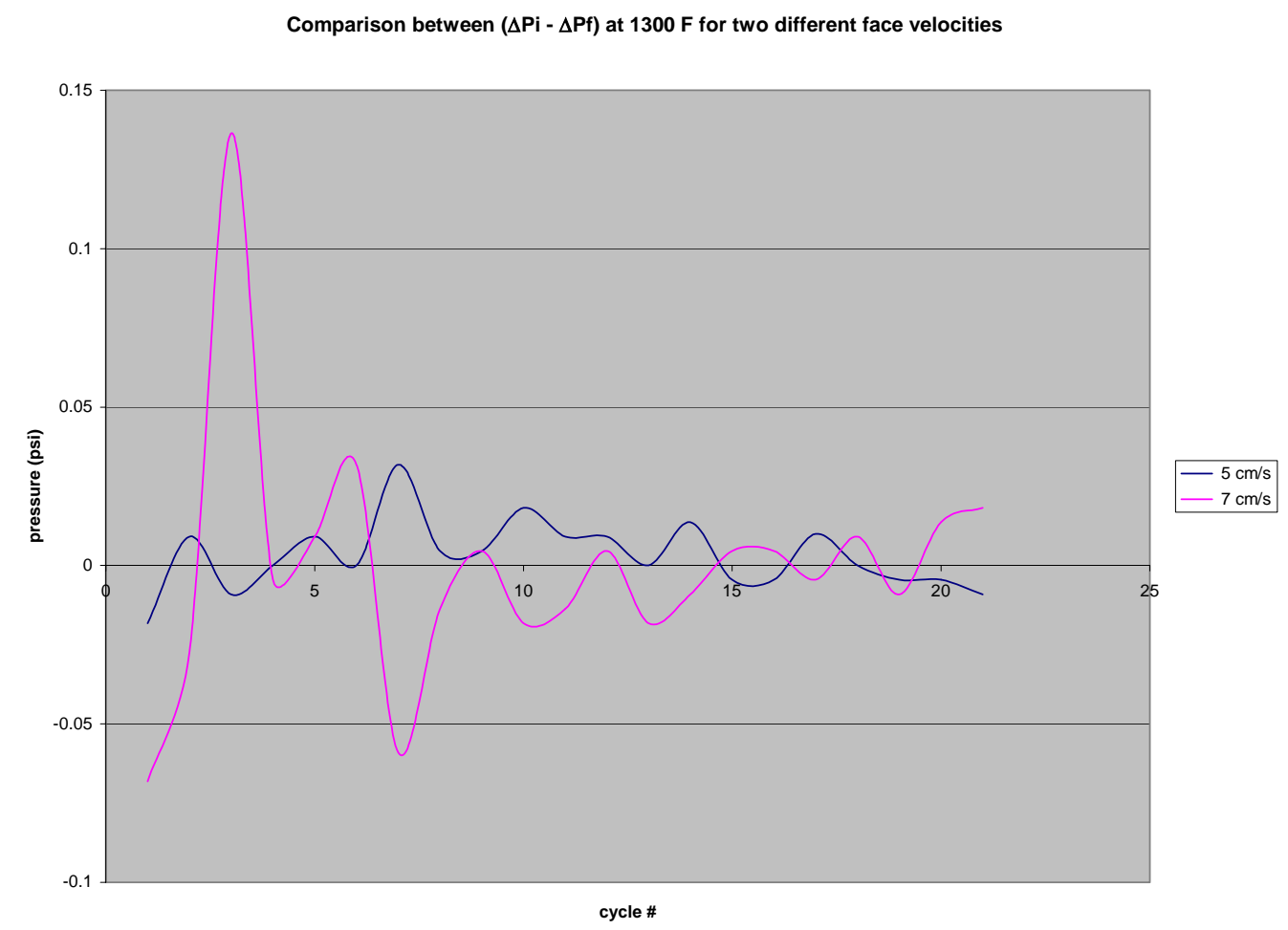

Figure 4.2.31 Comparison between (initial - final) pressure drop at $1300 \mathrm{~F}$ for two different face velocities 
regeneration \# 1

$1300 \mathrm{~F}, 5 \mathrm{~cm} / \mathrm{s}$
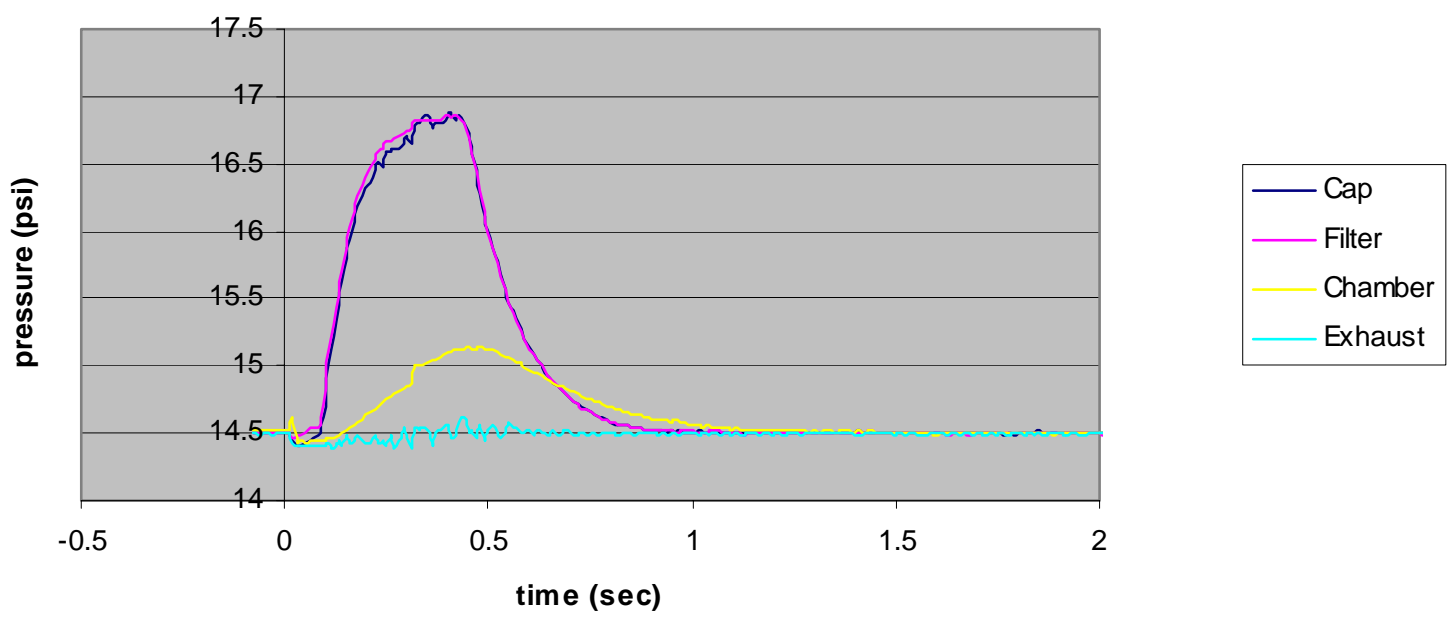

regeneration \# 1 95psi

$1300 \mathrm{~F}, 7 \mathrm{~cm} / \mathrm{s}$
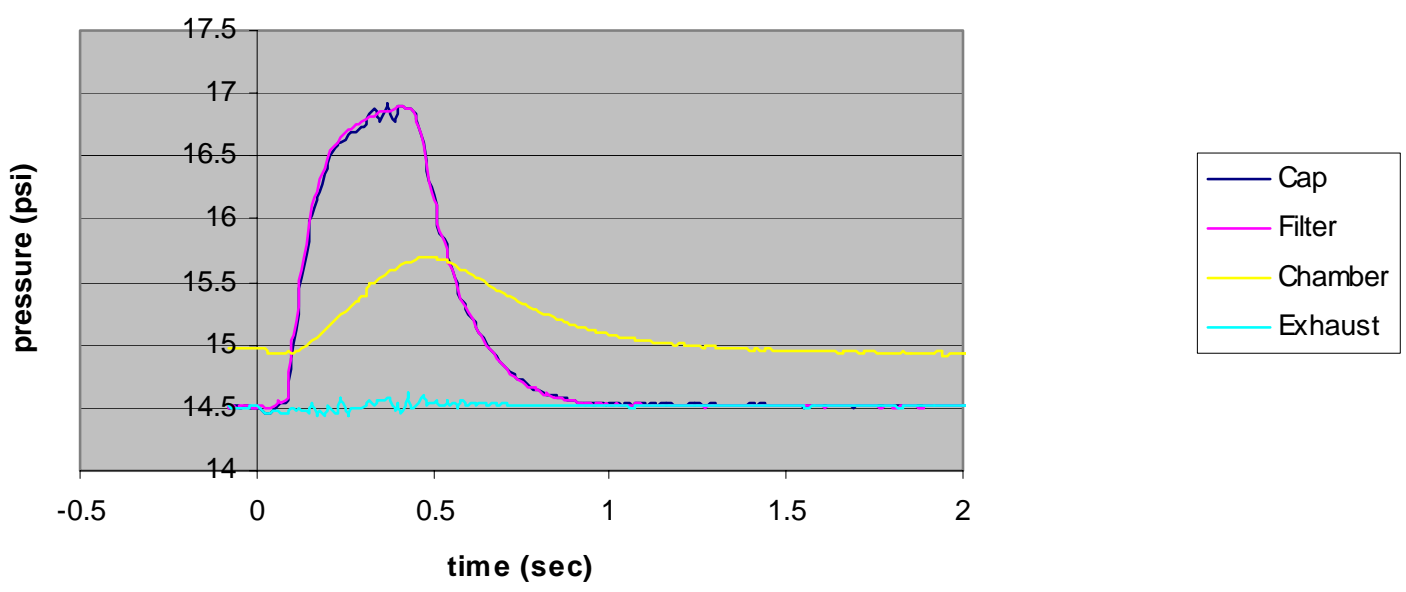

Figure 4.2.32 Pressure profiles for first cycle at $1300 \mathrm{~F}$, in two different face velocities. 
regeneration \#3, 95psi,

$1300 \mathrm{~F}, 7 \mathrm{~cm} / \mathrm{s}$
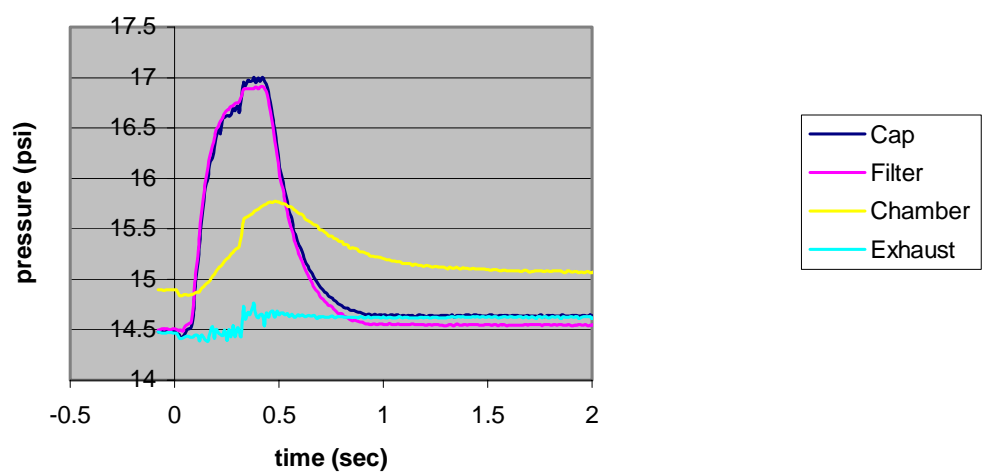

Figure 4.2.33 Pressure profile for third regeneration at $1300 \mathrm{~F}, 7 \mathrm{~cm} / \mathrm{s}$.

regeneration \# 18 95psi

$1300 \mathrm{~F}, 7 \mathrm{~cm} / \mathrm{s}$

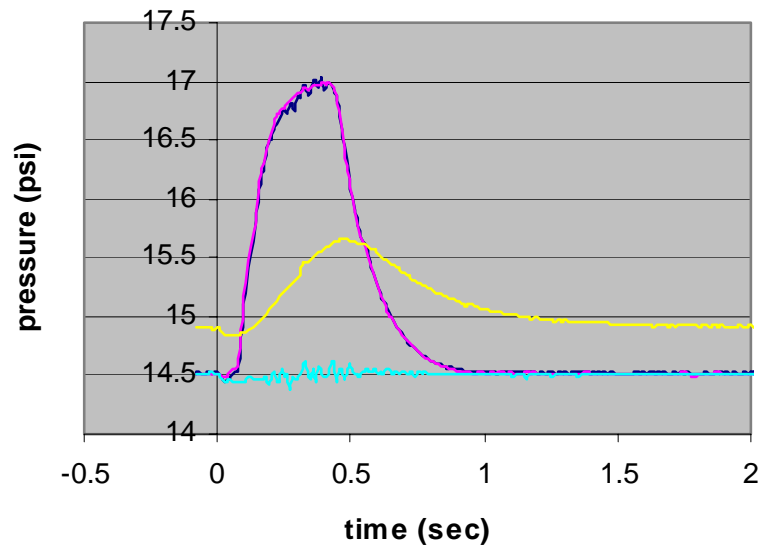

\begin{tabular}{|}
\hline Cap \\
Filter \\
Chamber \\
Exhaust
\end{tabular}

Figure 4.2.34 Pressure profile for $18^{\text {th }}$ regeneration at $1300 \mathrm{~F}, 7$ $\mathrm{cm} / \mathrm{s}$ 
Sequence of regenerations at $1400 \mathrm{~F}, 5 \mathrm{~cm} / \mathrm{s}$

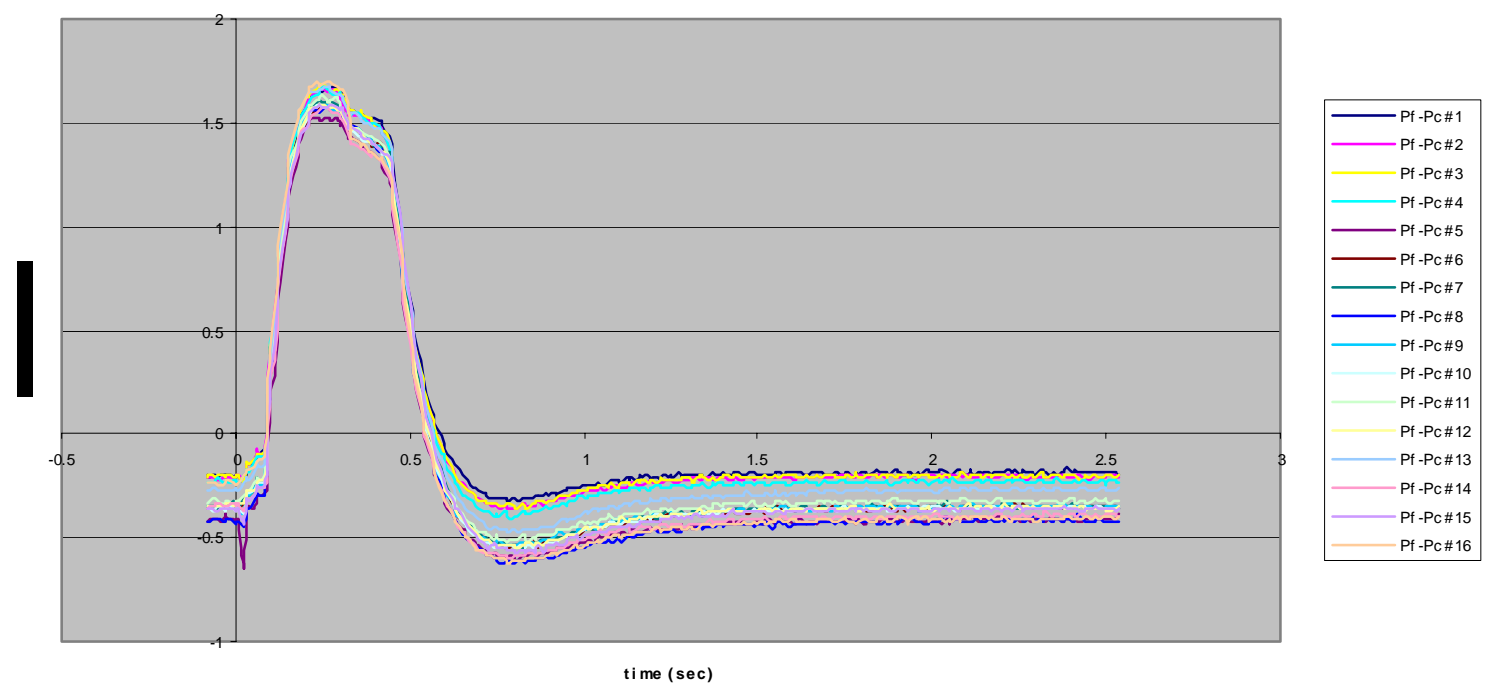

Figure 4.2.35 Sequence of regenerations at $1400 \mathrm{~F}, 5 \mathrm{~cm} / \mathrm{s}$

$\Delta \mathrm{Pi}$ vs cycle $1400 \mathrm{~F}, 5 \mathrm{~cm} / \mathrm{s}$

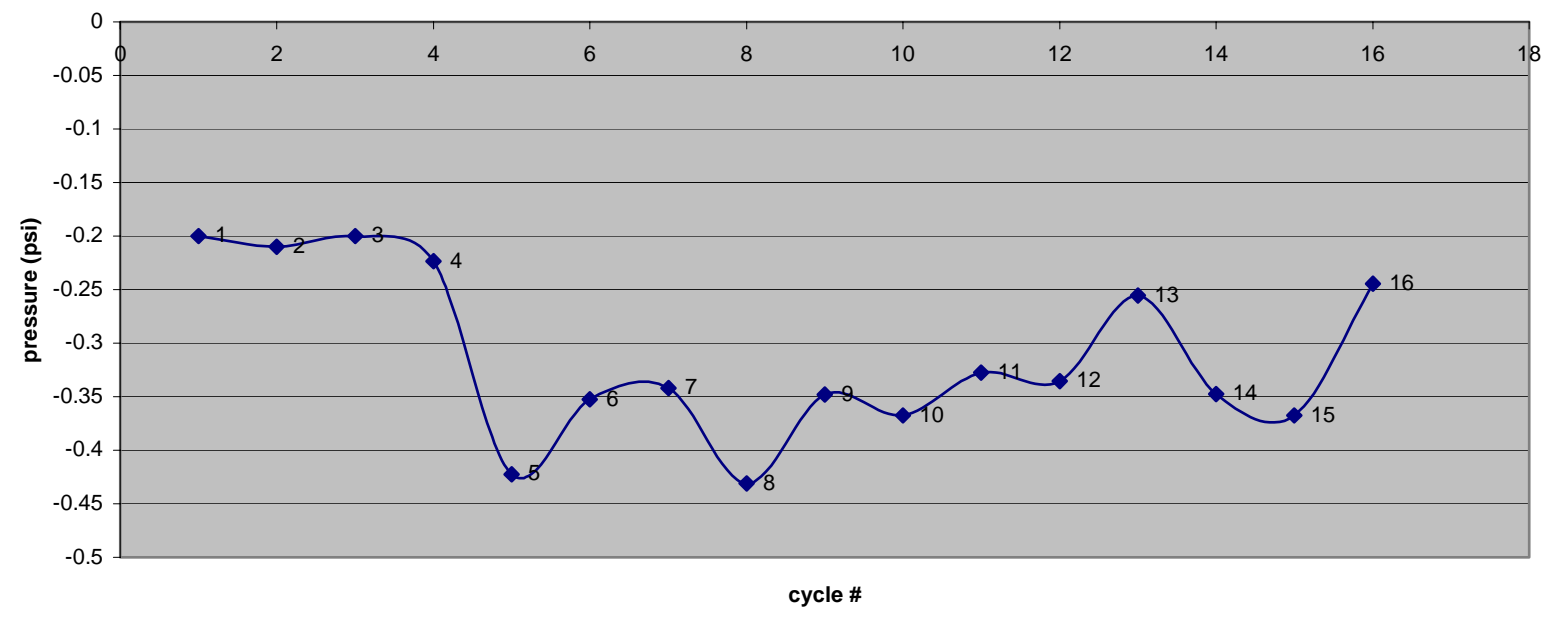

Figure 4.2.36 Initial pressure drop at $1400 \mathrm{~F}, 5 \mathrm{~cm} / \mathrm{s}$ 


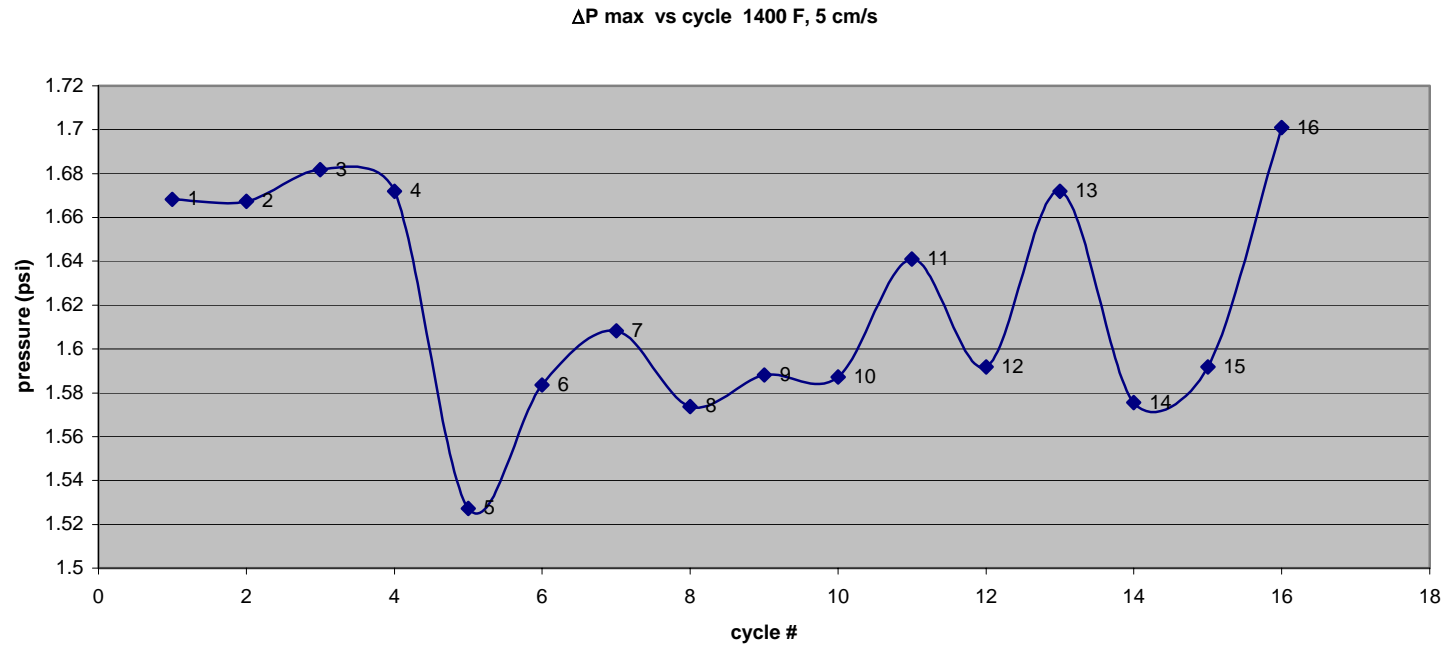

Figure 4.2.37 Maximum

pressure drop at $1400 \mathrm{~F}, 5 \mathrm{~cm} / \mathrm{s}$

$\Delta P_{\mathrm{f}}$ vs time

$1400 \mathrm{~F}, 5 \mathrm{~cm} / \mathrm{s}$

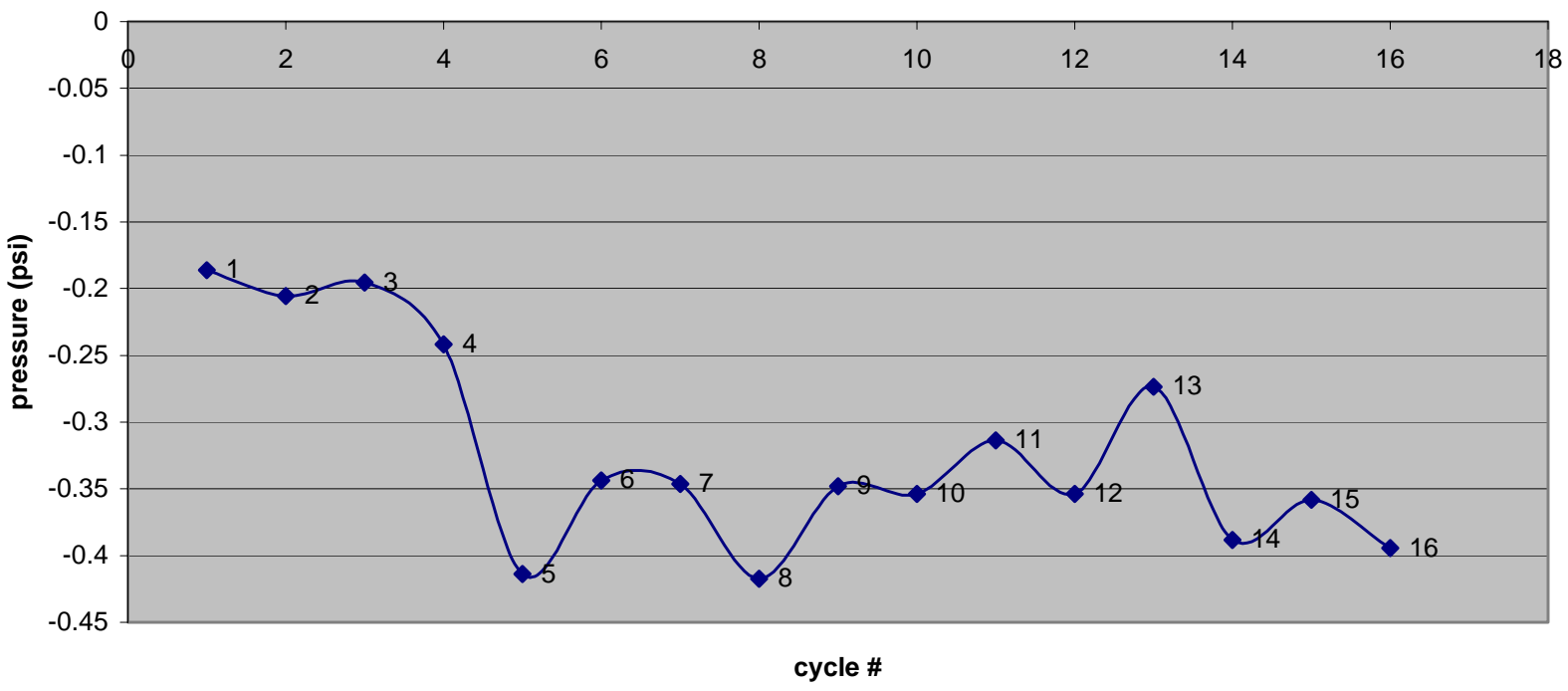

Figure 4.2.38 final pressure drop at $1400 \mathrm{~F}, 5 \mathrm{~cm} / \mathrm{s}$ 
$\Delta \mathrm{Pi}-\Delta \mathrm{Pf}$ vs cycle $1400 \mathrm{~F}, 5 \mathrm{~cm} / \mathrm{s}$

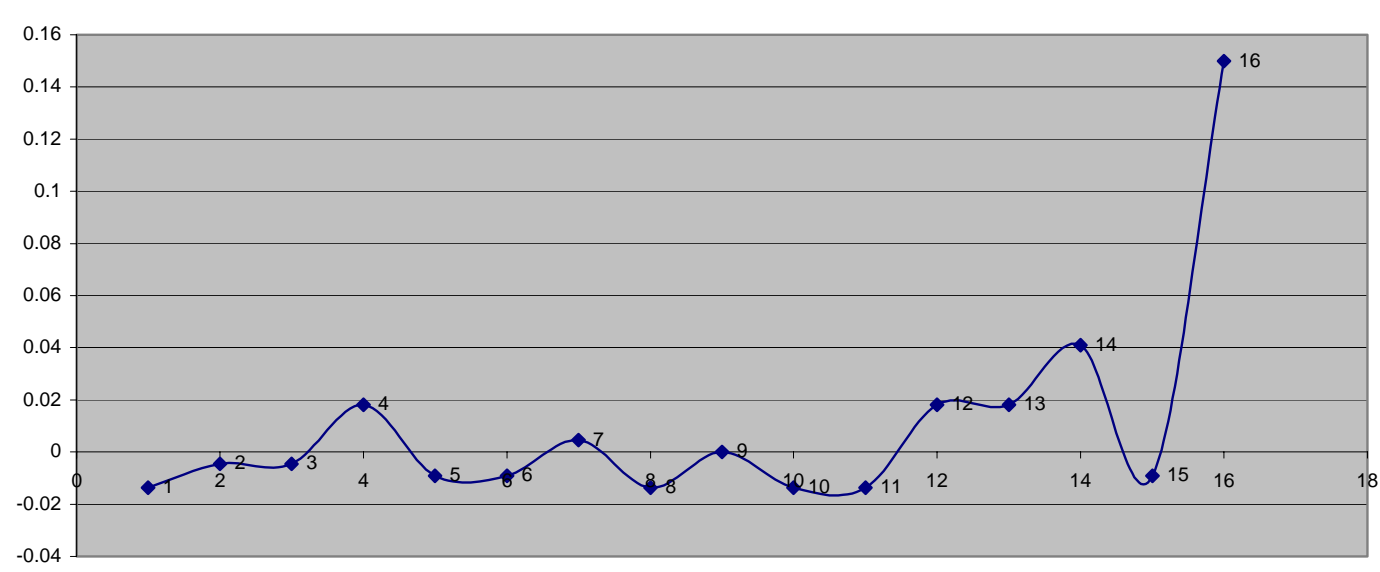

Figure 4.2.39 Initial - Final pressure drop difference at $1300 \mathrm{~F}, 7 \mathrm{~cm} / \mathrm{s}$ 


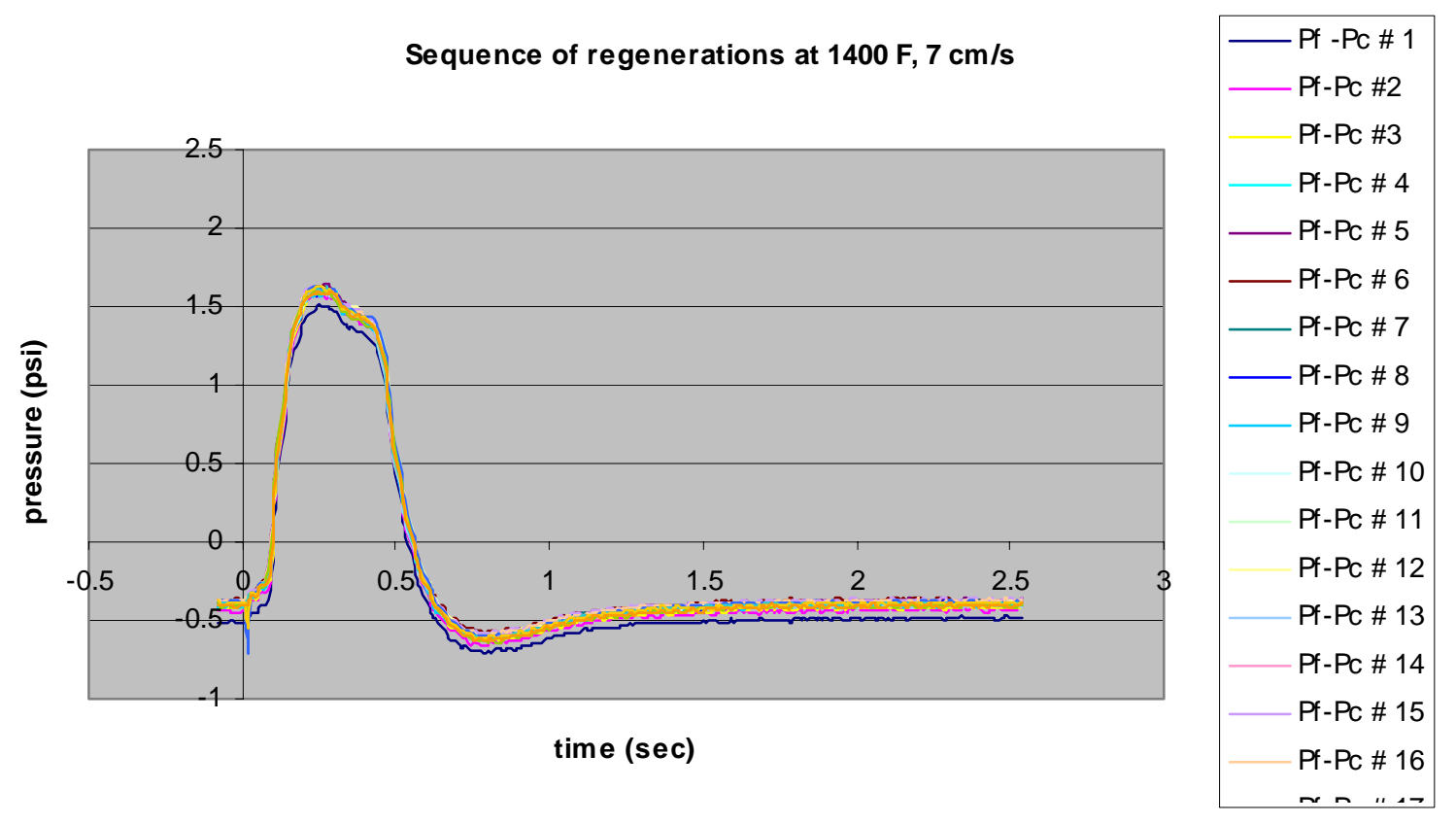

Figure 4.2.40 Sequence of regenerations at $1400 \mathrm{~F}, 7 \mathrm{~cm} / \mathrm{s}$

$\Delta \mathrm{Pi}$ vs cycle $1400 \mathrm{~F}, 7 \mathrm{~cm} / \mathrm{s}$

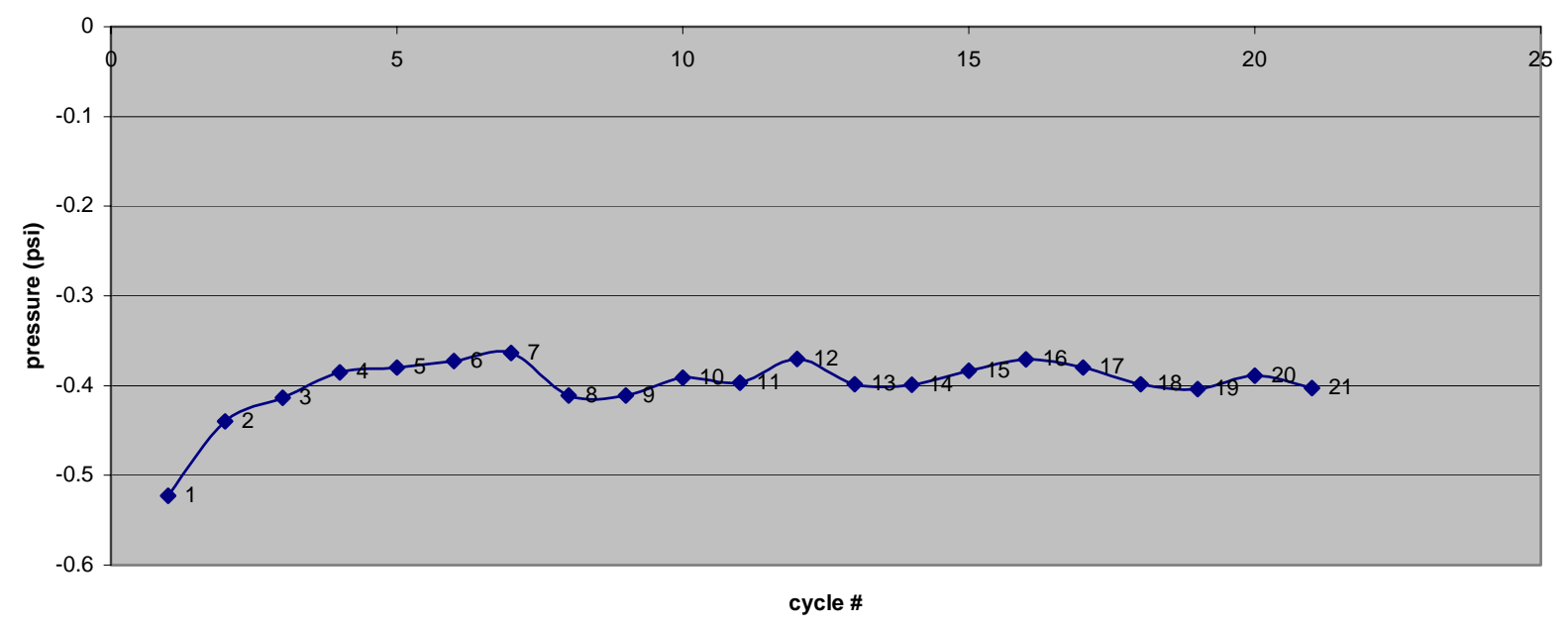

Figure 4.2.41 Initial pressure drop at $1400 \mathrm{~F}, 7 \mathrm{~cm} / \mathrm{s}$ 


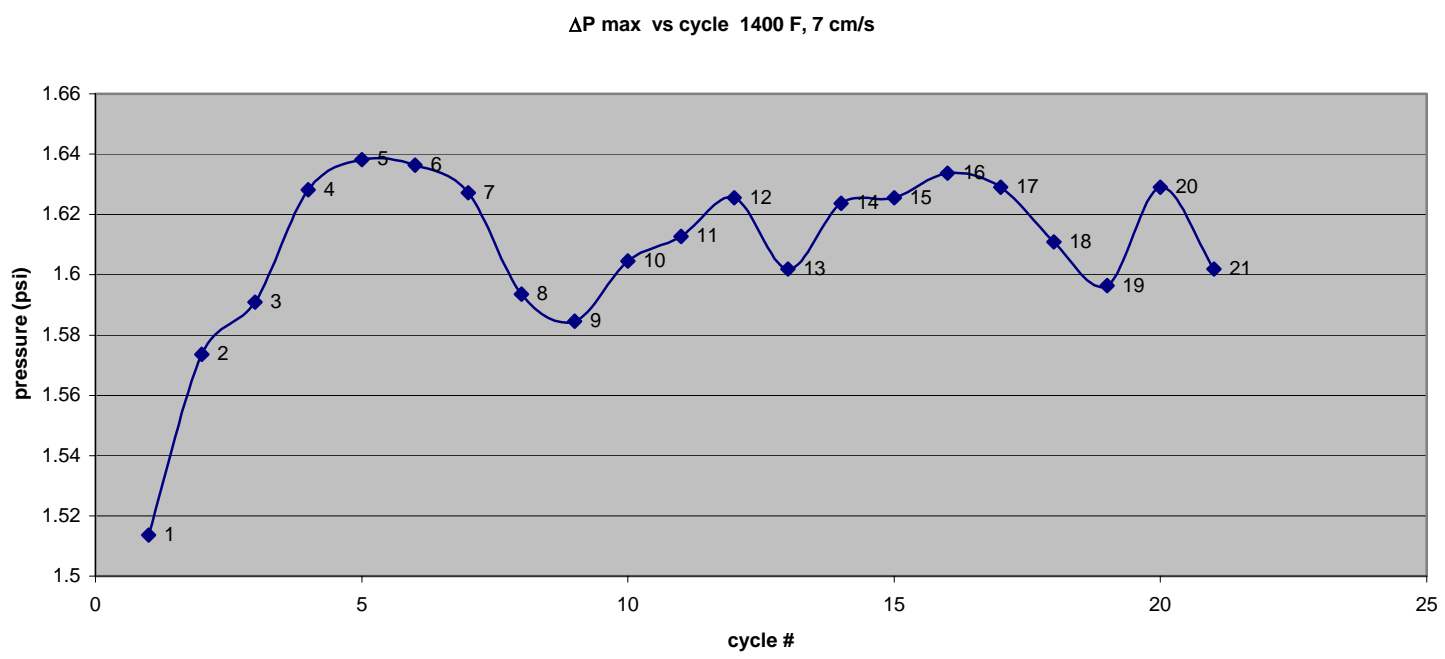

Figure 4.2.42 Maximum pressure drop at $1400 \mathrm{~F}, 7 \mathrm{~cm} / \mathrm{s}$

$\Delta \mathrm{Pf}$ vs time

$1400 \mathrm{~F}, 7 \mathrm{~cm} / \mathrm{s}$

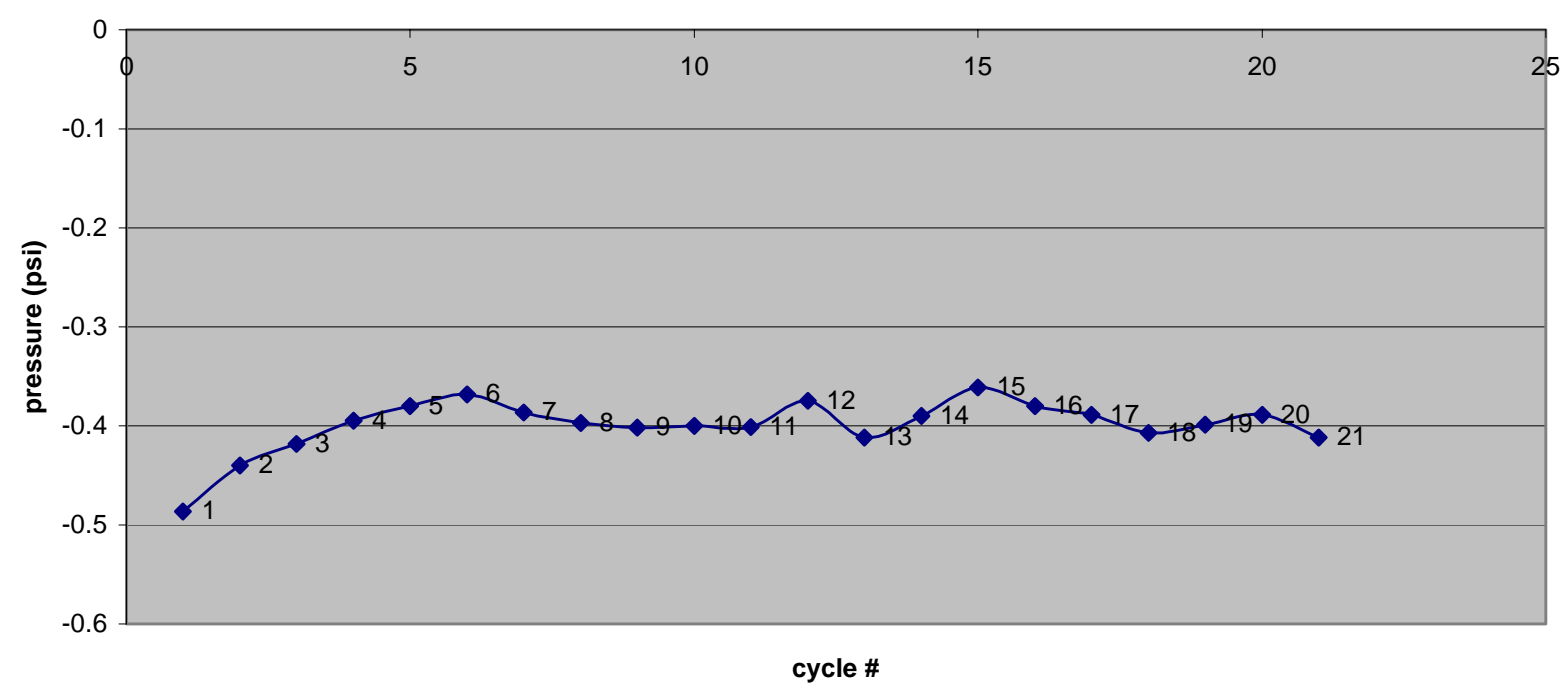

Figure 4.2.43 Final pressure drop at $1400 \mathrm{~F}, 7 \mathrm{~cm} / \mathrm{s}$ 
$\Delta \mathrm{Pi}-\Delta \mathrm{Pf}$ vs cycle $1400 \mathrm{~F}, 7 \mathrm{~cm} / \mathrm{s}$

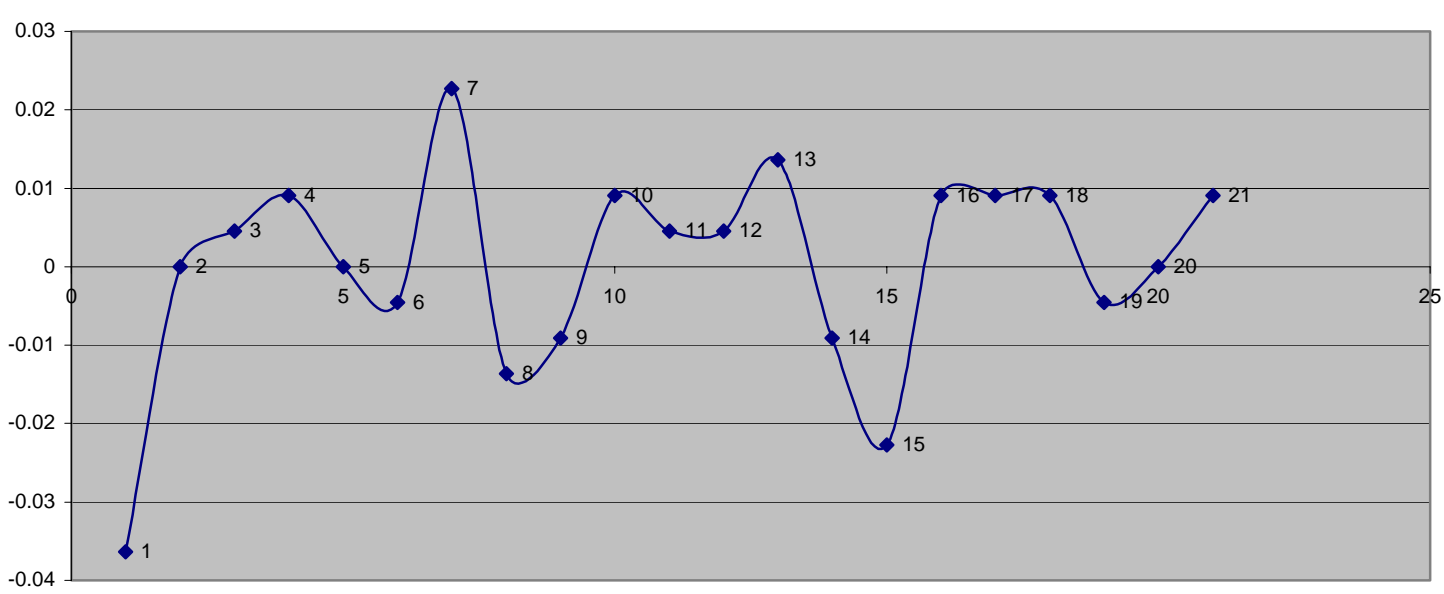

Figure 4.2.44 Initial - Final pressure drop difference at $1400 \mathrm{~F}, 7 \mathrm{~cm} / \mathrm{s}$ 
Comparison between $\Delta \mathrm{Pi}$ at $1400 \mathrm{~F}$ for two different face velocities

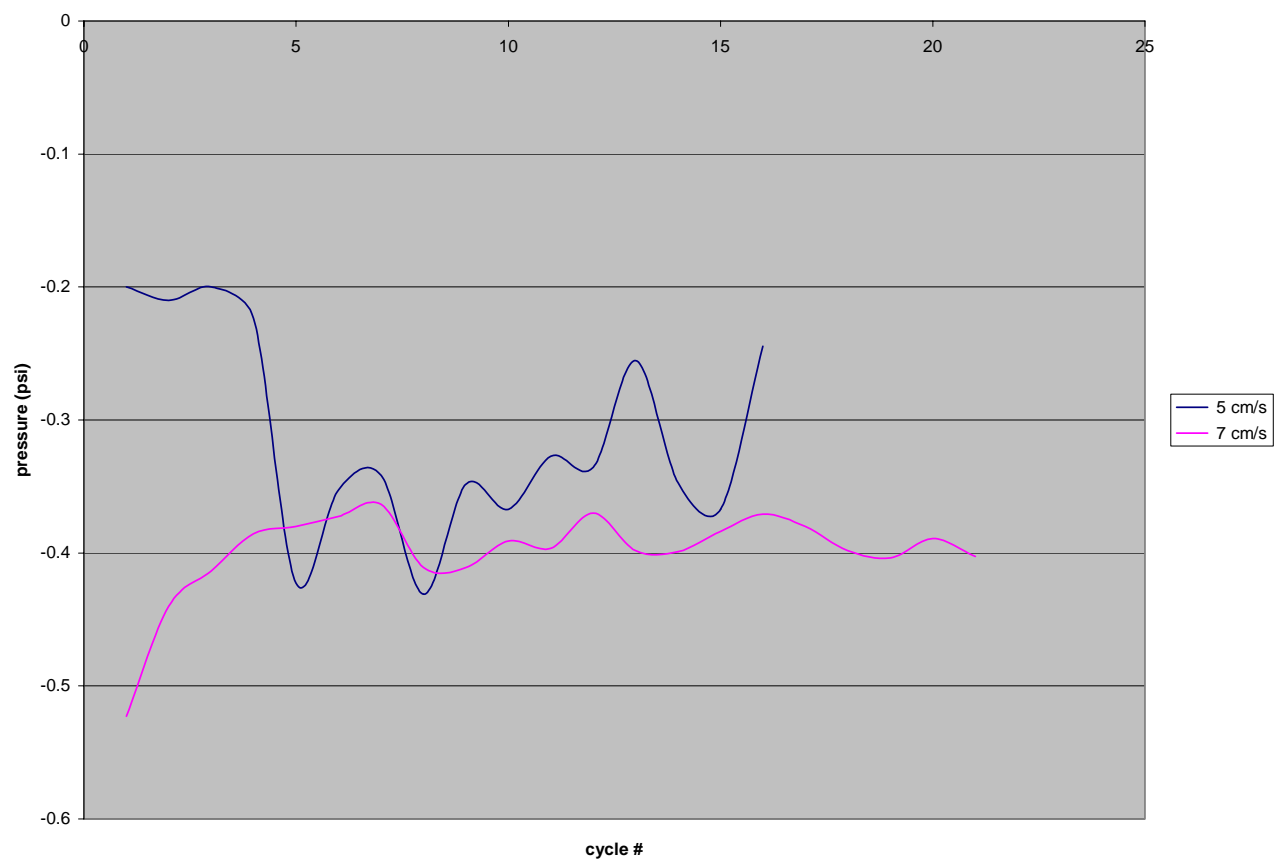

Figure 4.2.45 Comparison between initial pressure drop at $1400 \mathrm{~F}$ for two different face velocities

Comparison between $\Delta \mathrm{Pmax}$ at $1400 \mathrm{~F}$ for two different face velocities

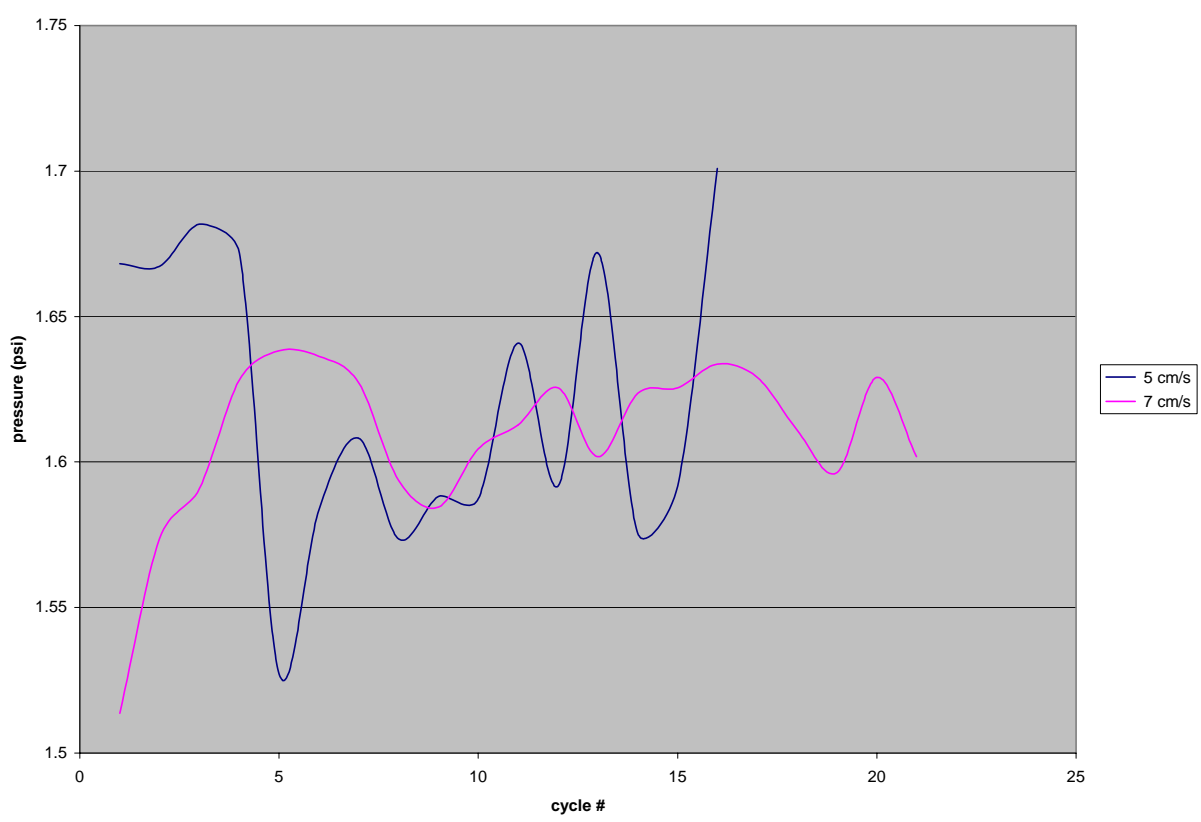

Figure 4.2.46 Comparison between maximum pressure drop at $1400 \mathrm{~F}$ for two different face velocities 


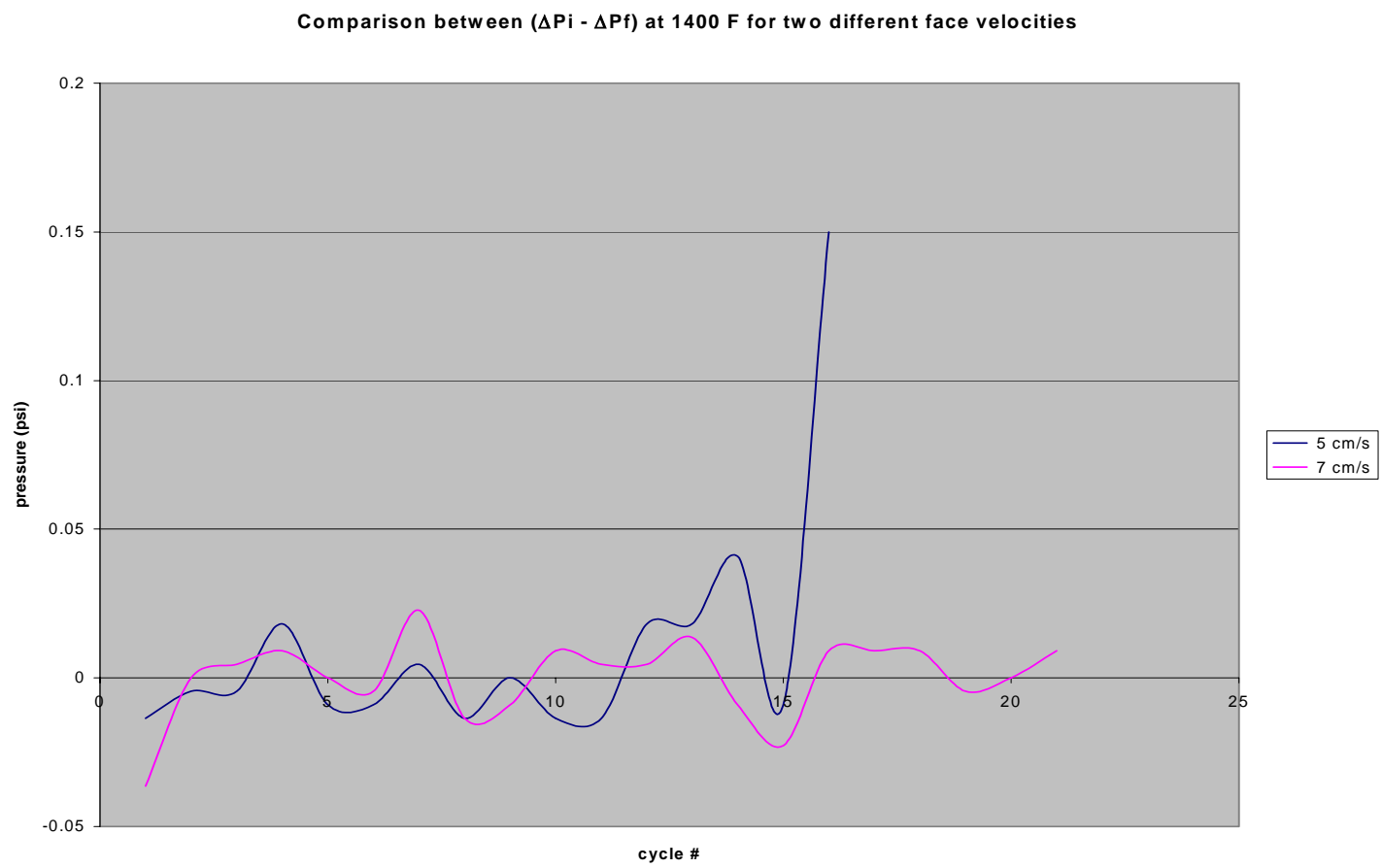

Figure 4.2.47 Comparison between initial - final pressure drop difference at $1400 \mathrm{~F}$, for two different face velocities
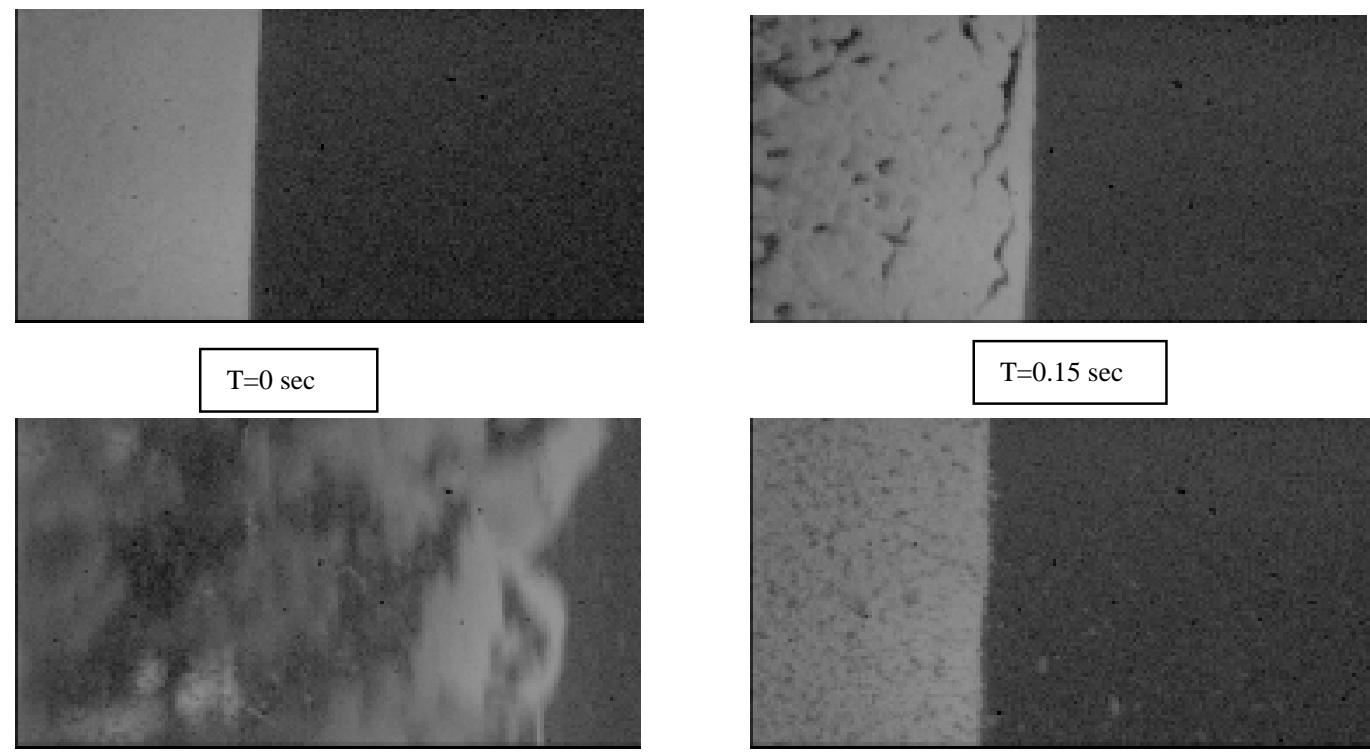

$\mathrm{T}=0.15 \mathrm{sec}$

$\mathrm{T}=0.3 \mathrm{sec}$

$\mathrm{T}=0.66$

Figure 4.2.48

Thick ash regeneration at first cycle with residual ash formation. $1400 \mathrm{~F}, 5 \mathrm{~cm} / \mathrm{s}$ 


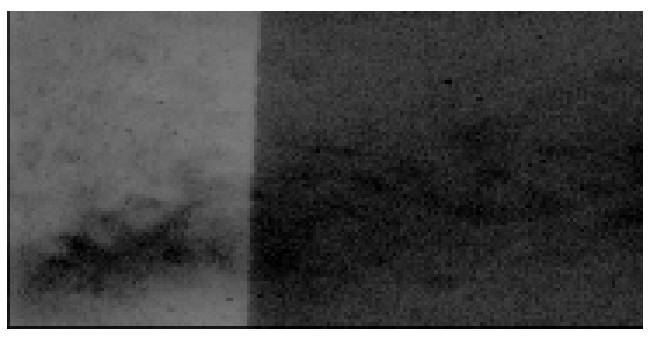

$\mathrm{T}=0 \mathrm{sec}$

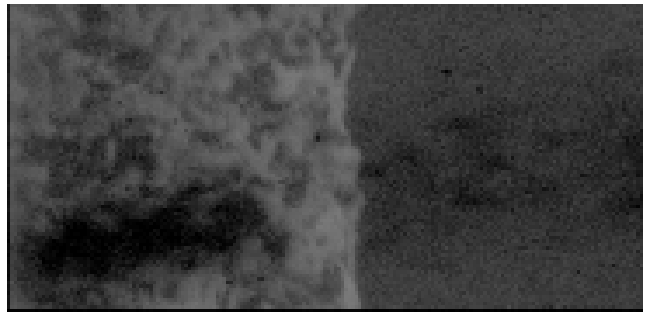

$\mathrm{T}=0.18 \mathrm{sec}$

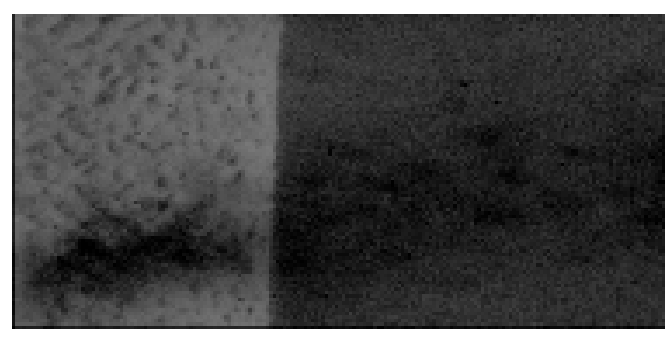

$\mathrm{T}=0.11 \mathrm{sec}$

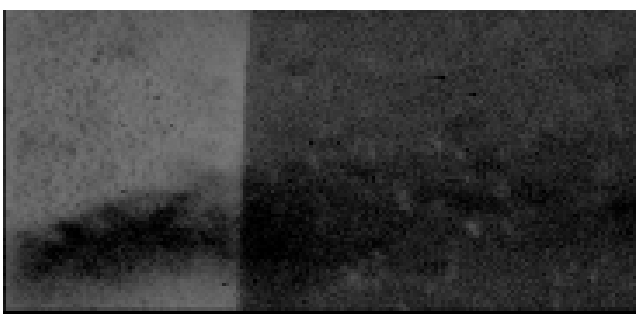

$\mathrm{T}=0.51 \mathrm{sec}$

Figure 4.2.49

Thin ash regeneration at fifh

cycle. $1400 \mathrm{~F}, 5 \mathrm{~cm} / \mathrm{s}$

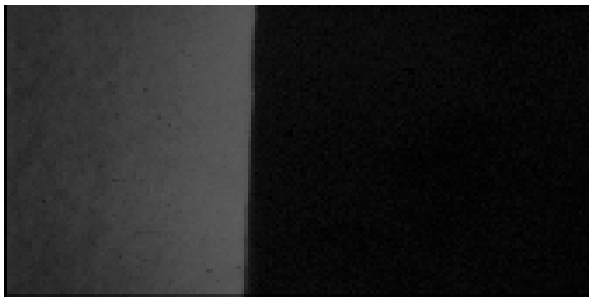

$\mathrm{T}=0 \mathrm{sec}$

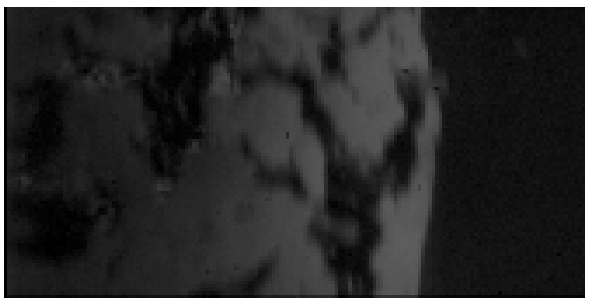

$\mathrm{T}=0.25 \mathrm{sec}$

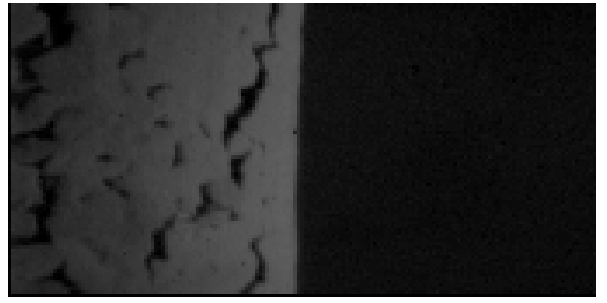

$\mathrm{T}=0.16 \mathrm{sec}$

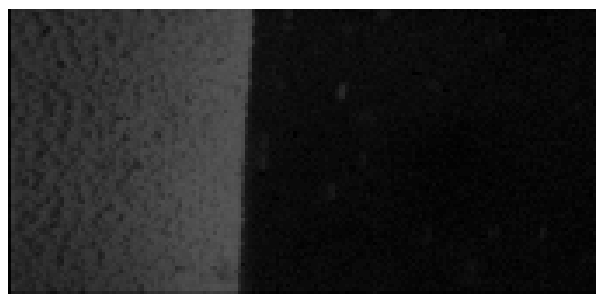

$\mathrm{T}=0.6 \mathrm{sec}$

Figure 4.2.50

Thick ash regeneration at first cycle with residual ash formation. $1400 \mathrm{~F}, 7 \mathrm{~cm} / \mathrm{s}$ 

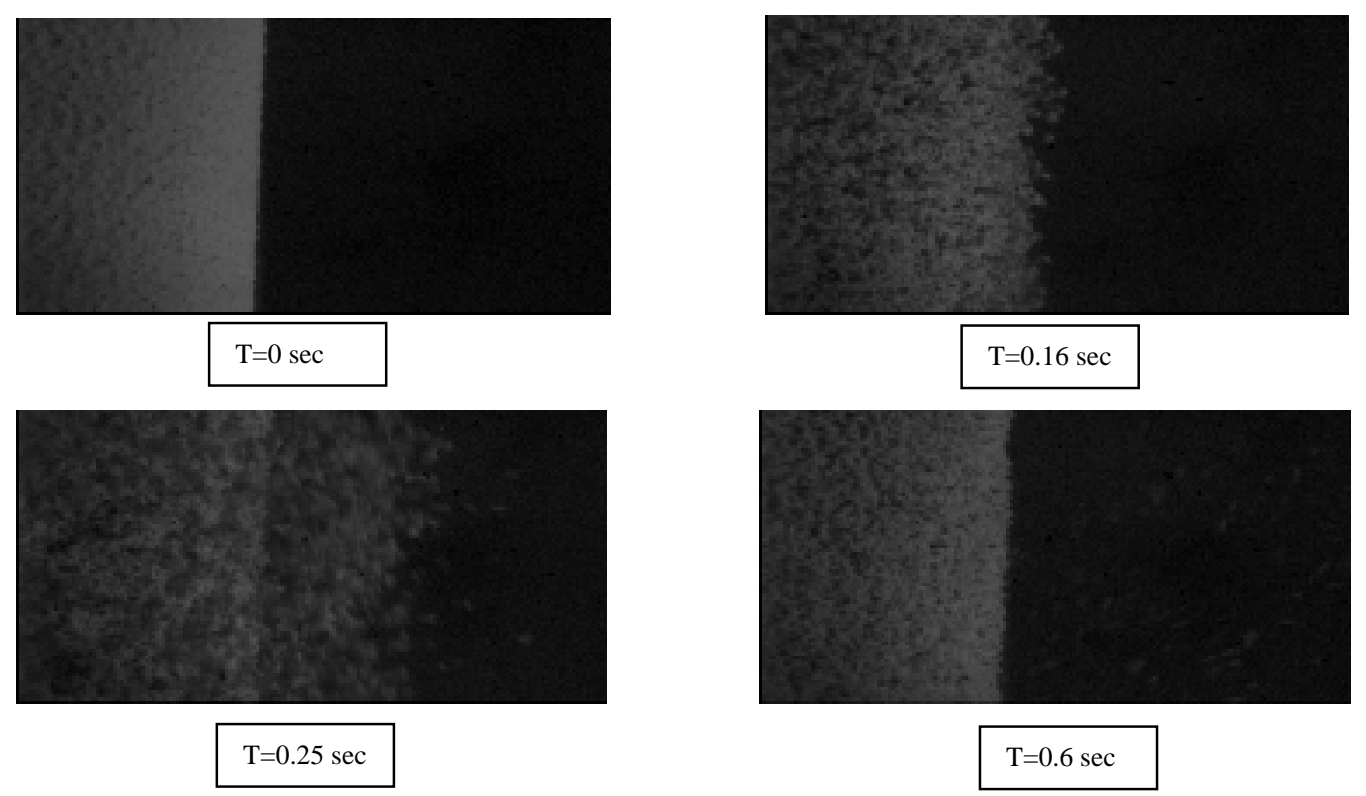

Figure 4.2.51

Thin ash regeneration at second cycle. $1400 \mathrm{~F}, 7 \mathrm{~cm} / \mathrm{s}$
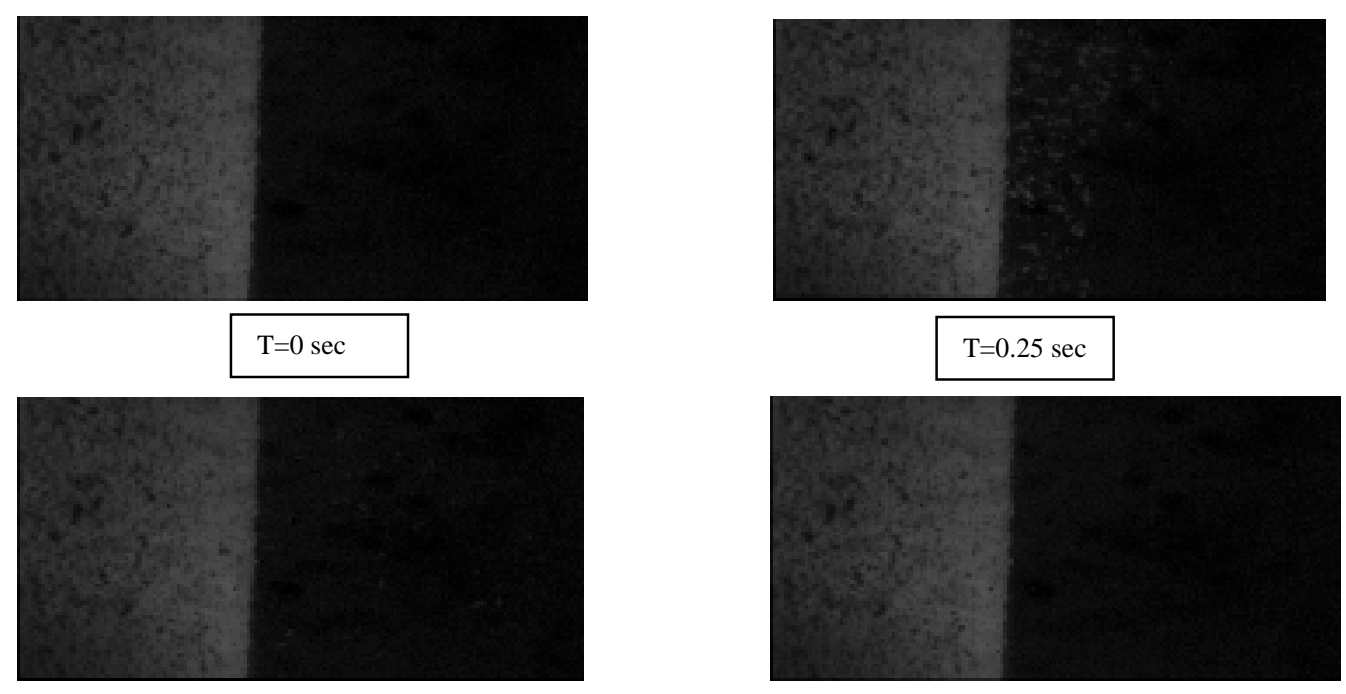

$\mathrm{T}=0.8 \mathrm{sec}$

$\mathrm{T}=1.66 \mathrm{sec}$

Figure 4.2.52

Regeneration with very few particles flying out at cycle $15^{\text {th }}$. $1400 \mathrm{~F}, 7 \mathrm{~cm} / \mathrm{s}$. 

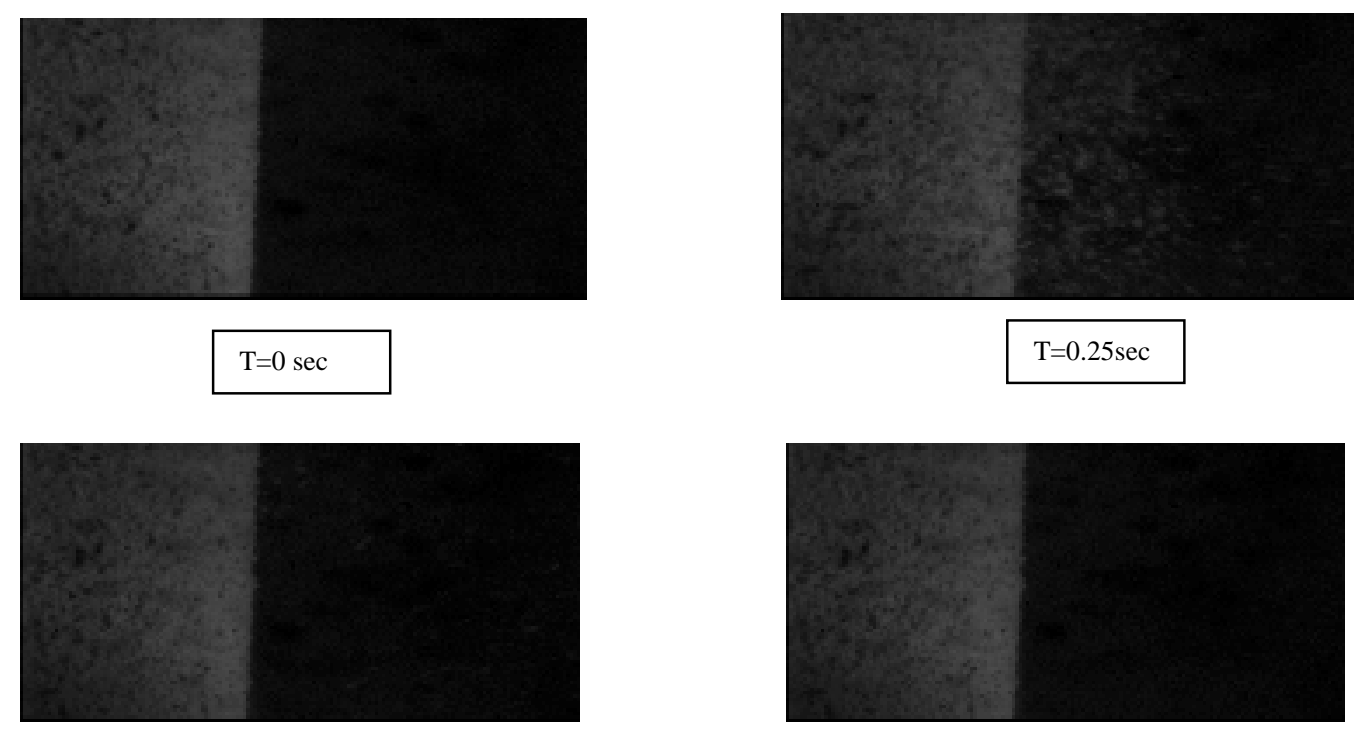

$\mathrm{T}=0.8 \mathrm{sec}$

$\mathrm{T}=1.66 \mathrm{sec}$

Figure 4.2.53 Regeneration with big amount of particles flying out at cycle 16 th. $1400 \mathrm{~F}, 7 \mathrm{~cm} / \mathrm{s}$. 


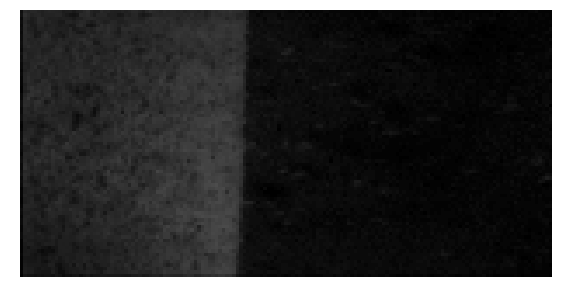

$\mathrm{T}=0.66$

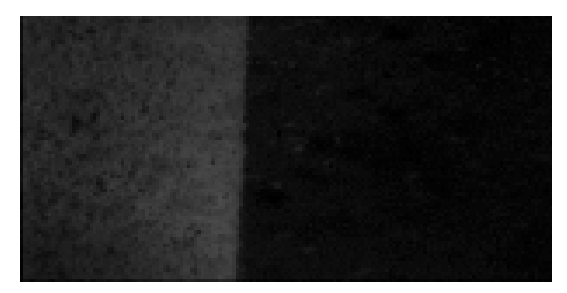

$\mathrm{T}=0.70$

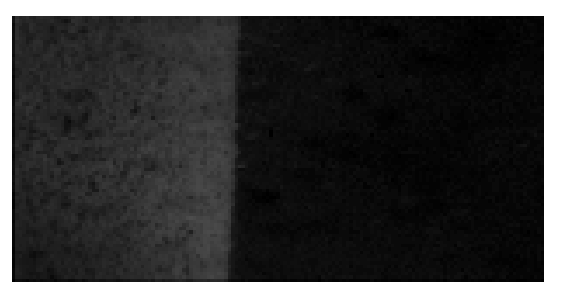

$\mathrm{T}=0.73$

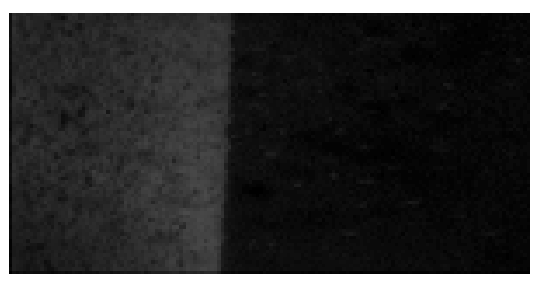

$\mathrm{T}=0.68$

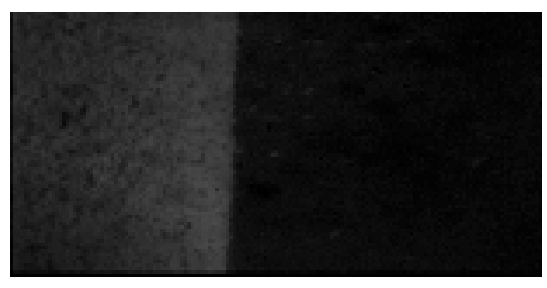

$\mathrm{T}=0.72$

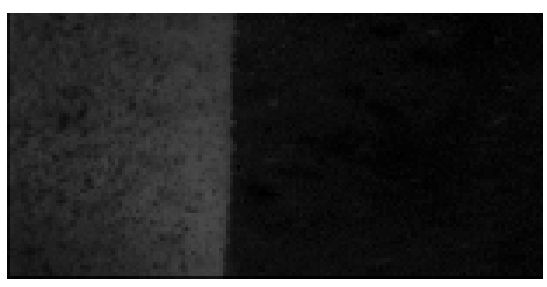

$\mathrm{T}=0.75$

Figure 4.2.54. Evidence of particle reentrainment at 16 th. regeneration cycle. $1400 \mathrm{~F}, 7 \mathrm{~cm} / \mathrm{s}$. 

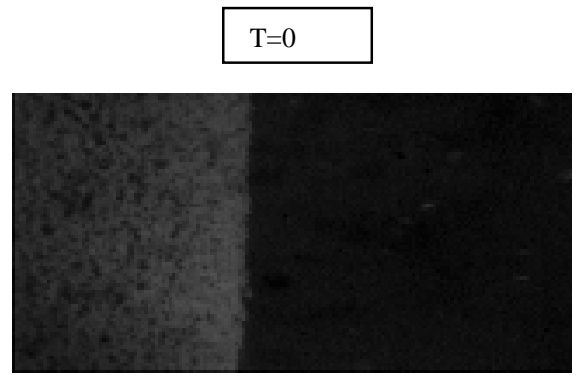

$\mathrm{T}=0.58$
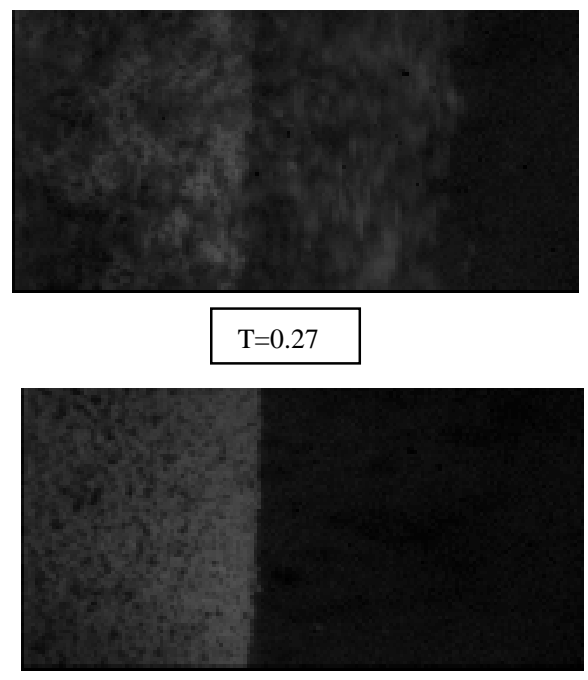

$\mathrm{T}=0.81$

Regeneration 9

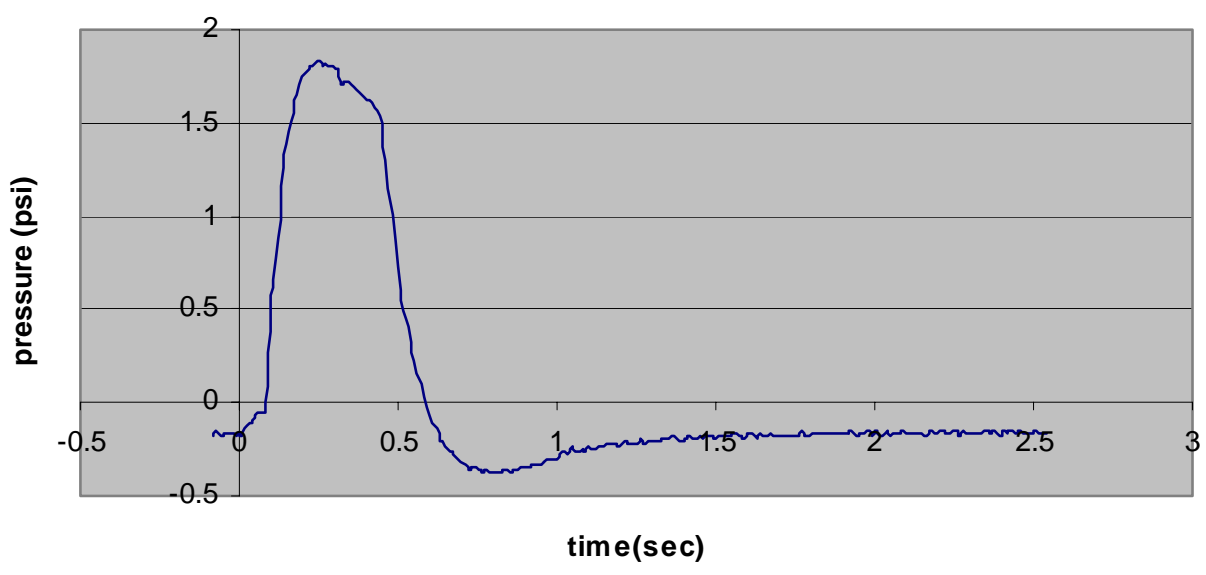

Figure 4.2.55 Regeneration \# 9 at test 1400 F, 7 cm/s 

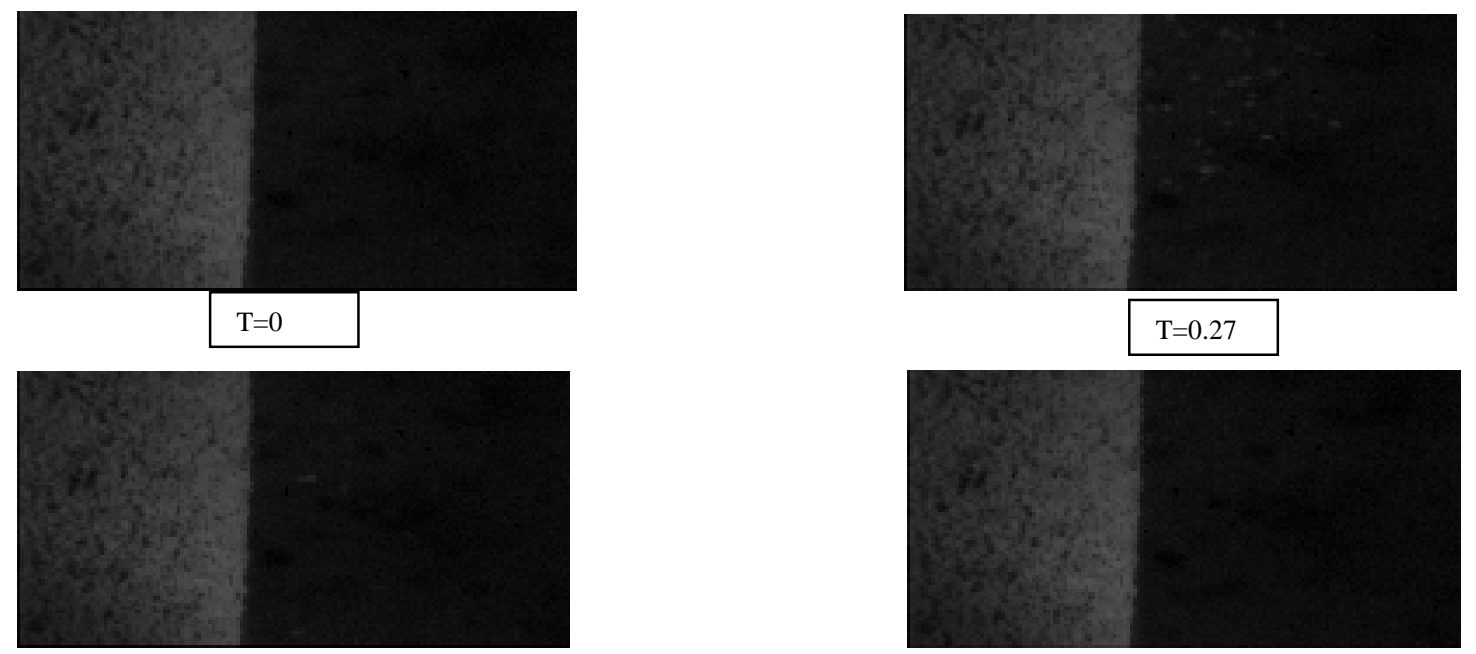

$\mathrm{T}=0.58$

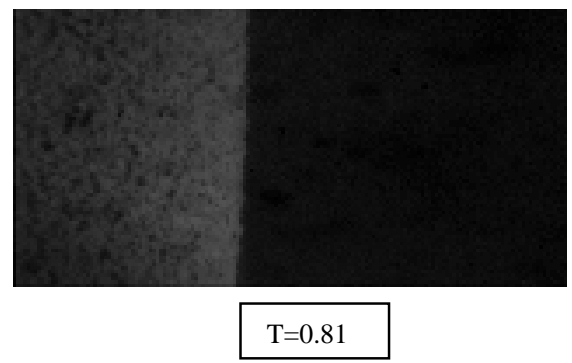

Figure 4.2.56 Regeneration \# 10 at test $1400 \mathrm{~F}, 7 \mathrm{~cm} / \mathrm{s}$

Sequence of regenerations at $1500 \mathrm{~F}, 7 \mathrm{~cm} / \mathrm{s}$
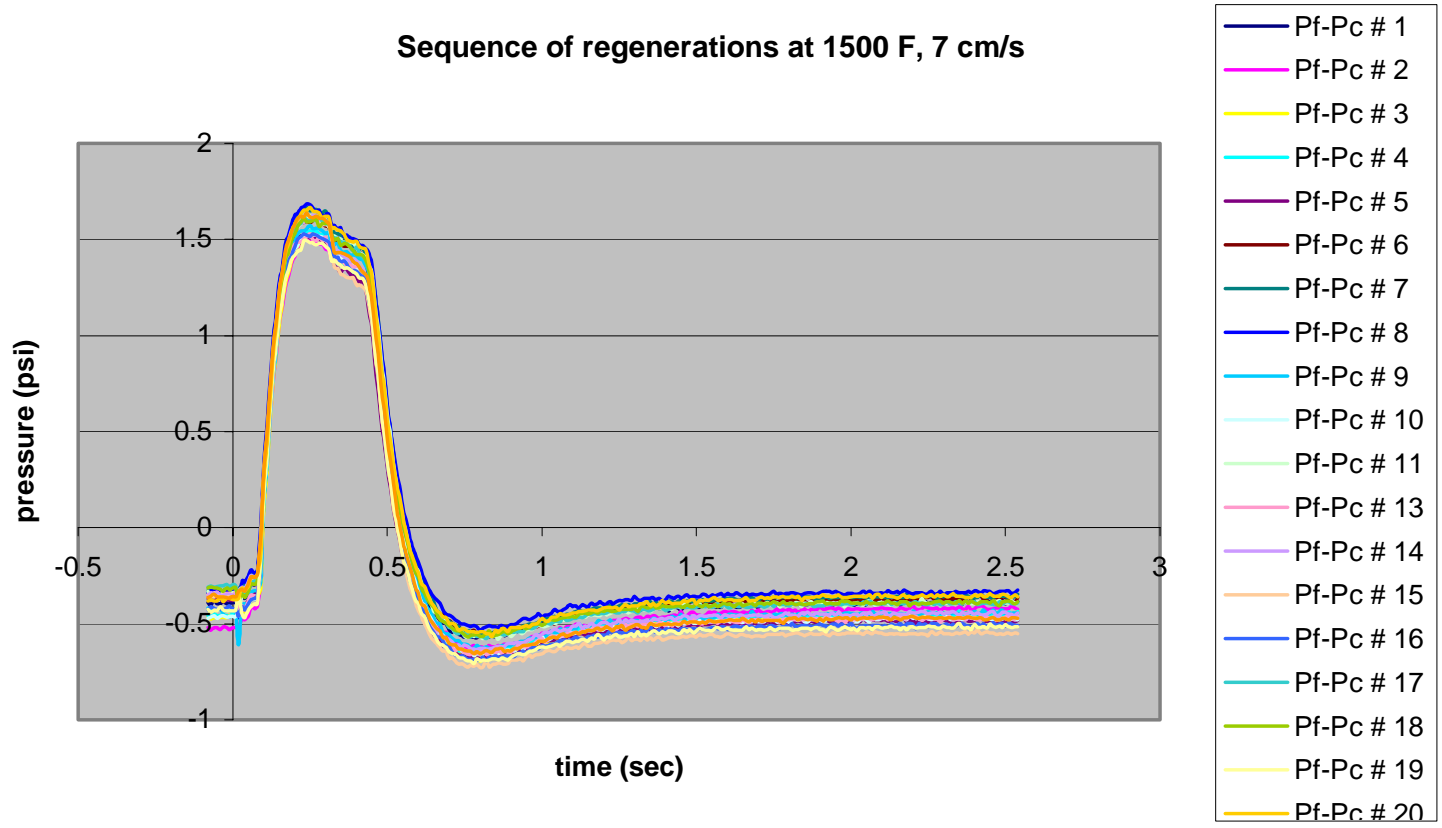

Figure 4.2.57 Pressure profile for sequence of regenerations at $1500 \mathrm{~F}, 7 \mathrm{~cm} / \mathrm{s}$ 
$\Delta \mathrm{Pi}$ vs cycle $1500 \mathrm{~F}, 7 \mathrm{~cm} / \mathrm{s}$

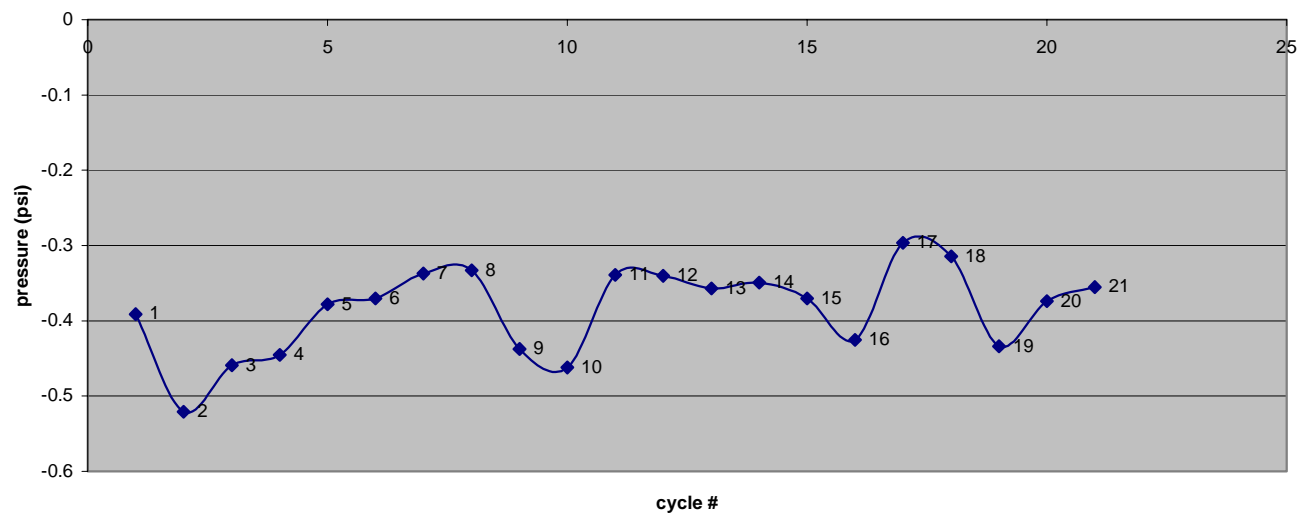

Figure 4.2.58 Initial pressure drop at $1500 \mathrm{~F}, 7 \mathrm{~cm} / \mathrm{s}$

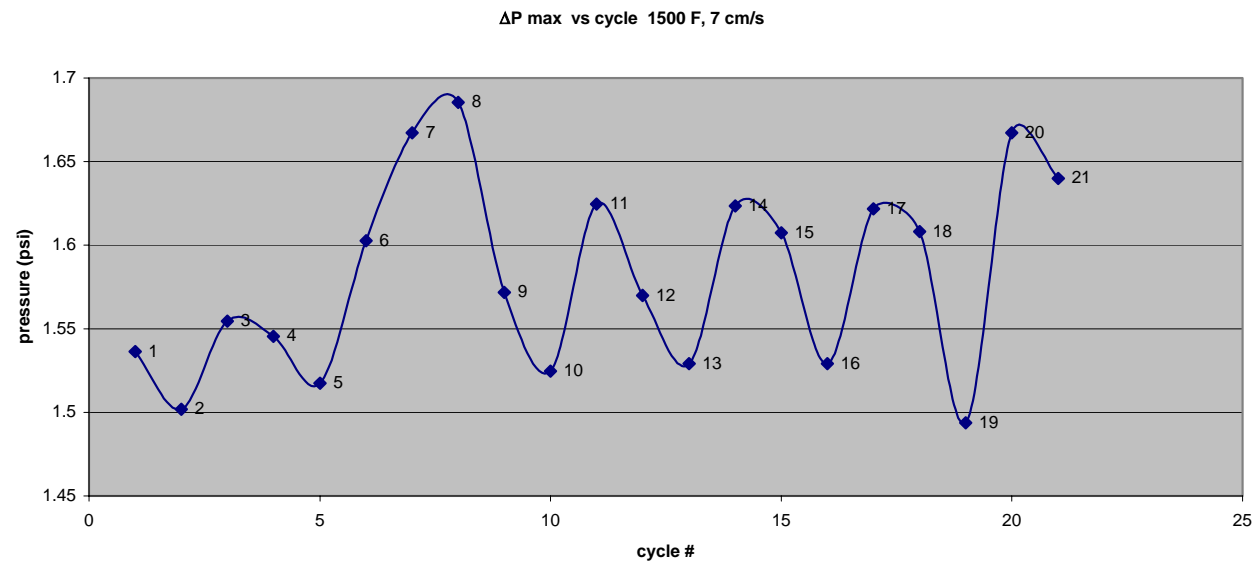

Figure 4.2.59 Maximum pressure drop at $1500 \mathrm{~F}, 7 \mathrm{~cm} / \mathrm{s}$ 
$\Delta \mathrm{Pf}$ vs time

$1500 \mathrm{~F}, 7 \mathrm{~cm} / \mathrm{s}$

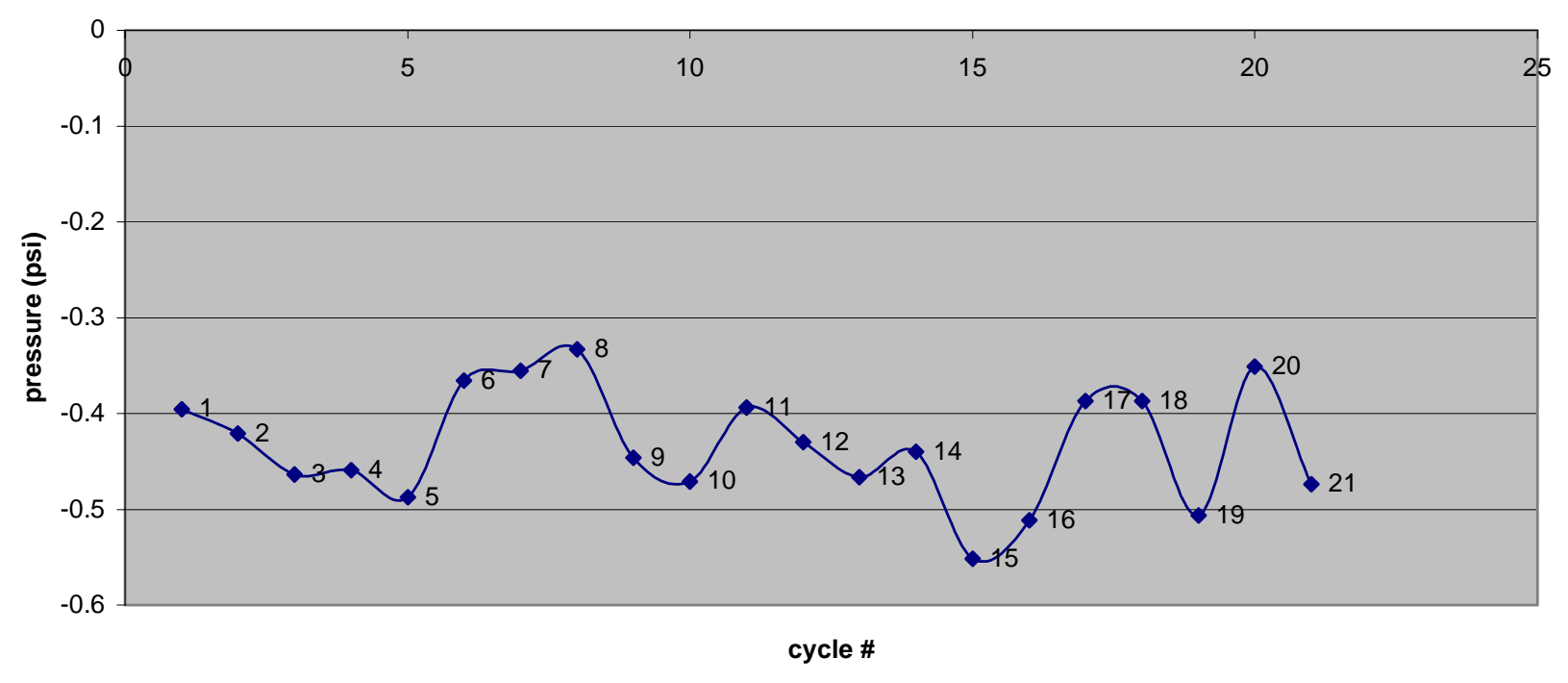

Figure 4.2.60 Final pressure drop at $1500 \mathrm{~F}, 7 \mathrm{~cm} / \mathrm{s}$ 
$\Delta \mathrm{Pi}-\Delta \mathrm{Pf}$ vs cycle $1500 \mathrm{~F}, 7 \mathrm{~cm} / \mathrm{s}$

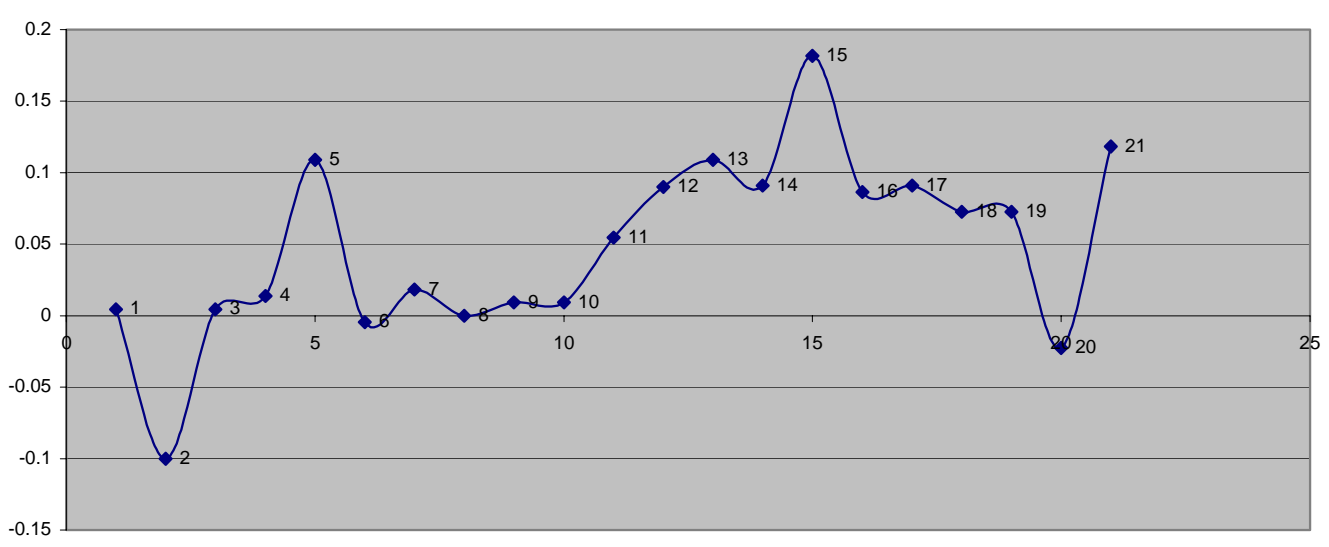

Figure 4.2.61 Initial - final pressure drop difference at $1500 \mathrm{~F}, 7 \mathrm{~cm} / \mathrm{s}$
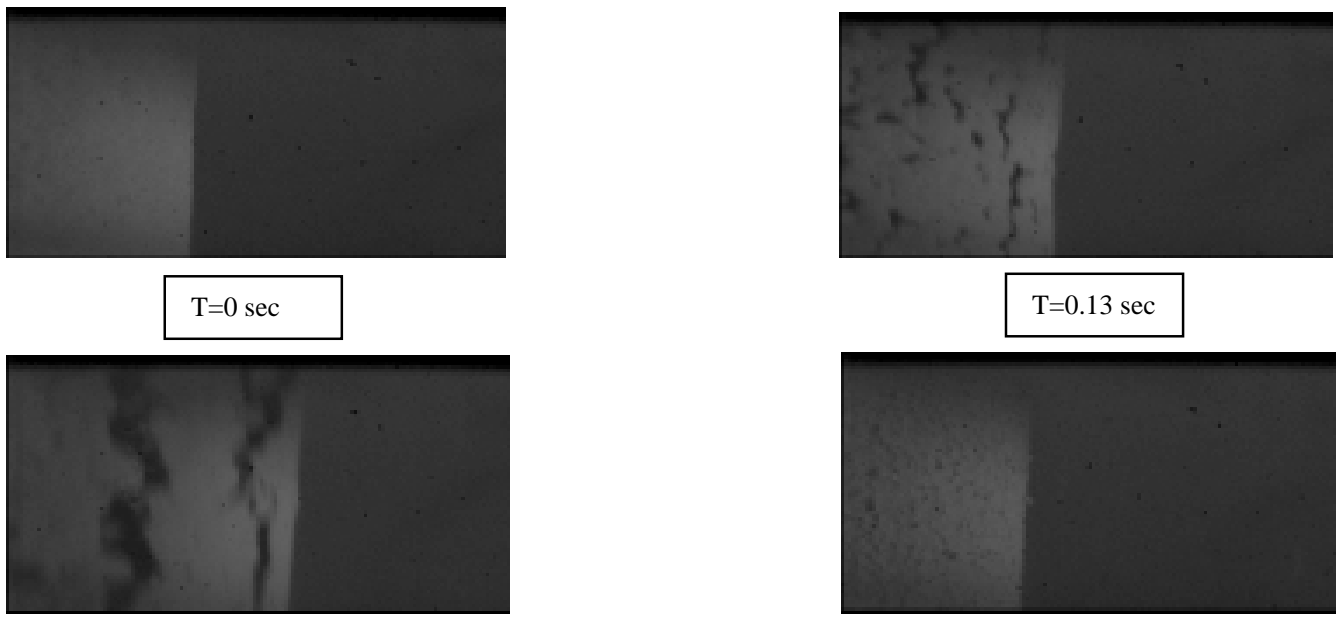

$\mathrm{T}=0.13 \mathrm{sec}$

$\mathrm{T}=0.18 \mathrm{sec}$

$\mathrm{T}=0.51 \mathrm{sec}$

Figure 4.2.62 Thick ash regeneration at first cycle. $1500 \mathrm{~F}, 7 \mathrm{~cm} / \mathrm{s}$. 


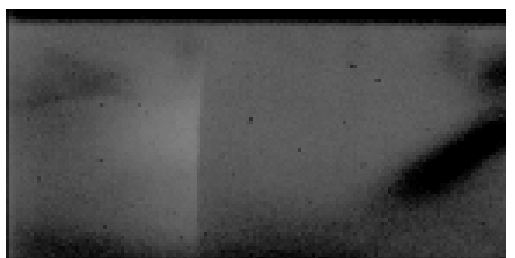

$\mathrm{T}=0 \mathrm{sec}$

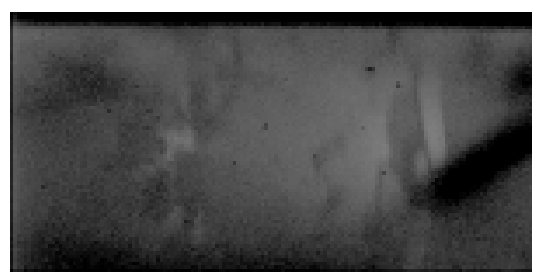

$\mathrm{T}=0.26 \mathrm{sec}$

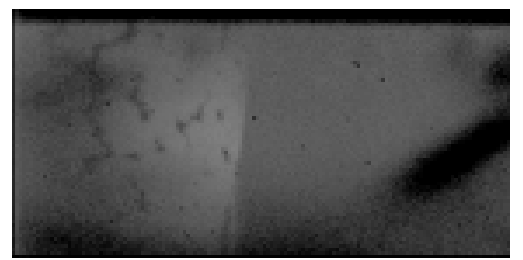

$\mathrm{T}=0.15 \mathrm{sec}$

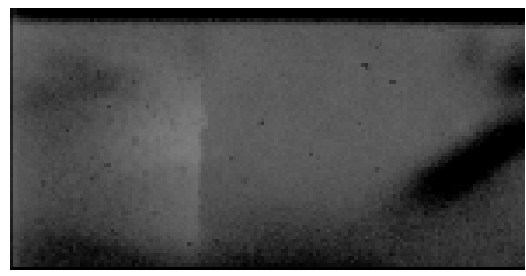

$\mathrm{T}=0.51 \mathrm{sec}$

Figure 4.2.63 Thick ash regeneration at fourth cycle. $1500 \mathrm{~F}, 7 \mathrm{~cm} / \mathrm{s}$.

\subsection{Particle distribution analysis.}

A Matlab particle counting program [17], was used in this section as a particle distribution analysis tool. Particle counting refers to the number of particles found in a specific range of particle size. Graphs showing the behavior of the particle size count for the three different mechanisms of particle detachment found in the previous analysis, section 4.2, are presented in Figures 4.3.1, 4.3.2 and 4.3.3. An area of $4 \mathrm{~cm}^{2}$ was the base for the counting. It is observed in all the three detachment mechanisms, that particle sizes of less than $100 \mu$ are the predominant group, followed by particles between $100 \mu$ and $250 \mu$ and then by particles between $250 \mu$ and $500 \mu$, with practically no particles bigger than $500 \mu$. 


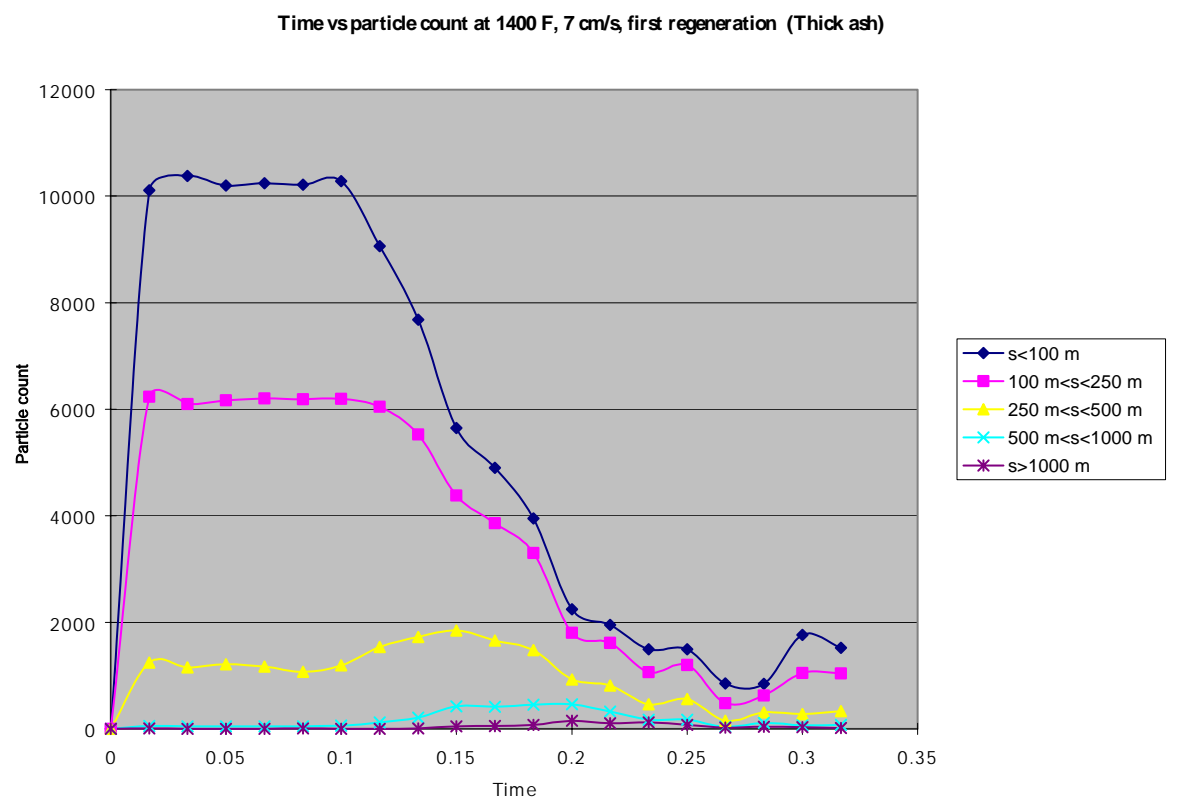

Figure 4.3.1 Particle counting for diferent sizes at $1400 \mathrm{~F}, 7 \mathrm{~cm} / \mathrm{s}$, Thick ash regeneration mechanism.

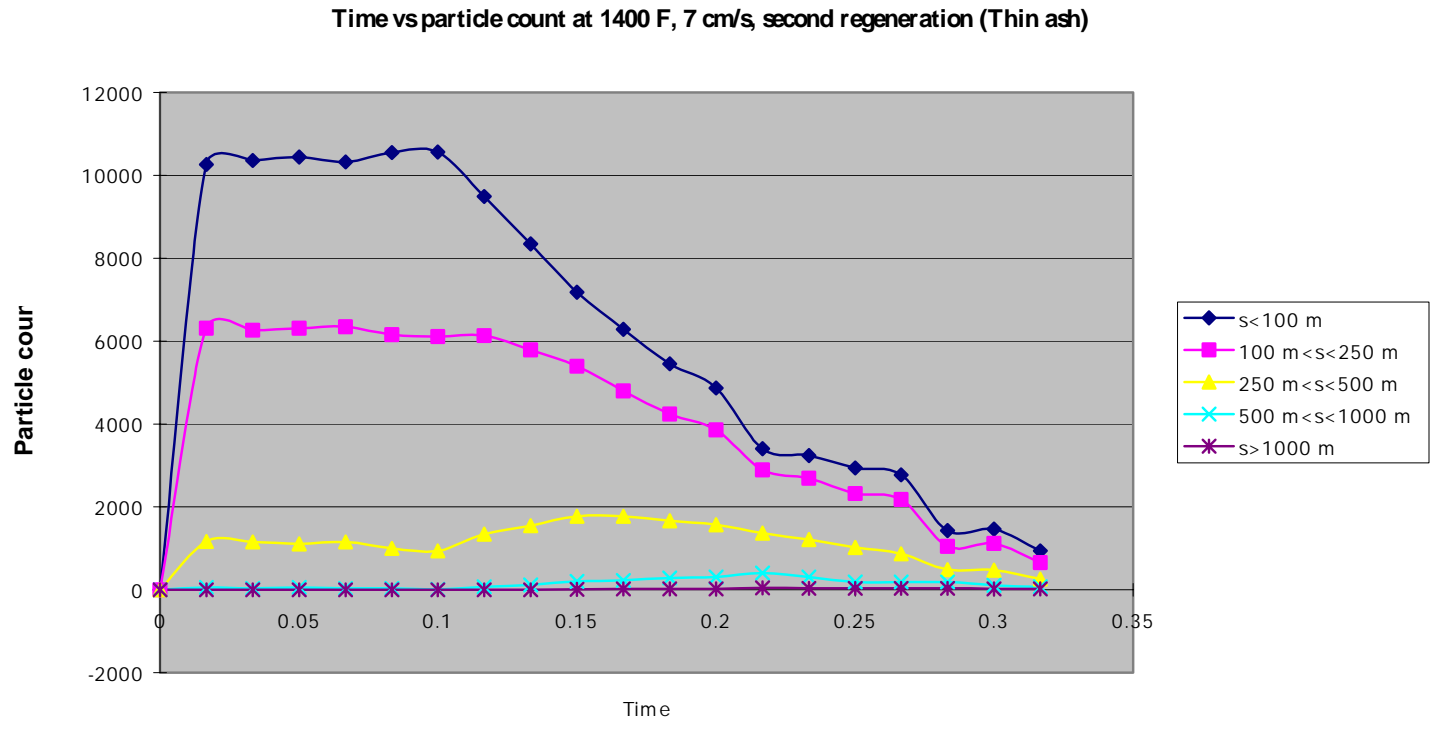

Figure 4.3.2 Particle counting for different sizes at $1400 \mathrm{~F}, 7 \mathrm{~cm} / \mathrm{s}$, Thin ash regeneration mechanism. 
However a difference in particle counts with time is observed for the three different detachment mechanisms. When a thick ash regeneration occurs, the particle count drops very fast with time. The particle count is under 1500 at 0.25 seconds for all the particle sizes, as shown in Figure 4.3.1. For a thin ash regeneration the particle count does not drop as rapidly. At 0.25 seconds a particle count of 3000 is observed as shown Figure 4.3.2. When the surface regeneration mechanism is particles flying out, a particle count above 6000 is observed at 0.25 seconds as shown in Figure 4.3.1.

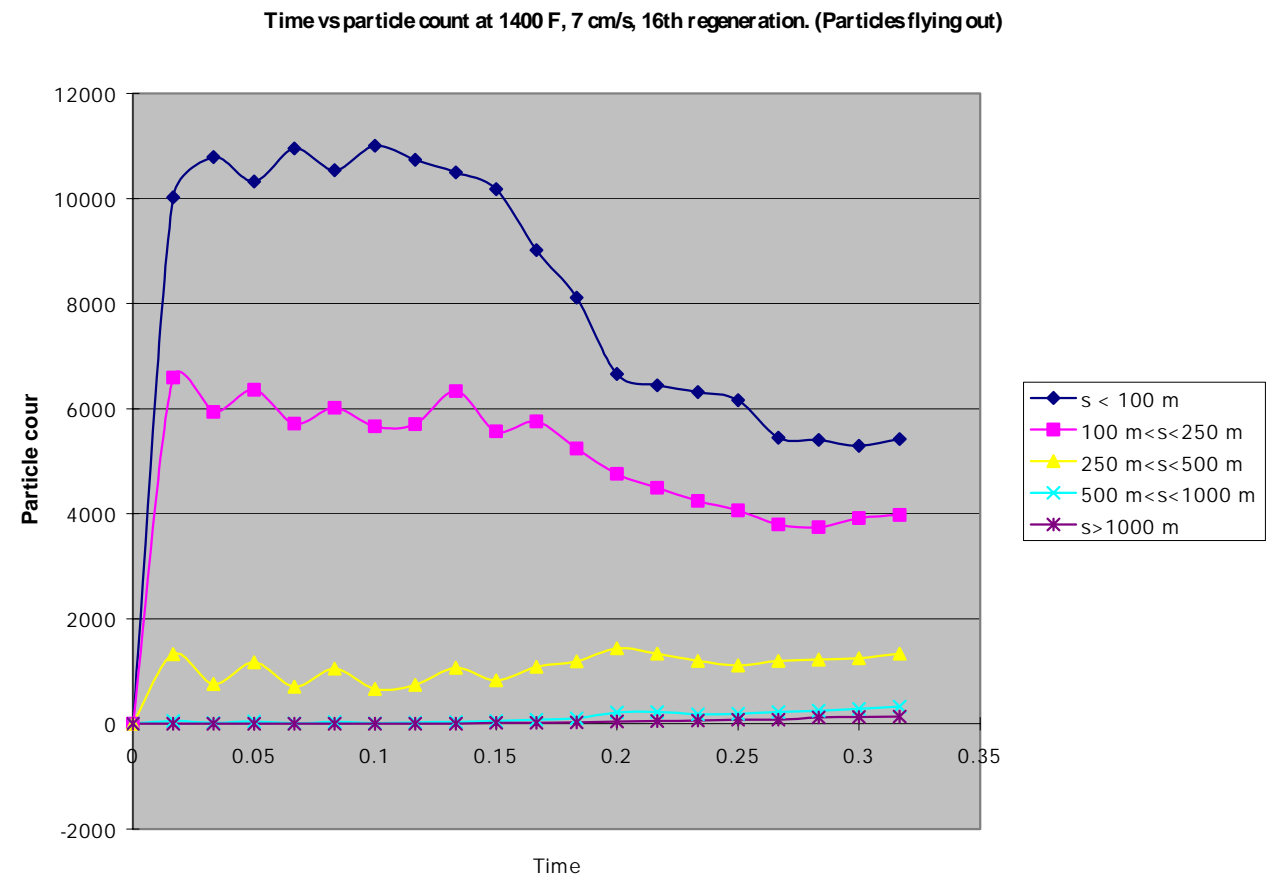

Figure 4.3.3 Particle counting for different sizes at $1400 \mathrm{~F}, 7 \mathrm{~cm} / \mathrm{s}$, particles flying out regeneration mechanism. 
This observed behavior is consistent with the notion that smaller particles may be suspended in the air flow for a longer period of time (particles flying out mechanism), while for bigger chunks of ashes (thick ash mechanism), they will fall quickly by the action of gravity. 


\section{Chapter 5. A study of gas velocities during surface regeneration}

5.1 Gas velocity measurements

Gas velocity measurements during surface regeneration were obtained along the axis filter using a hot wire anemometer, Figure 5.1.1

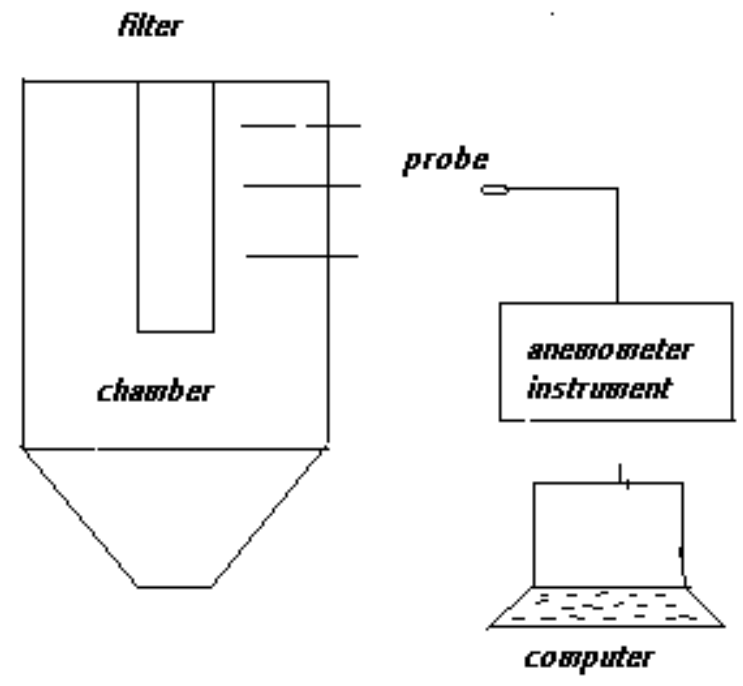

Figure 5.1.1 Gas velocity measurement set up. 
A special device was developed for probe calibration, Figure 5.1.2.

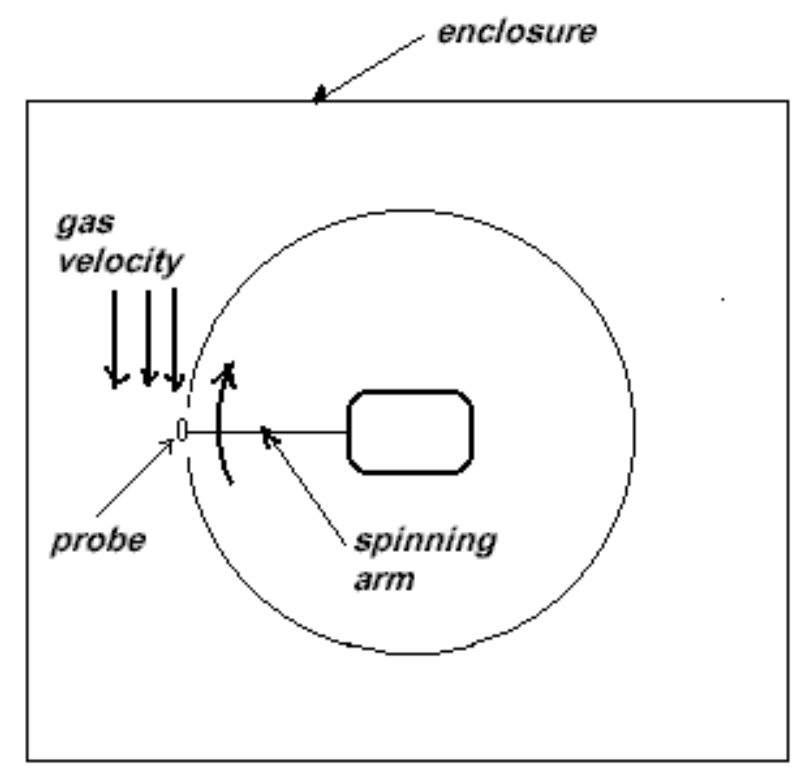

Figure 5.1.2 Probe calibration device

The anemometer probe was mounted on a slowly spinning arm driven by an electric motor. This created a constant tangential gas velocity for the probe, corresponding to the anticipated velocities during surface regeneration. The enclosure prevented disturbances from the surrounding air.

After the probe was calibrated, the gas velocity measurements were obtained 
during the surface regeneration process. A clean candle filter with $5 \mathrm{~cm} / \mathrm{s}$ of fluidizing air was used for this purpose.

Two thousand velocity readings per second were taken in a period of 8 seconds. However, for the purpose of this study, only the first 2.5 seconds of data have been taken for the analysis, due to the fact that it is the same period of time used before for the pressure analysis in Chapter 4. Results are shown in Figure 5.1.3. Note that the probe was a hot wire anemometer, consequently the initial and final velocities appear positive, but in reality, the flow should be to the filter and consequently negative.

Gas Velocity measurements for a 95 psi regeneration pulse

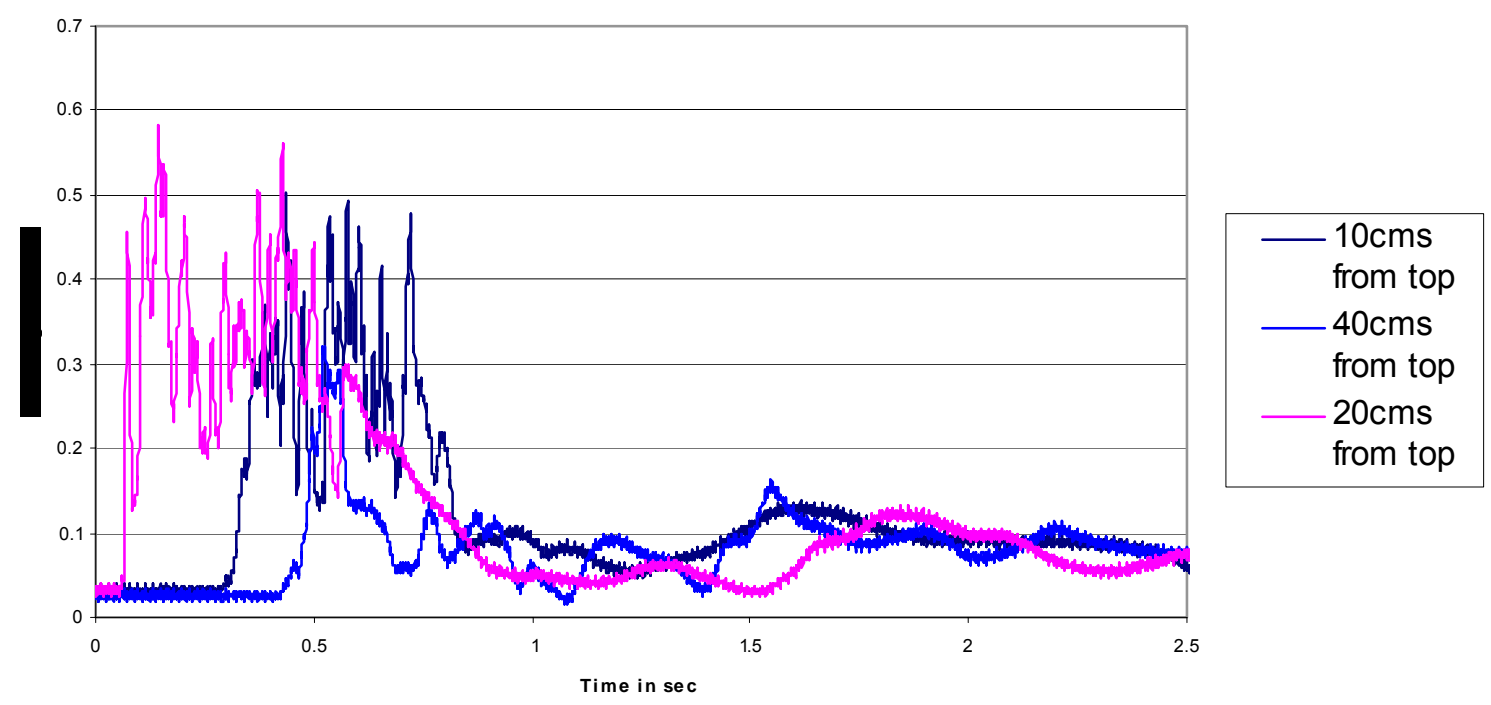

Figure No. 5.1.3 Gas velocity measurements for a $95 \mathrm{psi}$ regeneration pulse

The observed velocities at 0 and 2.5 seconds represented the face velocity for the fluidizing air. The location at $20 \mathrm{~cm}$ from the top was chosen as the most representative for this case, since that was the location in which images were 
obtained while the regeneration processes were taking place. The anemometer probe was located at $5 \mathrm{~mm}$ from the filter wall.

Using these experimental data combined with a mathematical model for the dynamics of the fluid and the particle, an estimation was made regarding how far the particle travels from the filter wall.

With this information, the probability of a particle hitting a nearby filter can be better estimated. Consequently, a better understanding of the filter interaction may be found. The probability of a particle returning to the surface can be better estimated also.

\subsection{The mathematical model}

If $v_{p}$ is the horizontal particle velocity and $v$ is the gas velocity, it follows that $d v_{p} / d t=\left(v-v_{p}\right) / \tau v$

where $\tau_{v}=\rho p d_{p}^{2} / 18 \mu$

with $\rho p=$ particle density

$d_{p}=$ particle diameter

$\mu=$ viscocity of the gas

and $\operatorname{Re}_{\mathrm{p}}<1$

A derivation for this equation can be found in the appendix. Equation [ 5.2.1] is a simple linear first order differential equation, with the initial condition, $\mathrm{v}_{\mathrm{p}}=0$ at 
$t=0$. The gas velocity was estimated from the experimental data. As a first simple approach a constant value of $0.4 \mathrm{~m} / \mathrm{s}$ was chosen for the first 0.5 seconds. After that, the face velocity of $-0.05 \mathrm{~m} / \mathrm{s}$ was the gas velocity.

Let

$a=1 / \tau_{v}$

Then equation [ 5.2.1] can be rewritten as

$d v_{p} / d t+a v_{p}=a v(t)$

This is a first order linear differential equation in the variable $v_{p}$, with a general solution of the form

$v_{p}=\left(\int u(t) v(t) d t+C\right) / u(t)$

where $u(t)=\exp \left(\int\right.$ adt $)=\exp ($ at $)$

solving for $v_{p}$ gives

$\mathrm{V}_{p}=\left(\int(\exp (\mathrm{at}) \mathrm{v}(\mathrm{t})) \mathrm{dt}+\mathrm{C}\right) / \exp (\mathrm{at})$

where $\mathrm{v}(\mathrm{t})=0.4 \mathrm{~m} / \mathrm{s}$ for $0<\mathrm{t}<0.5$ and -0.05 for $\mathrm{t} \geq 0.5$

Evaluating the integral and rearranging terms,

$\mathrm{V}_{\mathrm{p}}=(\mathrm{k} \exp (\mathrm{at})+\mathrm{C}) / \exp (\mathrm{at})$

where $\mathrm{k}=0.4$ for $0<\mathrm{t}<0.5$ and -0.05 for $\mathrm{t} \geq 0.5$

C can be found using the initial conditions at $t=0$ for the interval $\{0,0.5\}$ and at $t=0.5$ for the interval $\{0.5, t\}$.

The vertical movement of the particle is determined as follows.

The mathematical model for the vertical component of velocity is 
$d w_{p} / d t=\left(w-w_{p}\right) / \tau_{v}-g$

where

$\mathrm{w}_{\mathrm{p}}=$ vertical particle velocity component

$w=$ vertical gas velocity component

$\mathrm{g}=$ gravitational acceleration

In this particular case, w can be assumed to be negligible.

Then, rewriting equation [ 5.2.2]

$d w_{p} / d t+a w_{p}=-g$

This is a first order linear differential equation in variable $w_{p}$, where its solution can be found in a similar way to the previous differential equation solved for the horizontal velocity $v_{p}$.

The general solution for $w_{p}$ is given by

$w_{p}=((-g / a) \exp (a t)+C) / \exp (a t)$

where

$a=1 / \tau_{v}$

Evaluating the initial condition

$w_{p}(0)=0$

the particular solution will be

$w_{p}=g(1-\exp (a t)) /(a \exp (a t))$

With the solution for the horizontal and vertical components of the particle velocity, a graph showing the particle path can be drawn, similar to the one shown in Figure 5.2.1. 


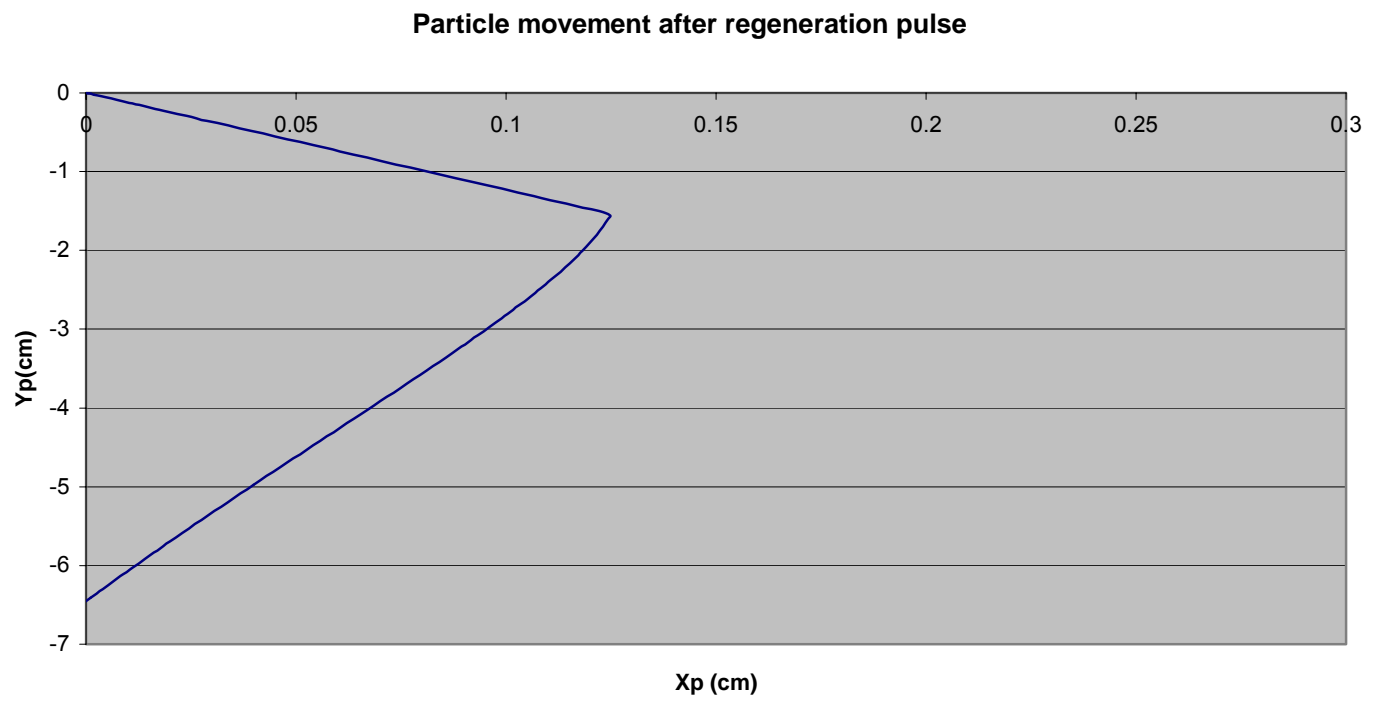

Figure 5.2.1. Path followed by a particle of $250 \mu$, after a $95 p s i$ regeneration backpulse.

In the particular case of the particle of $250 \mu$ diameter, it takes 1.4 seconds to complete its trip back to the surface location.

Solving the problem for a smaller particle, with a diameter of $100 \mu$, it takes 0.68 seconds, as it can be seen in Figure 5.2.2. 


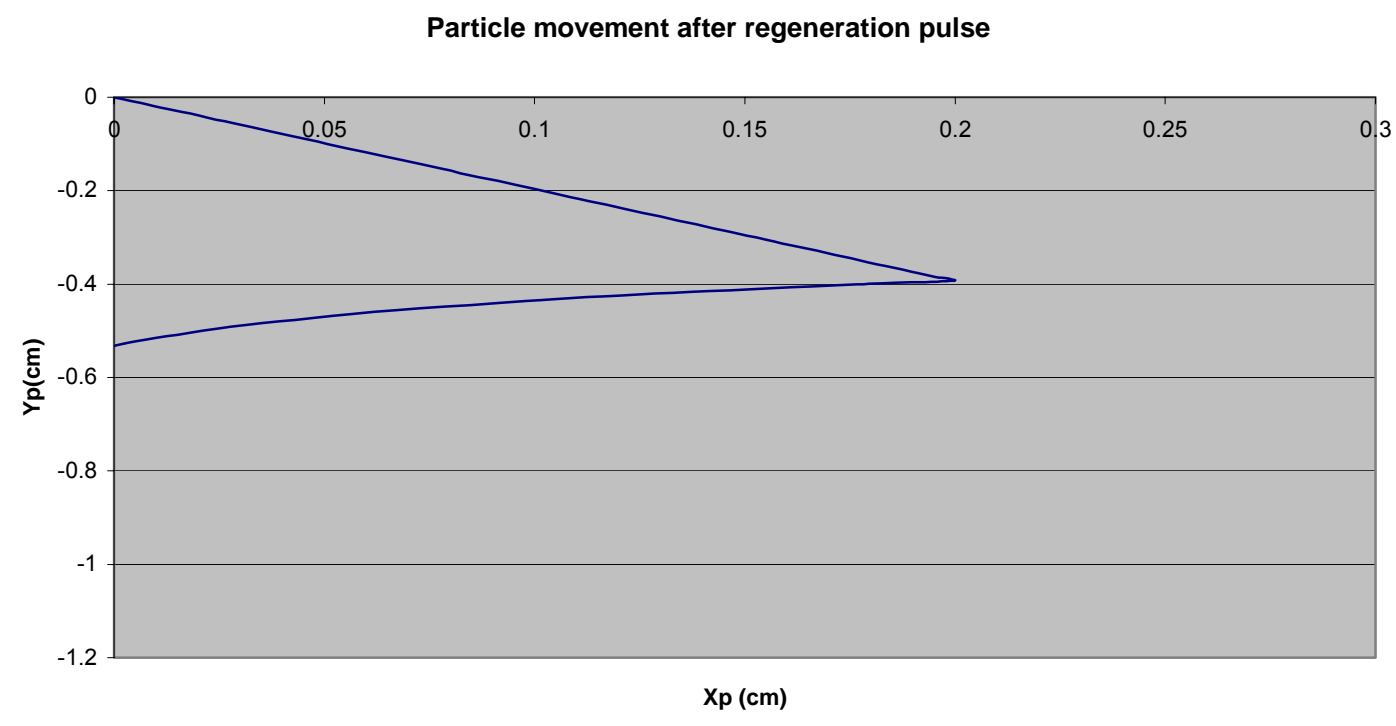

Figure 5.2.2. Path followed by a particle of $100 \mu$, after a 95psi regeneration backpulse.

\subsection{Results}

The goal of this mathematical model is to determine how the particle travels due to the regeneration process, and also to find the probability of a particle hitting a nearby filter. The problem was solved using several particle diameters, and the results are presented in table 5.3.1. 


\begin{tabular}{|c|c|c|}
\hline Particle diameter $(\mu)$ & $\begin{array}{c}\text { Maximum horizontal } \\
\text { displacement } \mathbf{( c m})\end{array}$ & $\begin{array}{c}\text { Maximum vertical } \\
\text { displacement } \mathbf{( c m})\end{array}$ \\
\hline 100 & 0.2 & 0.52 \\
\hline 150 & 0.186 & 1.54 \\
\hline 200 & 0.156 & 3.48 \\
\hline 250 & 0.124 & 6.46 \\
\hline 300 & 0.099 & 10.58 \\
\hline 350 & 0.083 & 15.67 \\
\hline
\end{tabular}

Table 5.3.1 Maximum horizontal and vertical displacements for different diameter particles

By analyzing the data, it can be concluded that the larger the particle diameter, the less it travels in the horizontal direction. However, the larger the particle, the greater the velocity and displacement in the vertical direction. Particles of different sizes leaving from the same location will return at different locations. Specifying the distance between neighboring filter surfaces and using the previous model, conditions for a particle to hit the adjacent filter surface can be found. 


\section{Chapter 6. Conclusions and Recommendations}

6.1 System design.

6.1.1 Facility

A HTTF system has been constructed and operated at specified temperatures. Temperature and pressure sensors associated with the high temperature of the HTTF system were developed, installed, and operated successfully. All the components of the system performed well after several modifications were performed on the system during the learning phase of the development process.

\subsubsection{Instrumentation}

Acquiring reliable pressure data from the facility at the high temperatures encountered in the test was the most delicate part of the system design and construction.

All the pressure sensors were water cooled and an appropriate water cooling system was developed consisting of a filter and flow rate meters. The pressures 
used in calculating pressure differences were rather small, so a more precise pressure measurement technique should be developed for future tests.

\subsection{Operability of the system}

Preliminary filter surface regeneration tests were conducted at temperatures 1100 ${ }^{\circ} \mathrm{F}, 1200{ }^{\circ} \mathrm{F}, 1300{ }^{\circ} \mathrm{F}, 1400{ }^{\circ} \mathrm{F}$ and $1500{ }^{\circ} \mathrm{F}$. Test results at $1300{ }^{\circ} \mathrm{F}$ and up showed drastically different ash regeneration characteristics, which may be due to the change of ash characteristics above $1300^{\circ} \mathrm{F}$.

Ashes were found adhering to the internal walls of the chamber after a complete cycle of filtration. This caused a reduction of the amount of ash available for fluidization in the ash hopper for the final cycles in each test.

For this reason, it would be better to measure test variables like ash deposition rate during subsequent tests in this HTTF.

In order to get and keep a better internal cleaning surface of the windows while a test is performed, it is recommended to blow compressed air through all orifices available in the window cleaning system. In the tests performed, only half of the available orifices were used. This caused dirty internal surfaces on the windows

and poor picture quality in some of the tests. A higher picture quality could be obtained using the four orifices available in each window. 


\subsection{Suggestions, recommendations and proposed improvements}

It is recommended that a continuously working dust feeder mechanism be installed in an improved facility. In this way a constant flow of particles to the filter may provide more reliable conditions during the tests.

Since the pressure profile curves were the data produced by the facility, it is recommended to keep the system free of any air leaks to the surroundings during the tests. In order to do so, valves V1 and V2 should be changed to high temperature resistance valves with metallic seats. The small amount of leakage within the system had no effect as all the air went to the filter. However, if leaks became excessive, this would hinder the ash fluidization process.

Since quick, easy and reliable access to the filter must be available for cleaning purposes after each test, it is recommended to change the design of the window frames in the chamber. The bolts were suffering repetitive heating and cooling cycles, causing them to break every few tests. A new design using fewer bolts would be more convenient.

If future tests involve frequent filter changes, a modification in the supporting structure of the facility should be done in order to avoid the need to raise the whole chamber every time a filter needs to be changed. The supporting beams should not 
be in contact with the bolts used to attach the cap to the chamber. The beams should support the chamber from a lower place on the chamber walls. This would allow enough space to turn the bolt heads, remove the cap and change the filter.

Although a room temperature calibration procedure for the pressure sensors with corrections made at high temperatures was the method used in the tests performed, a high temperature calibration procedure should be developed and implemented in subsequent tests. 


\section{References}

1. Steffen Heidenreich, Schumacher Umwelt-und Trenntechnik GmbH., "Hot Gas Filtration with Ceramics Filters. Experiences and New Developments", Filtration + Separation, May 2002, Vol 39 \# 4, pp. 2225.

2. Cicero Daniel C., Dennis, Richard A., Geiling, Donald W., and Schmidt, Dale K., "Hot- Gas Cleanup for Coal-based Gas Turbines", Mechanical Engineering, September, 1994, pp. 70-75.

3. T.E Lippert et al., "Development of Hot Gas Cleaning Systems for Advanced Coal Based Gas Turbine Cycles", Journal of Engineering for Gas Turbines \& Power, July 1993.

4. Jay M.Quimby \& K. Sam Kumar., "Hot Gas Cleanup for Advanced Power Generation Systems", Gas Cleaning at High Temperatures, Chapman and Hall, 1993, pp. 66-84.

5. T Christopher Dickenson. Filters \& Filtration Handbook. 4 th Ed. 1997.

6. Vasudevan., Venkatesh. "Study on Candle Filter Surface Regeneration Characteristics at Room Temperature", Thesis (M.S) -- West Virginia University. Morgantown West Virginia 2003. 
7. Gregory, Sean., "Development of Candle Filter Measurement Techniques".Thesis (M.S) -- West Virginia University.Morgantown, West Virginia 2001.

8. D. Koch, K. Schulz, J.P.K. Seville and R. Clift., "Regeneration of Rigid Ceramic filters", Gas Cleaning at High Temperatures, Chapman and Hall, 1993, pp. 244-263.

9. S. Laux, B. Giernoth, H. Bulak \& U. Renz., "Aspects of Pulse-Jet Cleaning of Ceramic Filter Elements", Gas Cleaning at High Temperatures, Chapman and Hall, 1993, pp. 203-224.

10. Ji, Z., Meng, X., Shi, M., and Ding, F., "The Interim Process between Pulse-backing Cleaning and Normal Filtration Processes of Ceramic Filter", High Temperature Gas Cleaning Volume II, 1999, G. Braun ems $\mathrm{GmbH}, \mathrm{pp} .211-219$.

11. S. Berbner \& F. Loffler., "Pulse Jet Cleaning of Rigid Filter Elements at High Temperatures", Gas Cleaning at High Temperatures, Chapman and Hall, 1993, pp. 225-243.

12. J-H. Choi., "Investigation into the Pulse Cleaning of the Ceramic Filter Candle". High Temperature Gas Cleaning Volume II, 1999, G. Braun ems $\mathrm{GmbH}$, pp. 200-210.

13. Simha Sharath J., "Investigation of the Formation of Residual Ash on Candle Filters". Thesis (M.S) -- West Virginia University. Morgantown West Virginia 1998. 
14. K Hubner et al., "Advances in the Use of Ceramic Candle Filters for Hot Gas Clean-up, Removing Dust Particles with Sticking Properties." , High Temperature Gas Cleaning Volume II, 1999, G. Braun ems $\mathrm{GmbH}$, pp. 59-70.

15. Johnson Eric, Kang Bruce., "Development and Utilization of a Test Facility for Studying Candle Filter", Project Final Report for DOE. West Virginia University. Morgantown, West Virginia 2003

16. Johnson E, Kang B and Rincón J., "Development of a Test Facility to Evaluate Hot Gas Filtration Characteristics of a Candle Filter", West Virginia University. Morgantown, West Virginia 2002.

17. Ming Zhang., "Optical Measurement of the Size and Velocity Distribution of Particles Moving Near the Wall in a Circulating Bed Riser",Thesis (M.S) in preparation. West Virginia University. Morgantown West Virginia 2003. 


\section{Appendix}

Development of the particle motion equation.

$m d v_{p} / d t=F_{D}$

For $\operatorname{Re}<1$

$\left(\pi d_{p}^{2} \rho_{p} / 6\right) \quad\left(d v_{p} / d t\right)=3 \pi \mu d_{p}\left(v-v_{p}\right)$ Stokes drag force

$d v_{p} / d t=\left(18 \mu / d_{p}^{2} \rho_{p}\right) \quad\left(v-v_{p}\right)$

if $\tau_{v}=\rho_{p} d_{p}^{2} / 18 \mu$

then

$d v_{p} / d t=\left(v-v_{p}\right) / \tau_{v}$ 


\section{VITA}

Juan Pablo Rincón

Date of Birth:

April 22, 1964

Place of Birth: Santa Fe de Bogota, Colombia

Education:

MS in Mechanical Engineering, West Virginia University

Date of Graduation: May 2003

BS in Mechanical Engineering, Universidad de Los Andes, Santa Fe de Bogota, Colombia

Date of Graduation: March 1987 